

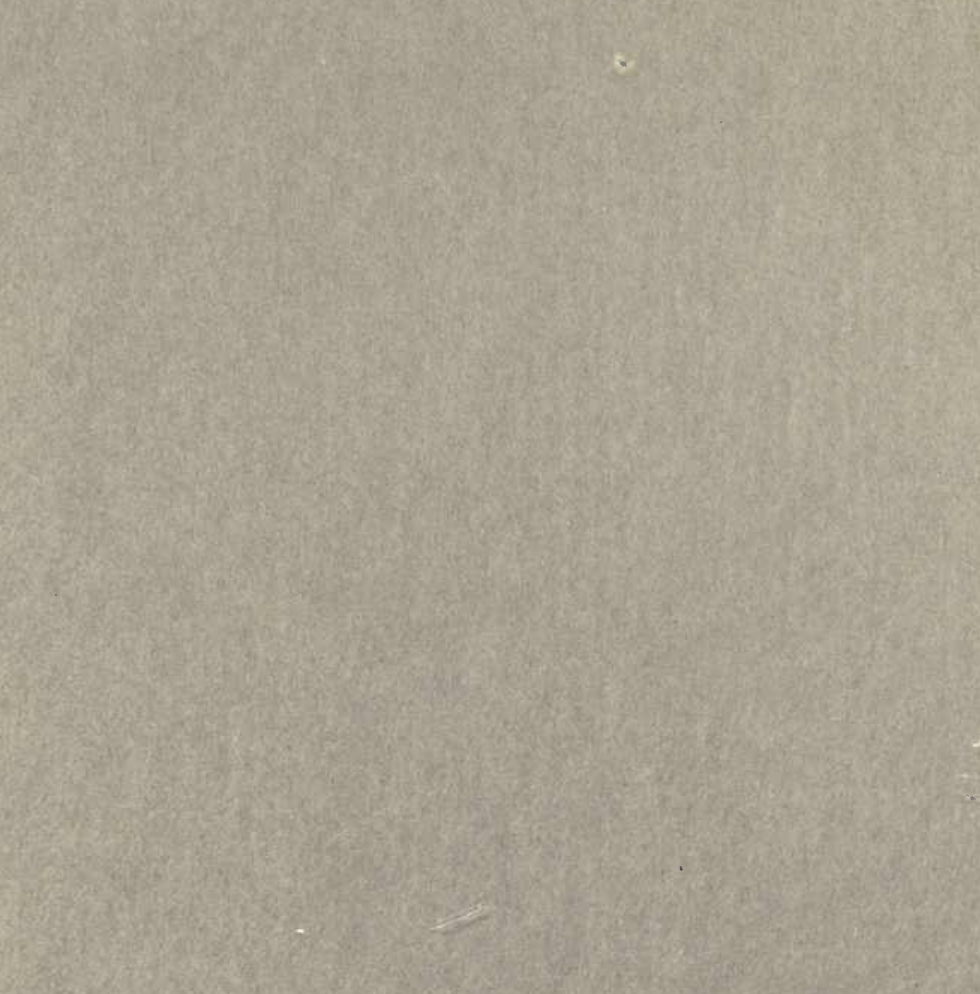

(5) 6.

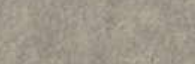

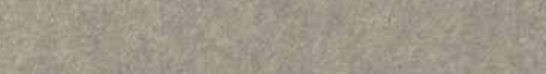




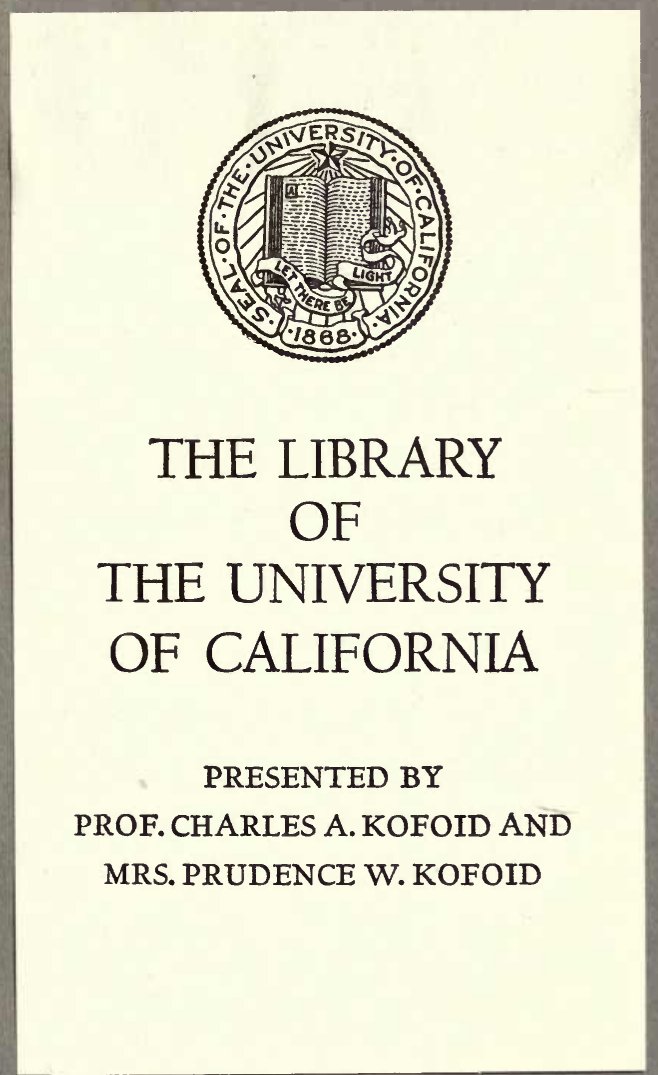




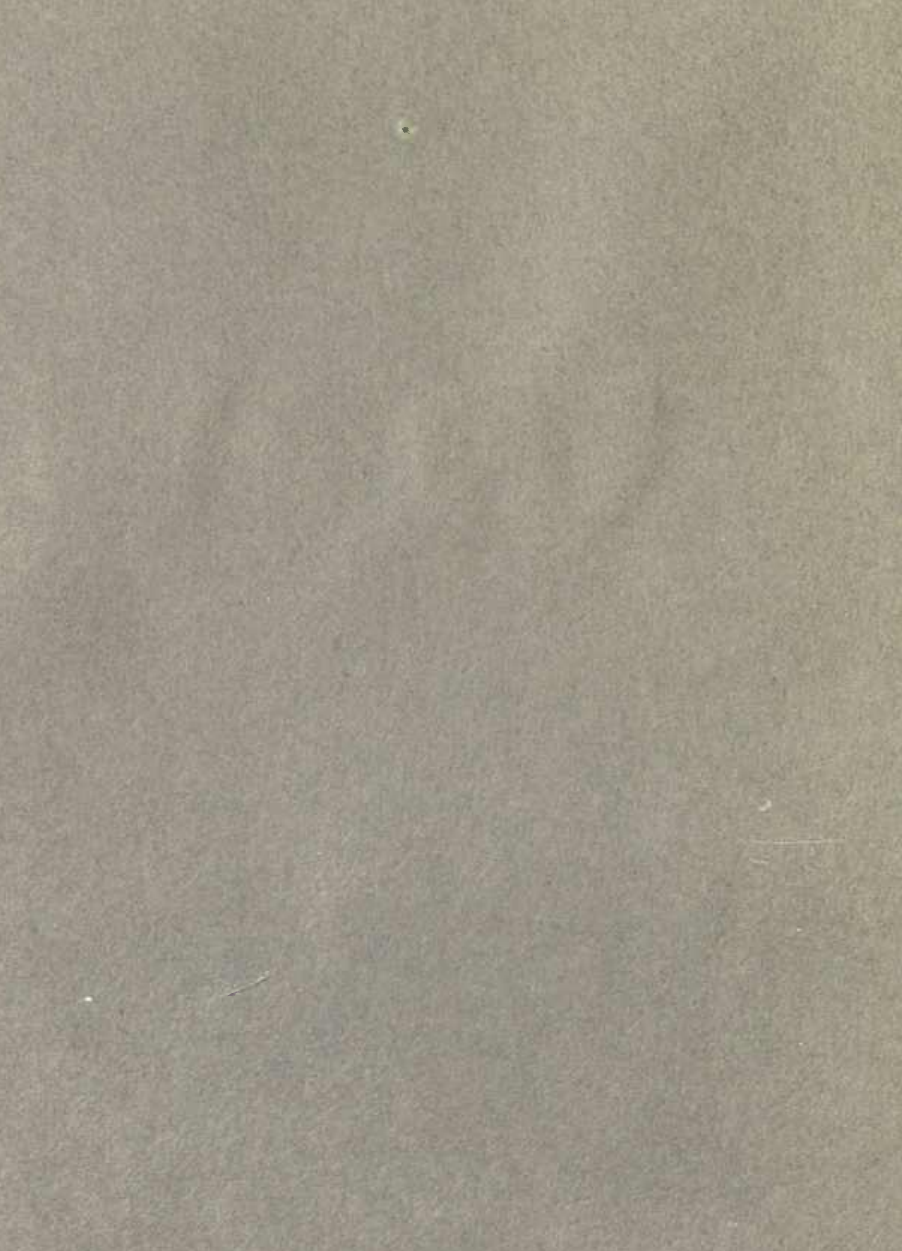

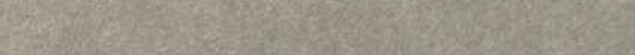

S. 


\section{REVISION OF THE PARASITIC HYMENOPTEROUS \\ INSECTS OF THE GENUS APHYCUS MAYR, WITH NOTICE OF SOME RELATED GENERA}

BY

P. H. TIMBERLAKE

Of the Bureau of Entomology, United States Department of Agriculture

No. 2136.-From the Proceedings of the United States National Museum, Vol. 50, pages 561-640, with Plates 26-31

Published May 31, 1916

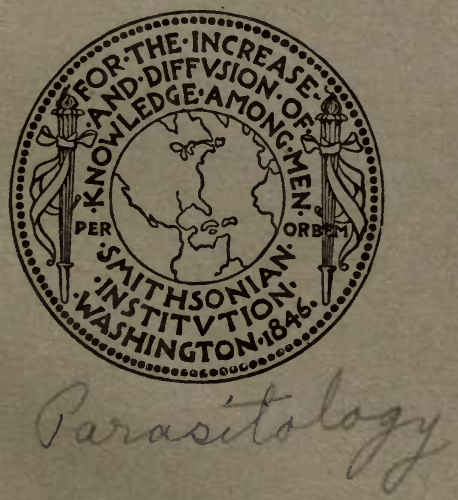

Washington

Government Printing Office 1916 


$$
-
$$




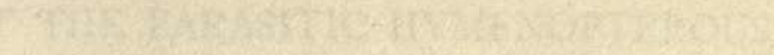

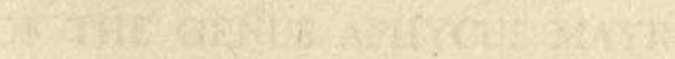

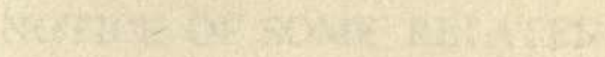

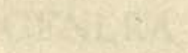

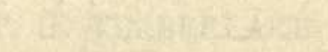

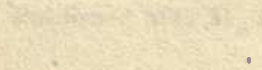





\section{REVISION OF THE PARASITIC HYMENOPTEROUS}

INSECTS OF THE GENUS APHYCUS MAYR, WITH NOTICE OF SOME RELATED

\section{GENERA}

BY

P. H. TIMBERLAKE

Of the Bureau of Entomology, United States Department of Agriculture

No. 2136.-From the Proceedings of the United States National Museum, Vol. 50, pages 561-640, with Plates 26-31

Published May 31, 1916

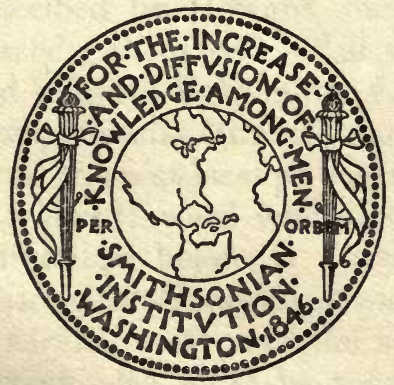

Washington

Government Printing Office 1916 



\section{K-QL 568 A56 T5 \\ Biol. Hien}

REVISION OF THE PARASITIC HYMENOPTEROUS INSECTS OF THE GENUS APHYCUS MAYR, WITH NOTICE OF SOME RELATED GENERA.

\section{By P. H. Trmberlake,}

Of the Bureau of Entomology, United States Department of Agriculture.

The genus Aphycus was erected by Gustav Mayr early in 1876 in "Die europaischen Encyrtiden" with three species, of which Aphycus apicalis (Dalman) was selected by Ashmead in 1900 as the genotype. As treated in the present paper, most of the species of the genus Aphycus are more similar to Aphycus punctipes (Dalman), the third species listed by Mayr, but are also congeneric with $A$. apicalis as far as can be made out from descriptions and the limited material of the latter at hand.

Since the publication of Mayr's paper thirty-nine species have been described under this genus or later referred to it. Three of these, however, were removed later by Howard and Ashmead to other genera, $A$. chrysopae falling in the genus Isodromus Howard, $A$. niger forming the type of Holcencyrtus Ashmead, and A. unicolor being placed in Phaenodiscus Foerster. It is apparent, nevertheless, even after the removal of these species, that the genus in its present state contains several discordant elements. Chief among these are three Ectromine species described by Howard, namely $A$. dactylopii, $A$. nigritus, and $A$. townsendi, all of which fall naturally in the genus Anagyrus Howard, and a fourth Ectromine, A. albiclavatus Ashmead, which is more like Paraleptomastix Girault than any other described genus and may be placed there at least provisionally. Other discordant elements are $A$. angelicus Howard, which forms the type of the new genus Pseudaphycus described below; A. texanus Howard, here considered to be congeneric with Acerophagus coccois Emily Smith; $A$. austratiensis Howard, serving as type of the new genus Aphycopsis; $A$. terryi Fullaway, which also must be separated under the new genoric name Pseudococcobius; and, finally, A. pulchellus Howard, which must be placed in Girault's recent genus Aenasioidea. The types of $A$. brunneus Howard and $A$. howardi Cockerell were not available for study or, as in case of the latter species, in too poor

Proceedings U. S. National Museum, Vol. 50-No. 2136.

$10600^{\circ}$-Proc.N.M.vol.50-16-36 
condition for generic diagnosis, and it is not unlikely that the accession of fresh material will necessitate the removal of both species from the genus. Types or any other specimens of $A$. immaculatus Howard, A. amoenus Howard, A. hederaceus (Westwood), A. punctipes (Dalman), A. phitippiae Martelli, and A. nitens Kourdumoff have also not been available for study, but there is no reason for believing that any of these is not now properly placed.

For the convenience of the student a table of the genera herewith proposed has been drawn up, including those forms that have been or are most likely to be confused with Aphycus but excluding Anagyrus and Paraleptomastix, which properly belong to the Ectromini and need not cause confusion if careful attention is paid to tribal characters. The table also includes the genus Astymachus Howard, placed near Aphycus in Ashmead's tables, but excludes Heterathrellus Howard, which is an Ectromine and should run next to Anagyrus in any natural classification. It may be pointed out, also, that Ashmead was wrong in trying to separate Astymachus from Aphycus by the alleged absence and presence of the postmarginal vein in the respective genera. The postmarginal is wanting or, more properly speaking, reduced to a mere spur in both of these genera. Attention is called to the abdominal character made use of in the following table. Unfortunately it is one not always readily made out in dry material, although easily seen in fresh specimens and usually also in balsam mounts. As it plays a large part in the economy of the insects, either causing or having been brought about by different habits of oviposition, it has consequently great taxonomic importance. All of the genera here treated have a nonmetallic coloration.

\section{ANALYTICAL KEY TO GENERA.}

1. Mandibles short and thick with equal or nearly equal teeth............... 5 . Mandibles comparatively long and slender with noticeably unequal teeth; ovipositor inclosed by the 5 th ventral sclerite........................

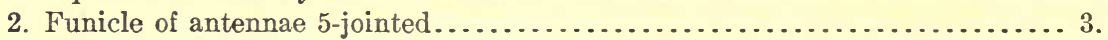
Funicle of antennae 6 -jointed................. Pseudococcobius, new genus.

3. Front and vertex not punctate, cheeks longer......................... 4 . Front and vertex punctate, cheeks as short as width of eyes.

Bothriocraera, new genus.

4. Two upper teeth of mandibles nearly equal, lower tooth more basal and smaller. Acerophagus Smith.

Upper and lower teeth of mandibles equal, middle tooth larger and very sharp.

Pseudaphycus Clausen.

5. Fifth ventral sclerite reaching about to the middle of the venter, ovipositor free.. 6 . Ovipositor inclosed by the 5 th sclerite, which reaches to the anus.

Aenasioidea Girault.

6. Postmarginal vein short and spurlike, no longer or not so long as the marginal... 7

Postmarginal well developed, nearly as long as the stigmal, antennal scape rather short, clavate cylindrical and furrowed at apex........ Aphycopsis, new genus. 
7. Body elongate; abdomen much longer than wide, pointed at apex.

Astymachus Howard.

Body short, robust; abdomen ovate, rarely over one-half longer than wide; and rather obtusely rounded at apex....................... Aphycus Mayr.

\section{PSEUDOCOCCOBIUS, ${ }^{1}$ new genus.}

In general facies much resembles Aphycus Mayr but differs especially in the dentition of the mandibles and the structure of the abdomen.

Female.-Head seen from in front about as wide as the length of the vertical axis, or a little wider in P. terryi; the front and vertex moderately convex and pass over into the face by a rather sharp angle but angle not at all carinate; face and cheeks short in genotype, the antennal scrobes fairly deep; eyes large, about four-fifths as wide as long, or sometimes smaller and narrower, pubescent; ocelli placed in an acute to a right-angled triangle (nearly equilateral in the genotype), the posterior pair removed from the rim of the occiput and about their own diameter or less from the eye margin; vertex varying considerably in width. Mandibles rather long, tridentate, with the middle tooth much longer and stouter than the others. Antennal scape flattened, linear or nearly so or cylindrical, reaching a little beyond the plane of front and vertex; pedicel about as long as the first three or four funicle joints combined; funicle as a whole short, increasing slightly in diameter distad, all the joints wider than long; club large, in general shape oval, sometimes slightly obliquely truncate, about as long as the funicle joints combined. Thoracic structure nearly as in Aphycus, but the mesoscutum shorter and much wider than long; abdomen rather short, ovate, the dorsum more or less concave after death, the fifth ventral sclerite ${ }^{2}$ reaching to the anus and inclosing base of the ovipositor; the latter protruded and slender. Wings fully developed, the marginal vein punctiform, the postmarginal short, hardly longer than the marginal, stigmal rather short, forming an angle of about 60 to $70^{\circ}$ with the margin of wing, submarginal with the usual row of bristles tending to become reduced or weak; hind wing narrow, the costal cell very narrow but extending to the hooklets. Sculpture, vestiture, and type of coloration not differing from Aphycus.

Male.-Closely resembles the female in all but the sexual characters. Type of genus. - Aphycus terryi Fullaway.

The species belonging to this genus are parasitic in mealy bugs of the genera Pseudococcus and Phenacoccus so far as known.

\footnotetext{
1 From Pseudococcus, a genus of Coccidae, and $6 B 10 s$, referring to the host relationship.

2 The so-called hypopygium of authors and the valvula ventralis of Thomson is morphologically, I believe, a part of the seventh abdominal segment, as the propodeum seems really composed of the first two abdominal segments in the Encyrtidae.
} 
ANALYTICAL KEY OF SPECIES.

FEMALES.

1. Front and vertex narrow, about three times as long as wide...................

Front and vertex wide, about one-half longer again than wide; ocelli in a rightangled triangle; wings hyaline; antennal scapecylindrical; general color pale orange yellow............................. ehrhorni, new species.

2. Wings slightly dusky with a deeper stain beneath marginal and stigmal veins; scape flat, slightly expanded; ocelli nearly in an equilateral triangle; general color orange yellow, the antennae dusky but whitish at apex......... terryi (Fullaway).

Wings bifasciate with apex and medial band hyaline, scapecylindrical; ocelli in an acute-angled triangle; general color deep orange yellow, antennae uniformly yellowish................................... bifasciatus, new species.

1. PSEUDOCOCCOBIUS EHRHORNI, new species.

Female.-Front and vertex about one-half longer again than wide, margin of eyes parallel; ocelli in a right-angled triangle, the posterior pair their own diameter from the eye margin, and twice their diameter from the occipital border; eyes rather small, about one-third longer than wide, with fine, short and rather thick pubescence; head as seen from in front as wide as long; cheeks a little longer than greatest. width of eyes; antennal scrobes narrow, rather pronounced and uniting above. Antennal scape slender, cylindrical; pedicel narrowed at base, as long as the first three funicle joints combined; funicle nearly cylindrical, increasing but slightly in width distad, all joints, however, a little wider than long, the first four nearly equal in length, the last two slightly longer; club large, ovate, slightly obliquely truncate at apex, about twice as wide as the last funicle joint, and as long as all the funicle joints combined, the sutures plainly indicated. Wings uniformly ciliated; the oblique hairless streak widened below, not interrupted, and nearly connecting with the hairless streak on the posterior border of the wing; bristles on the submarginal vein weak; stigmal vein at angle of about $70^{\circ}$ with the margin of wing. Ovipositor protruded about one-half the length of the abdomen. Length: 1.0 to $1.1 \mathrm{~mm}$., exclusive of ovipositor.

General color nearly uniformly pale orange yellow, deeper on the notum of thorax, a little paler on the head and underparts; the propodeum pale brown; a deeper brown spot on each side of the venter at the apex of abdomen, and another pair of brown spots surround the dorsal vibrissal plates ${ }^{1}$ of the abdomen. Antennae uniformly orange yellow, somewhat duskier than the body, possibly due to discoloration; legs concolorous with the underparts, the last joint of the tarsi blackish. The short, appressed hair of the notum dusky in color and rather sparse. Wings hyaline, the veins pale yellowish.

1 These plates are usually called spiracles by most authors but as pointed out by Alice $\mathrm{L}$. Embleton (Trans. Linn. Soc. Lond., ser. 2, Zool., vol. 9, p. 247, pl. 12, figs. 39, 42, and 43) they are probably tactile plates and have no connection with the spiracles. They are characteristic of the Encyrtidae and especially of the Encyrtinae. 


\section{Male.-Not known.}

Described from. three females (type and paratypes $a$ and $b$ ) reared from Pseudococcus ryani (Coquillett), San Francisco, California (E. M. Ehrhorn), no date given.

Type.-Cat. No. 19113, U.S.N.M.

\section{PSEUDOCOCCOBIUS TERRYI (Fullaway).}

Fig. 35.

Aphycus terryi Fullaway, Proc. Hawaiian Ent. Soc., vol. 2, 1913, p. 281.

Female.-Front and vertex nearly three times as long as wide, margins of eyes parallel; ocelli nearly in an equilateral triangle, the posterior pair slightly closer together than the distance from either to the anterior ocellus, and nearly touching the eye margin, the anterior ocellus a little behind the center of the front and vertex; eyes very large, about four-fifths as wide as long, with thick but fine, short pubescence; head as seen from in front a little wider than long, the face and cheeks short; antennal scrobes moderately deep and uniting above. Antennal scape flattened, very slightly expanded below, widest across the apical half; pedicel not greatly wider at apex than at base, as long as the first four funicle joints combined; funicle increasing gradually in width distad so that the sixth joint is about two and one-half times as wide as the first joint, all being wider than long and all but the first distinctly transverse; club large, oval, somewhat obliquely truncate at apex, apparently solid with no sutures visible, a little longer than all funicle joints combined. Wings uniformly ciliated; oblique hairless streak widened and subinterrupted below, not quite attaining the posterior margin of disk; bristles on submarginal vein very weak and inconspicuous; stigmal vein at an angle of about $60^{\circ}$ with the anterior margin of wing. Ovipositor protruded about one-fourth the length of abdomen. Length: 1.0 to $1.1 \mathrm{~mm}$., exclusive of ovipositor.

Head and upper parts of the body orange yellow; lower part of face, cheeks and the underparts of body pale yellowish; occiput, a transverse band on pronotum, the thoracic sutures, the metanotum, propodeum and center of the dorsum of abdomen more or less dusky. Appressed pubescence of notum dusky. Antennal scape pale brownish, the dorsal margin and especially the lower margin on the apical half narrowly blackish; pedicel and first four funicle joints pale brownish, the last two funicle joints and club dusky white. Wings slightly smoky with a more distinct smoky blotch beneath the stigmal vein, the discoloration entirely integumentary and not due to the ciliation.

Male.-Almost identical with the female in all but the sexual characters, but the wings are slightly less deeply stained. The male 
described by Fullaway is not the male of this species and evidently something quite different. A male included in the material loaned for study which answers to his description is an Ectromine.

Redescribed from two females and one male on a slide labeled "exmealy bug on sugar cane, Ewa, 11-29-12," and one female in alcohol without data, all loaned by the Hawaiian Sugar Planters' Station through the kindness of Mr. D. T. Fullaway. The specimens are apparently metatypes. The recorded host is Pseudococcus saccharifolii (Green).

\section{PSEUDOCOCCOBIUS BIFASCIATUS, new species.}

Female.-Front and vertex about three times as long as wide, the margins of the eyes slightly converging anteriorly; ocelli in an acute-angled triangle, the posterior pair about one-half their diameter from the eye margin and a little over twice their diameter from the occipital margin; eyes large, about one-third longer than wide, with a fine, short, thick pubescence; head as seen from in front slightly longer than wide, but nearly circular in outline, cheeks as long as the greatest width of the eyes; antennal scrobes rather wide and deep, meeting above at an angle of about $40^{\circ}$. Antennal scape cylindrical, shorter and stouter than in P. ehrhorni; the pedicel narrowed at base and as long as the first four funicle joints combined; funicle joints increasing gradually in width, the last joint about twice as wide as the first and twice as long, the first three joints of nearly equal length and distinctly transverse, the last three increasing in length, not so distinctly transverse, the fifth and sixth subequal in length; club smaller than usually, ovate, obliquely rounded at apex, about one-half wider again than the last preceding joint and as long as the last five funicle joints combined, the sutures plainly indicated. Wings not uniformly ciliated, the apex, base, and a cross band at end of stigmal vein with paler, weaker cilia; oblique hairless streak of nearly uniform width, subinterrupted just below the middle, and nearly connecting with the hairless streak on the posterior border of wing; bristles on the submarginal vein strong; stigmal vein at angle of about $70^{\circ}$ with margin of the wing. Ovipositor protruded about one-third the length of the abdomen. Length, $1.1 \mathrm{~mm}$., exclusive of ovipositor.

Head, notum, and pleura of thorax, the basal and apical segments of the abdomen bright orange yellow; antennal scrobes of face, collar of pronotum, prepectal plates and tegulae yellowish white, the latter with a brown spot on its posterior margin; center of occiput and concealed part of pronotum dusky; the metanotum, propodeum, and a broad band extending across the center of the abdomen brownish black, the band on the abdomen appearing on both dorsum and venter. The appressed pubescence of face, cheeks, and thorax 
white and conspicuous; present also on the front and vertex but weaker. Antennae pale yellowish brown, the club still paler or yellowish. Coxae and femora of legs yellowish white, the front femora dusky along the lower margin; anterior and middle tibiae more yellowish, especially at apex, the middle pair dusky on the outer surface; posterior tibiae dilute brownish black, fading to yellowish at apex; all tarsi yellowish, with the last joint blackish. Wings with two conspicuous blackish cross bands, one with its center beneath the marginal vein, the other on apical half of disk, separated by a whitish band, of which the basal margin is concave and the apical margin straight; basal third of wing and extreme apex also whitish; the blackish bands due in part to integumentary pigment and in part to the ciliation. Exserted part of the ovipositor yellow, but becoming blackish at the apex.

Male.-Similar to the female, but differs in the following particulars: Front and vertex broader than in the female, hardly over twice longer than wide; the ocelli in a less acute-angled triangle. Antennal scape slightly flattened, and a little shorter than in the female, the funicle and club slenderer. Wings uniformly ciliated. Length, 0.9 to $1.0 \mathrm{~mm}$.

Vertex more or less blackish around ocelli; the center of the occiput, concealed part of the pronotum, the mesoscutum except the sides, the metanotum, propodeum, metapleura, and abdomen brownish black; the vertex otherwise, sides of the mesoscutum, axillae, and scutellum orange yellow, the latter somewhat dusky in the center; the mesopleura dusky orange yellow; the front, face, cheeks, and propleura yellow to yellowish white; collar of pronotum, tegulae, and prepectal plates as in the female. Antennae pale brownish, but the scape, pedicel, and club somewhat paler; legs colored as in the female; wings hyaline.

Described from a female and male (type and allotype) reared July 3, 1914, from a nearly full-grown female of a Phenacoccus sp. on apple tree, Lancaster, New Hampshire (Miss G. G. Timberlake); and one male (paratype) reared April 19 from small overwintering female of the same species collected by the writer on March 31 on the bark of apple tree at the same locality.

Type.-Cat. No. 19114, U.S.N.M.

\section{BOTHRIOCRAERA, ${ }^{1}$ new genus.}

Very similar to Pseudaphycus described below, but differs in shortness of face and cheeks and in the punctation of the front and vertex.

Female.-Head somewhat hemispherical in shape, but the width greater than the vertical axis; the dorsal aspect gently rounded, sloping forward and downward, and passing into the face abruptly

1 From $\tau \hat{~} \beta \circ \theta \rho i o \nu$, small pit, and ì $\kappa \rho a \epsilon \rho a$, head. 
by a rounded angulation; face and cheeks short, the length of the former about equal to the greatest transverse diameter of the eyes; antennal scrobes prominent, extending the length of the face and uniting above so as to form a half ellipse; eyes large, nearly perfectly oval; occiput rather flat, or but slightly concave, the neck inserted considerably above the center; ocelli in an equilateral triangle, with the posterior pair about twice their own diameter from the occipital rim: Mandibles tridentate with the middle tooth the largest as in Pseudaphycus. Antennae inserted far apart and close to the border of the mouth, 10-jointed; the scape flattened but narrow, extending considerably above the plane of the vertex; pedicel as long as the entire funicle; the latter 5-jointed, its joints short, and increasing in width distad; club large, oval, rather acutely rounded at apex, as long as the pedicel and funicle combined. Body rather robust, the mesoscutum twice as wide as long, the axillae meeting, the scutellum large and acute at apex; abdomen ovate, about one-half longer than wide, the dorsum becoming slightly concave after death, the fifth ventral sclerite reaching to apex of abdomen and enclosing base of the ovipositor, the latter slender and protruded considerably. Legs rather short and stout, the femora flattened: Wings fully developed but very narrow; the marginal vein punctiform, the postmarginal nearly one-half the length of the stigmal, the latter moderately long, knobbed at apex and with two short, nearly parallel prongs, the submarginal with well-developed bristles. Hind wings narrow, the costal cell extremely narrow, but as wide near the hooklets as at base of the wing. Head and thorax smooth and shining, the front and vertex with several rows of minute punctures, the notum of thorax with scattered punctures of the same sort; the pubescence of head and thorax very fine and dark-colored. General coloration black, but not metallic.

Male.-Essentially like the female in all but the sexual characters. Type of genus.-Bothriocraera flavipes, new species.

BOTHRIOCRAERA FLAVIPES, new species.

Female.-Front and vertex a little over twice as long as the width at the anterior ocellus; dorsal orbits of eyes slightly diverging anteriorly and to a less degree posteriorly; the ocelli in an equilateral triangle, with the posterior pair about their own diameter from the eye margin; eyes large, oval, with a very fine, short pubescence. Antennal scape flattened and linear; pedicel narrowed at base, as long as all five funicle joints combined; the latter all of equal length, the first rounded, as long as wide, the following increasingly transverse, the fifth about twice as wide as long; club oval, somewhat pointed at apex, about as long as the pedicel and four of the funicle joints combined, not quite twice as wide in greatest breadth as the last preceding 
joint. Wings uniformly ciliated, the oblique hairless streak narrow and nearly reaching the posterior border of the wing; stigmal vein forming an angle of about $45^{\circ}$ with the postmarginal. Ovipositor protruded about one-half the length of the abdomen. Length, 0.85 mm., exclusive of ovipositor.

Head and thorax shining black but not metallic; the metanotum and propodeum browner; dorsum of abdomen pale brown, the venter dusky yellowish. Antennal scape and funicle brown, the pedicel paler brown, the club yellowish white. Legs uniformly pale straw yellow, the last joint of the tarsi brownish. Exserted part of the ovipositor brownish yellow, becoming blackish at apex. Wings hyaline, the veins pale brownish.

Male.-Very similar to the female, but the front and vertex a little wider, not quite twice as long as wide; the ocelli with posterior pair slightly farther apart than the distance from either to the anterior ocellus. Other structural characters apparently identical, as nearly as can be made out in a single poor specimen. Coloration the same, except the abdomen is blackish brown, a little paler on the venter. Length, $0.65 \mathrm{~mm}$.

Described from a female and male (type and allotype) reared from a Dactylopiine coccid on Elymus, August 16-21, 1912, Kimballs, Utah (C. N. Ainslie), Webster No. 8823.

Type.-Cat. No. 19115, U.S.N.M.

\section{Genus PSEUDAPHYCUS Clausen.}

Pseudaphycus Crausgne, Bull. 258, Cal. Agric. Exp. Stat., 1915, p. 41.

Comes closest to Bothriocraera, but differences in the shape of the head and the sculpture will serve to separate the species so far known.

Female.-Head as seen from the side more distinctly triangular in outline than in Bothriocraera; the dorsal aspect considerably less rounded, the plane of the front meeting the plane of the face at a right angle or but little more (considerably more in Bothriocraera), the angulation between the two rounded; width of head about equal to vertical length; face and cheeks usually long, but sometimes shortened; antennal scrobes usually pronounced, and meeting above as in Bothriocraera; eyes large, imperfectly oval, being wider anteriorly; occiput moderately to slightly concave, the neck inserted a little above the center; vertex rather narrow, the ocelli in an equilateral or acute-angled triangle, and the posterior pair at least twice their own diameter from the occipital rim. Mandibles rather long and slender, tridentate, the middle tooth longest, the other two nearly opposite each other and subequal. Antennae of the same type as in Bothriocraera. Structure of the thorax and abdomen the same, but the latter more elongate ovate; ovipositor more or less protruded. Legs somewhat longer. Wings fully developed but narrow; the submarginal 
vein without strongly developed bristles; marginal punctiform or but very little longer than thick; postmarginal poorly developed, usually but slightly longer than the marginal; stigmal moderate in length, either clavate in shape or suddenly enlarged near apex; hind wings narrow, the costal cell very narrow but extending to the hooklets. Sculpture of head and thorax alutaceous, punctures if present wholly microscopic; vestiture of rather coarse, appressed, whitish hairs as in Aphycus Mayr. Coloration nonmetallic, shades of yellow predominating.

Male.-Closely resembling the female in all but the sexual characters.

Type of genus.-Aphycus angelicus Howard.

ANALYTICAL KEY OF SPECIES.

FEMALES.

1. Wings more or less infuscated, face longer than width of eyes.

Wings hyaline, face and cheeks shortened. Coloration pale yellow.

1. graminicola, new species.

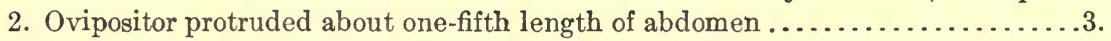

Ovipositor barely protruded, fifth funicle joint and club white.

2. prosopidis, new species.

3. Dorsal orbits of eyes parallel, front ocellus at center of front and vertex.

3. websteri, new species.

Dorsal orbits of eyes diverging anteriorly, front ocellus behind center of front and

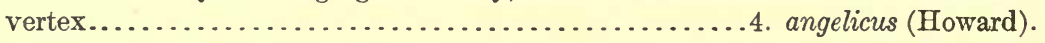

1. PSEUDAPHYCUS GRAMINICOLA, new species.

Female.-Front and vertex about twice as long as wide; dorsal orbits of eyes parallel; ocelli nearly in an equilateral triangle, the posterior pair about their own diameter from the eye margin, and twice as far from the occipital rim; face and cheeks unusually short, face being no longer than the greatest width of eyes; the latter rather large and covered with an extremely fine, short pubescence. Antennal scape narrow, linear; pedicel as long as the first four funicle joints combined, narrowed at base; funicle joints subequal in length, all wider than long and increasingly transverse, the fifth not quite twice as wide as the first; club elongate ovate, a little obliquely rounded at apex, hardly wider than the last funicle joint and as long as the funicle and one-half the pedicel combined. Wings uniformly ciliated; oblique hairless streak interrupted at the middle, its lower part rather widely separated from the lower margin of wing; the postmarginal vein about one-fourth as long as the stigmal, the two veins forming an angle of about $45^{\circ}$. Ovipositor protruded onefourth the length of the abdomen. Length, 0.8 to $1.1 \mathrm{~mm}$., exclusive of ovipositor.

Front, vertex and notum of thorax chrome lemon yellow, slightly dusky; face, cheeks, occiput, and underparts of body including 
venter of abdomen paler yellow; metanotum, propodeum, and dorsum of abdomen except the lateral and posterior yellowish margins blackish brown; sutures of mesonotum narrowly lined with black, especially the suture between pronotum and mesoscutum; collar of pronotum otherwise whitish or sometimes entirely so; tegulae pale yellowish, slightly brownish on posterior margin. Antennal scape, pedicel, and first one or two joints of the funicle dusky yellowish, with the margins of the scape narrowly blackish; remainder of the funicle and the extreme base of club black, club otherwise yellowish white. Legs concolorous with the underparts, the outer surface of the femora and tibiæ slightly dusky, the last joint of the tarsi blackish. Exserted part of ovipositor yellowish, changing to blackish at apex. Wings hyaline, the veins pale brownish.

Male.-Similar to the female, but the antennae slightly slenderer, and the dorsum of the abdomen more blackish with the pale margins orange yellow. Length: 0.6 to $0.9 \mathrm{~mm}$.

Described from ten females and five males (type, allotype and paratypes $a$ to $m$ ) reared from a Dactylopiine coccid on Stipa, Las Vegas, New Mexico, Jan. 16 to March 20, 1912 (C. N. Ainslie), Webster No. 6690; and three females, two males (paratypes $n$ to $r$ ) reared from a Dactylopiine coccid on Elymus condensatus, Kimballs', Utah, Aug. 13-24, 1912 (C. N. Ainslie), Webster No. 8823. Paratypes $e, f, o$, and $p$ more or less broken, the rest of the specimens in good condition, four of them being mounted on slides.

Type.-Cat. No. 19116, U.S.N.M.

\section{PSEUDAPHYCUS PROSOPIDIS, new species.}

Female.-Front and vertex about twice as long as wide; dorsal orbits of eyes parallel; ocelli in an acute-angled trianglo, the posterior pair nearly touching the eye margin; no pubescence on the eyes. Antennal scape linear, slightly narrower at base; pedicel as long as the first four funicle joints combined, wider at apex than in $P$. angelicus; funicle joints one to three shorter than the last two, but all wider than long, the last two about twice as wide as the first; club oval, obliquely rounded at apex, as long as the funicle and a little wider than the preceding joint. Wings uniformly ciliated; oblique hairless streak interrupted near its lower end; no bristlelike hairs on any of the veins. Ovipositor barely protruded. Length: $0.8 \mathrm{~mm}$.

Front, vertex and mesonotum dull orange yellow, the apex or the scutellum dusky; face, cheeks, and underparts yellowish white; concealed part of occiput and of the pronotum blackish; the metanotum, propodeum, and dorsum of the abdomen brownish black; tegulae and collar of pronotum whitish, former with lower posterior 
corner brown, latter with a brown dot on each corner. Antennal scape, pedicel, and first four funicle joints brown, the base of the scape shading into whitish; fifth funicle joint and club white. Legs yellowish white, the tarsi more yellowish with apex of last joint blackish. Wings faintly clouded with brown, but lacking the hyaline cross band of $P$. angelicus, the whole apex of wing beyond tip of stigmal vein more faintly clouded, the clouded area extending proximad to just beyond the hairless streak, and an additional small spot of pale brown at base of wings along the posterior border; veins pale brownish.

Male.-Not known.

Described from eight females (type and paratypes) reared from Pseudococcus prosopidis (Cockerell), Aug. 4, 1898, Mesilla, New Mexico (T. D. A. Cockerell), Insectary No. $8182^{\circ} .^{1}$

Type.-Cat. No. 19117, U.S.N.M.

\section{PSEUDAPHYCUS WEBSTERI, new specles.}

Female.-Very close to $P$. angelicus but differs as follows: Dorsal orbits of eyes parallel and not diverging anteriorly; the anterior ocellus exactly at the center of the front and vertex. A bristle-like hair at base of marginal vein and another near apex of the postmarginal; oblique hairless streak not interrupted.

Orange yellow of front, vertex, and mesonotum brighter; the anterior margin of mesoscutum black, and the axillary sutures lined with black; face, cheeks, and underparts pure white, the venter of abdomen at the middle slightly brownish, the brown band on cheeks more distinct than in $P$. angelicus, and follows around to the anterior orbits of eyes. Antennae the same except that the fifth funicle joint is brownish instead of black. Legs white, the anterior femora dusky along their upper margin near apex, hind femora with nearly the whole lower surface slightly dusky; front and middle tibiae with one, the hind tibiae with two wide, but faint dusky annuli, and an additional, very narrow annulus at the apex of the tibiae, especially of the middle pair; tarsi yellowish and not much infuscated on the last joint. Wings clouded as in $P$. angelicus, the veins darker.

Length: $1.2 \mathrm{~mm}$., exclusive of ovipositor. The maximum size of $P$. angelicus does not exceed $1 \mathrm{~mm}$., apparently.

Described from one female (type) reared from the stems of Elymus virginicus, in Feb., 1903, Villa Ridge, Illinois (F. M. Webster), Webster No. 1924b. Undoubtedly from a Dactylopiine coccid on the Elymus.

Type.-Cat. No. 19118, U.S.N.M.

1 Numbers on labels of specimens refer to notes on file at the Bureau of Entomology unless otherwise stated. 


\section{PSEUDAPHYCUS ANGELICUS (Howard).}

Figs. 34, 51.

Aphycus angelicus Howard, Proc. U. S. Nat. Mus., vol. 21, 1898, pp. 241, 245.

Female.-Front and vertex nearly three times as long as wide, slightly wider anteriorly, the dorsal orbits of eyes diverging; ocelli in an acute-angled triangle, the lateral pair about half their own diameter from eye margin, the front ocellus a little behind the center of the front and vertex; the eyes nearly glabrous. Antennal scape flattened and gradually becoming wider on apical half; pedicel but little longer than the first three funicle joints combined; all funicle joints distinctly wider than long and subequal in length, the fifth twice as wide as the first; club oval, obliquely rounded at apex, slightly wider at apex than the last funicle joint and as long as the entire funicle. Wings uniformly ciliated; the oblique hairless streak not quite reaching the posterior margin of wing, and interrupted a little below the middle; none of the veins with bristle-like hairs. Ovipositor protruded about one-fifth the length of abdomen. Length: 0.7 to $1 \mathrm{~mm}$., exclusive of ovipositor.

Front, vertex, and mesonotum rather dull orange yellow, the mesonotum usually somewhat dusky, with the anterior margin of the scutum sometimes blackish, but the axillary sutures usually not lined with black; face, cheeks, and underparts pale yellowish white, the venter of abdomen slightly dusky, the cheeks with a pale fuscous, narrow, transverse band following the lower orbits of eyes; the concealed part of occiput and of pronotum, the metanotum, propodeum, and dorsum of the abdomen black; collar of pronotum and tegulae whitish, former with a brown dot on each corner, latter with the lower apical corner brown. Antennae excepting the club black, the base of scape especially on inner surface whitish, the club snow white; rarely the fifth funicle joint is also white. Legs concolorous with underparts, the tarsi more yellowish, with tip of the last joint blackish; middle tibiae with a very faint, dusky annulus near the middle. Wings with a faint brownish, integumentary, transverse cloud beyond the oblique hairless streak, interrupted by a narrow, transverse, hyaline band at end of stigmal vein, and by a still narrower, longitudinal streak following posterior margin of wing opposite the marginal vein; veins pale brownish. Exserted part of ovipositor yellow, the apex dusky.

Male. Similar to the female, but the front and vertex hardly over twice as long as wide; the dorsal orbits of eyes parallel; face and cheeks shorter; antennae slenderer, the pedicel and club proportionately longer, pedicel as long as the first four funicle joints, the club as long as the funicle and one-half the pedicel. 
Coloration the same, except that the sides of the abdomen behind the vibrissal plates are yellowish, and the antennal scape blackish, paler at base, pedicel paler blown, first two funicle joints and most of club white, rest of funicle and extreme base of club black. Wings nearly hyaline. Length: 0.65 to $0.8 \mathrm{~mm}$.

Material as follows has been examined: Three females, (cotypes) reared from Pseudococcus sp. on passion-flower in summer of 1886 (A. Koebele), three females reared from Pseudococcus sp., Nov. 9, 1907, Los Angeles, California (E. M. Ehrhorn), two females, two males reared from Pseudococcus ryani (Coquillett), Pasadena, California, the females July 28-30, 1911, the males some time later (P. H. Timberlake), one male reared from Pseudococcus sp. on Ariemisia californica, Nov. 22, 1912, Whittier, California (P. H. Timberlake), one female reared from Pseudococcus citrophitus Clausen, Sept. 1, 1914, Uplands, California (C. P. Clausen), and a series of both sexes reared from Pseudococcus longispinus (Targioni Tozzetti) during the latter part of Sept., 1914, Pasadena, California (R. S. Woglum).

Type.-Cat. No. 5044, U.S.N.M.

\section{Genus ACEROPHAGUS Emily A. Smith.}

Acerophagus Smith, North Amer. Entom., vol. 1, 1880, p. 83.

Rhopoideus Howard, Proc. U. S. Nat. Mus., vol. 21, 1898, p. 235.

Comes nearest to Pseudaphycus, but the shorter, more robust body, the broader head, as well as differences in the dentition of the mandibles will separate the known species.

Female.-Head as seen from the side imperfectly triangular, moderately thick antereo-posteriorly, dorsal aspect gently rounded, passing into face by a rounded angulation; face and cheeks moderate in length, the former a little longer than the transverse diameter of eyes, as seen from in front the head, therefore about as wide as long, nearly circular in outline; antennal scrobes moderately deep, extending nearly the length of face and uniting above; eyes rather small, oval or a little wider anteriorly, frequently pubescent, the long axis obliquely vertical; occiput rather deeply concave, the neck inserted near the middle; front and vertex usually broad, the ocelli more frequently arranged in a right or obtuse-angled triangle, the posterior pair about twice their own diameter from the occipital rim. Mandibles rather long and slender, tridentate, the two upper teeth subequal, the lower tooth smaller and more basal. Antennae inserted near the mouth, their bases far apart, scape moderate in length, slender and flattened, reaching but little beyond the plane of front and vertex; pedicel about as long as the first three funicle joints; funicle 5-jointed, all the joints short, increasingly transverse; club oval, about as long as the funicle. Thorax short and robust, the mesoscutum twice as wide as long, the axillae meeting, scutellum nearly as wide as long, its apex 
slightly rounded. Abdomen short, subrotund and flat in life, but after death the dorsum becomes more or less concave, and the sides compressed; the fifth ventral sclerite reaches to the apex of abdomen and incloses the ovipositor; the latter usually shortly protruded. Legs moderate in length, rather slender, but the hind femora may be slightly or moderately flattened. Wings moderate or small in size; the marginal vein punctiform, the postmarginal but little longer; stigmal moderately developed, running nearly parallel with the anterior margin of the wing, and enlarged at apex. Hind wings narrow, the costal cell very narrow throughout its length but reaching to the hooklets. Sculpture of head and thorax alutaceous, punctures if present microscopic, pubescence very fine and inconspicuous but sometimes abundant. Coloration entirely yellow of different shades, the antennae and legs concolorous.

Male.-Similar to the female in all characters.

Type of genus. - Acerophagus coccois Smith.

The species here included in Acerophagus are all parasitic in Dactylopiine hosts, so far as definitely known, belonging to the genera Pseudococcus, Phenacoccus, and Erium.

Metallon Walker differs in being metallic and in having rudimentary wings; Rhopus Foerster has the body much flattened and the antennae dissimilar in the male sex; Psylledontus Crawford is separated by metallic coloration, the much smaller antennal club and by the noncompression of the abdomen after death. In these three genera the structure of the fifth ventral sclerite is not described, but probably in all three it reaches only to the middle of the venter and leaves the ovipositor free. Rhopoideus Howard can not be distinguished from what is here considered to be Acerophagus Smith. Howard was misled in stating that the mandibles of Rhopoideus citrinus are edentate, as there are three teeth as described for the other species here considered. Rhopoideus has no affinity with Arrhenophagus Aurivillius, with which it was placed by Ashmead.

ANALYTICAL KEY OF SPECIES.

1. Ocelli in a right or obtuse-angled triangle, ovipositor protruded ................ Ocelli in a rather acute-angled triangle, ovipositor not protruded.1. coccois Smith.

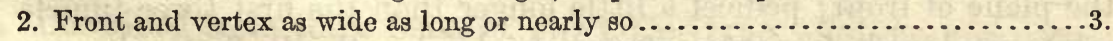
Front and vertex about one-half longer again than wide.

Anterior ocellus in center of front and vertex, ocellar angle slightly less than $90^{\circ}$.

2. texanus (Howard).

Anterior ocellus considerably behind the center of front and vertex, ocellar angle

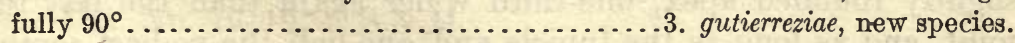

3. Front and vertex fully as long as wide.................... erii, new species.

Front and vertex wider than long, wings small, extending but shortly beyond apex of abdomen.................................... citrinus (Howard). 
1. ACEROPHAGUS COCCOIS Smith.

Acerophagus coccois Sмiтн, North Amer. Entom., vol. 1, 1880, p. 84, figs. 20-23.

Rhopus coccois Howard, Rept. Comm. Agric. for 1880, 1881, p. 361, pl. 24, fig. 2.

Metallon coccois Ashmead, Proc. U. S. Nat. Mus., vol. 22, 1900, p. 407.

Female.-Front and vertex about twice as long as wide; ocelli in rather an acute-angled triangle. Antennal scape short and flattened; pedicel nearly as long as the funicle joints combined; the latter all short, wider than long, subequal in length, and increasing in width, the fifth nearly twice as wide as the first; club large, oval, rather pointed at apex, and as long as funicle and pedicel combined. Wings uniformly ciliated, the oblique hairless streak narrowed above and separated below from the posterior border of the wing by only one row of cilia. Ovipositor not protruded. Length, $0.6 \mathrm{~mm}$.

Notum of thorax and abdomen orange yellow, head chrome lemon yellow, under side of thorax, the antennae, and legs pale yellowish. Wings hyaline, the veins nearly colorless.

Redescribed from one female reared from Phenacoccus acericola King, July 20, 1898, Springfield, Massachusetts (R. A. Cooley), apparently correctly identified. The head and antennae are much shriveled so that the above description may not be fully accurate in all details. The location of Miss Emily Smith's types is not known, if indeed they are still in existence.

\section{ACEROPHAGUS TEXANUS (Howard).}

Fig. 52.

Aphycus texanus Howard, Proc. U. S. Nat. Mus., vol. 21, 1898, pp. 241, 245.

Female.-Front and vertex about three-fourths longer again than wide, narrowest near the middle; ocelli in a little less than a rightangled triangle, the posterior pair not quite their own diameter from the eye margin and nearly twice their diameter from the occipital rim, the front ocellus at the center of the front and vertex; face as long as the length of the eyes, the scrobes deep and prominent, gradually converging and uniting above; eyes about one-fourth longer than wide, covered with a thick but very short, fine pubescence. Antennal scape slender, slightly thicker at the middle, hardly extending beyond the plane of front; pedicel a little longer than the first three funicle joints combined; funicle joints subequal in length, the first as long as wide, the following increasingly transverse, the fifth being twice as wide as the first; club thicker near base, gradually tapering to a slightly rounded apex, one-third wider again than the last funicle joint, and as long as the funicle and one-half the pedicel combined. Wings uniformly ciliated; oblique hairless streak widened below and narrowly separated from the posterior margin of wing. Ovipositor protruded about one-fourth the length of the abdomen, exserted portion covered with long pubescence. The pubescence of head and 
thorax abundant but inconspicuous on account of its pale color. Length, $0.8 \mathrm{~mm}$., exclusive of ovipositor.

Head, thorax, and abdomen uniformly deep orange yellow, with a slight brownish tinge, antennae and legs concolorous but slightly paler. Wings nearly hyaline, but a faint, integumentary yellowish cloud present on the basal half to the tip of the stigmal vein; the veins pals brownish. Exserted part of ovipositor blackish at apex.

Male.-Similar to the female, but the front and vertex a little wider, not over one-half longer than wide; the front, face, cheeks, and underside of body paler yellow; the wings perfectly hyaline. Length: $0.7 \mathrm{~mm}$.

Redescribed from eight females (cotypes), one male reared from Pseudococcus virgatus (Cockerell), July 3, 1895, Brownsville, Texas (C. H. T. Townsend), Insectary No. $5636^{03}$, the male not forming a part of the type series.

Type.-Cat. No. 5046, U.S.N.M.

\section{ACEROPHAGUS GUTIERREZIAE, new species.}

Aphycus texanus Cockerell and Parrott (not Howard), Industrialist, May, 1899, p. 278.

Female.-Similar to A. texanus (Howard) in all respects but the following: Front and vertex a little wider, about one-half longer than wide, more coarsely alutaceous; the ocelli fully their own diameter from the eye margin, the anterior ocellus considerably posterior to the center of the front and vertex, the ocellar angle fully $90^{\circ}$. Antennal scape slenderer, the pedicel as long as the first four funicle joints. Wings with the oblique hairless streak more narrowly separated from the posterior margin of wing. Ovipositor protruded slightly more or nearly one-third the length of abdomen. Length: $0.7 \mathrm{~mm}$.

Coloration entirely paler than in $A$. texanus, the notum of thorax pale orange yellow, the head, underparts, and appendages still paler yellow. Wings nearly hyaline, showing but a slight trace of a yellowish cloud on basal half.

Male.-One poorly preserved male with the head missing shows no marked divergence from the female in coloration.

Described from three females, one male (type, allotype, and paratypes) reared from Pseudococcus gutierreziae (Cockerell), Las Cruces, New Mexico (T. D. A. Cockerell), Insectary No. $7282^{\circ 1}$, all in poor condition.

Type.-Cat. No. 19119, U.S.N.M.

\section{ACEROPHAGUS ERII, new species.}

Female.-Front and vertex but very slightly longer than wide; the ocelli in a slightly obtuse-angled triangle, the posterior pair their own diameter from eye margin, and nearly twice their diameter from $10600^{\circ}$-Proc.N.M.vol.50-16-37 
the occipital rim; face as long as the length of the eyes, the antennal scrobes obscure; eyes about one-fourth longer than wide, nearly bare. Antennal scape reaching but little beyond plane of the front, flattened and a little wider near the middle; pedicel as long as the first four funicle joinst combined; funicle joints one to four subequal in length, the first a little wider than long, the following increasingly transverse, the fifth one-half wider again than the first and one-third longer; club elongate oval, one-half wider again than last funicle joint and as long as the funicle and one-third of the pedicel combined. Wings uniformly ciliated; the oblique hairless streak with an enlarged and cutoff portion below, which does not quite reach the posterior border of wing. Ovipositor protruded about one-fifth the length of the abdomen, the exserted portion hardly pubescent. Pubescence of head and thorax scanty. Length, $0.7 \mathrm{~mm}$., exclusive of ovipositor.

Notum of thorax gamboge yellow, the head and underparts paler yellow, and abdomen more decidedly orange; antennae and legs concolorous with head and underparts; exserted portion of ovipositor almost entirely black. Wings hyaline, the veins nearly transparent. Pubescence of head and thorax whitish.

Male.-In all respects similar to the female, but the front and vertex a little wider than long, and the posterior ocelli farther removed from the eye margin. Coloration the same but thorax paler and contrasting more with the deeper orange-colored abdomen. Length: $0.6 \mathrm{~mm}$.

Described from ten females, two males (type, allotype, and paratypes $a$ to $j$ ) reared from Erium lichtensioides (Cockerell), Salt Lake City, Utah, July 14-16, 1913 (P. H. Timberlake), three of the females (paratypes $g$ to $i$ ) mounted in balsam, rest tag-mounted.

Type.-Cat. No. 19120, U.S.N.M.

\section{ACEROPHAGUS CITRINUS (Howard).}

Rhopoideus citrinus Howard, Proc. U. S. Nat. Mus., vol. 21, 1898, p. 235.

Female.-Front and vortex distinctly wider than long, rather coarsely alutaceous; ocelli in an obtuse-angled triangle of about 105 degrees, anterior ocellus at the center of the front and vertex, posterior pair their own diameter from the eye margin and twice as far from the occipital rim; face and cheeks of normal length, the former as long as the length of the eyes, antennal scobes rather deeply impressed; eyes rather small, one-fourth longer than wide, hardly pubescent. Antennal scape reaching but shortly beyond plane of the front, flattened but narrow; pedicel as long as first four funicle joints combined; funicle joints all wider than long, nearly equal in length, and gradually increasing in width so that the fifth is nearly twice as wide as the first; club large, oval, rather pointed at apex, twice as wide as last funicle joint and as long as the funicle and two-thirds of 
the pedicel combined. Wings small, reaching but little beyond apex of abdomen; uniformly ciliated; oblique hairless streak wide especially on its lower half and separated by about one row of cilia from the hairless streak on the posterior margin of wing; stigmal vein thick and not much narrowed at base. Ovipositor protruded about onefourth the length of the abdomen, the exserted portion pubescent. Pubescence of head and thorax scanty. Length: $0.6 \mathrm{~mm}$., exclusive of ovipositor.

General color, pale orange yellow, the head and underparts slightly paler; antennae and legs concolorous; exserted portion of ovipositor blackish at apex. Wings hyaline, the veins pale brownish. Pubescence of head and thorax whitish.

Male.-Similar to the female, but head, thorax, and underparts paler, more gamboge yellow, and the abdomen deep bright orange yellow. Length: $0.55 \mathrm{~mm}$.

Redescribed from eight females, one male (cotypes), Truckee, California, September, 1885 (A. Koebele), Insectary No. 3821x, one female not belonging to the type series. Host unknown; neither of the insects mentioned by Howard seem likely to be hosts, as all the closely allied forms have been reared from Dactylopiine coccids.

Type.-Cat. No. 5027, U.S.N.M.

\section{Genus AENASIOIDEA Girault.}

Aenasioidea Grrault, Can. Ent., vol. 43, 1911, p. 171.

Female.-Differs from Aphycus Mayr only in the following particulars: Teeth of the mandibles slightly less equal, the upper two being blunt and broad, the lower a little shorter and more acute; antennal pedicel shorter, no longer than the first two funicle joints combined, sometimes no longer than the first joint alone; funicle joints longer and narrower, all usually longer than wide, rarely with the terminal joints a little wider than long, and not increasing greatly in width distad, the club smaller and oval; flagellum on the whole therefore more cylindrical, but the scape is flattened and usually widely expanded below, as in many species of Aphycus. The fifth ventral sclerite of the abdomen reaching to the anus and inclosing the ovipositor, but not plowshare-shaped as originally described, except possibly to a slight degree after death through shrinkage. In shape of head, thorax, and abdomen, in sculpture, vestiture, type of coloration, and venational characters not differing from Aphycus.

Male.-Like the female except, that the head is thinner antereoposteriorly and wider, the front and vertex therefore wider; eyes smaller and the ocelli larger; antennae of a more primitive structure than in the female, the scape being flattened but not much expanded below, the pedicel shorter than the first funicle joint, the funicle 
cylindrical and hardly at all increasing in width distad, clothed with an abundant and rather long pubescence, which is suberect and equally thick throughout, the club solid and pubescent at its base like the funicle.

Type of genus.-Aenasioidea latiscapus Girault.

Aenasioidea has no close affinity with Aenasius Walker, with which it was compared by Girault, but on the other hand has descended evidently from an ancestral type common to both itself and Aphycus. The four known species, three from North America and one from Japan, were all reared from species of Kermes.

ANALYTICAL KEY OF SPECIES.

FEMALES.

1. Front and vortex longer than wide.

Front and vertex wider than long, the ocelli in an obtuse-angled triangle.

1. A. pulchella (Howard).

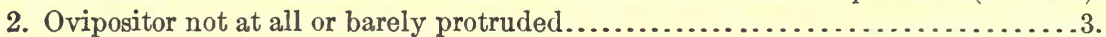
Ovipositor protruded prominently, the scape wider on the basal half, the apical half narrow ............................... A. tenuicornis, new species.

3. Notum of throrax blackish brown, the tibiae annulated with black.

3. A. kermicola, new species.

Notum of thorax orange yellow, the tibiae not marked....4. A. latiscapus Girault.

\section{r. AENASIOIDEA PULCHELLA (Howard)}

Fig. 3.

Aphycus pulchellus HowARD, Proc. U.S.Nat.Mus., vol. 21, 1898, pp. 240, 242.

Female.-Front and vertex wider than long; ocelli in a slightly obtuse-angled triangle, the posterior pair more than their own diameter from the eye margin; antennal scrobes narrow and deep and not uniting above. Antennal scape more than one-half as wide as long, widest beyond the middle; pedicel about one-third longer than the first funicle joint; funicle joints but slightly increasing in width, the first three a little longer than wide, the last three about as wide as long; club oval, somewhat pointed at apex, a little wider than the preceding joint, and equal in length to the last two funicle joints and one-half of the fourth combined. Wings uniformly ciliated; oblique hairless streak contracted above, subinterrupted below, the cut-off portion nearly reaching the posterior border of wing and connecting with a spur of the hairless streak present on the posterior margin of wing. Ovipositor not protruded. Length: 1.3 to $1.4 \mathrm{~mm}$.

Front, vertex, upper rim of occiput, and entire mesonotum deep orange yellow; hidden portion of occiput and of pronotum, entire metanotum, propodeum and dorsum of abdomen blackish brown; face, cheeks, collar of pronotum, tegulae except for brownish spot, and 
underparts, including venter of abdomen and the legs, yellowish white. Antennal scape black with the base, upper margin, and apex narrowly yellowish; pedicel brown with apex yellowish white; first two to four funicle joints brown gradually fading into the pale yellowish of the last two or more joints of the funicle and the club. Wings hyaline, the veins dilute yellowish.

Male. Similar to the female in structural and colorational characters except as to the antennae. Scape but slightly expanded, widest beyond the middle, and about one-fourth as wide as long; pedicel shorter than the first funicle joint, its width at apex nearly equal to its length; funicle joints not increasing in width, first two of nearly equal length, about one-half longer than wide, last two slightly shorter but longer than wide; club elongate oval, hardly wider than preceding joint and as long as the last two and one-half of the fourth fanicle joint, rounded at apex. The scape concolorous with the face, its upper margin on the outer side blackish brown; the pedicel, funicle, and club uniformly brown. Length: $1.3 \mathrm{~mm}$.

Redescribed from seven females, three males (cotypes) reared from Kermes sp. on Quercus tinctoria, Ithaca, New York, January 25-30, 1890 (L. O. Howard), Insectary No. 763 ${ }^{01}$ Originally described from nine specimens all supposed to be females, and it seems impossible to determine which one of the above ten specimens can not be considered a cotype.

An additional female from Oklahoma is considerably larger, but identical in coloration as far as preserved, the antennae being broken off at the end of the fourth funicle joint. Differs only that the first funicle joint is hardly longer than wide, noticeably smaller than the second, the pedicel proportionately a trifle longer, and the scape slightly wider, its lower margin more fully rounded. Length: 1.8 mm. Specimen is labeled "Okla., 727."

Type.-Cat. No. 5035, U.S.N.M.

\section{AENASIOIDEA TENUICORNIS, new species.}

Fig. 20.

Female.-Front and vertex about three-fourths longer again than wide; ocelli nearly in a right-angled triangle, the posterior pair about one-half their own diameter from the eye margin; antennal scrobes deep; eyes nonpubescent. Antennal scape expanded on the basal half, rapidly narrowing so that most of the apical half is narrow, the greatest width nearly one-third the length; pedicel a little longer than the first and about equal to the second funicle joint; all joints of the funicle longer than wide, not increasing in width, filiform, first and last about equal, the second to fifth a little longer and about three times as long as thick; club cylindrical like the funicle, very little wider, as long as the last two joints and one 
half of the fourth funicle joint, rounded at apex, its first joint longer than either of the following two. Wings uniformly ciliated; oblique hairless streak widened below with the small rounded cut off portion widely separated from the posterior margin of the wing, and not connecting with the basal hairless streak which hardly extends by point opposite the end of the oblique streak. Ovipositor protruded about one-fourth the length of the abdomen. Length: 1.4, exclusive of ovipositor.

Front, vertex, and mesonotum orange yellow, the front paler and the vertex slightly dusky behind the ocelli; face, cheeks, lower half of occiput, and entire underparts yellowish white, the face with a narrow, interrupted blackish band between the lower corners of the eyes, and the cheeks with a large blackish spot in their middle; upper half of occiput, concealed part of pronotum, the metanotum, propodeum, and dorsum of the abdomen black, the sides of the latter narrowly whitish from near base to apex; collar of pronotum and tegulae whitish, the former with a blackish brown dot on each corner, the latter with a pale brown dot on the posterior margin. Basal expanded portion of the antennal scape black, the black continuing in a narrow line to apex on the outer face, a narrow line along base and upper margin of inner face of expanded portion and the whole of the apical portion except the black line whitish; funicle and club nearly uniformly brownish black, but apex of the last four funicle joints have a whitish dot on the upper side. Legs concolorous with the underparts, each tibiae with two pairs of blackish dots and an additional dot at the knee joint and at apex of tibiae, the dots at the middle of the middle and hind tibiae obliquely arranged; tip of last joint of all tarsi blackish. Exserted portion of ovipositor pale brown but more yellowish on the under side. Wings hyaline, the veins pale yellowish.

Male.-Front and vertex as wide as long; ocelli in a right-angled triangle, the posterior pair about one-third of their own diameter from the eye margin. Antennal scape shaped as in the female, but slightly narrower; pedicle shorter than the first funicle joint, about one-third as long again as wide; funicle joints all of the same length and cylindrical, a little more than twice as long as thick; club as long as the two preceding joints combined and no thicker. Length: $1.0 \mathrm{~mm}$.

A spot on the cheeks, the vertex, upper half of occiput, concealed part of pronotum, most of the mesonotum, the metanotum, propodeum, and dorsum of abdomen black; face, cheeks otherwise, lower half of the occiput and the underparts pale yellowish; posterior corners of the mesoscutum yellow; tegulae and collar of the pronotum whitish and marked as in the female. Antennal scape whitish with a narrow black line.along the upper margin of the outer face and 
with a black, oval spot on inner face of expanded portion; the flagellum brownish. Legs and wings as in the female.

Described from three females, one male (type, allotype, and paratypes) reared from Kermes miyasakii Kuwana, Akabane, Japan, August, 1909 (S. S. Kuwana).

Type.-Cat. No. 18376, U.S.N.M.

3. AENASIOIDEA KERMICOLA, new species.

Fig. 4.

Female.-Front and vertex about one-half longer again than wide; ocelli in an equilateral triangle, the posterior pair about their own diameter from the eye margin; antennal scrobes narrow and deep, uniting above, but not so conspicuous as in $A$. puchella; the eyes with a scanty, fine pubescence. Antennal scape over half as wide as long, widest across the middle; pedicel about one-third longer than the first funicle joint; funicle joints all of nearly equal length and increasing slightly in width, the first three a little longer than wide, the fourth as wide as long, the last two slightly wider than long; club oval, with apex rounded, about one-third wider than the last funicle joint and nearly as long as the last three funicle joints combined. Wings uniformly ciliated; oblique hairless streak widened and interrupted below, the cut-off portion connecting with a branch of the basal hairless streak on posterior margin of wing. Ovipositor not protruded. Length: 0.75 to $1.25 \mathrm{~mm}$.

Front and vertex, upper rim of occiput, and upper part of face above the lower corners of the eyes gamboge yellow; rest of face, cheeks, and sides of occiput pale chrome yellow; collar of pronotum, tegulae, and underparts grayish white, the venter of abdomen more dusky, especially in the middle, and a brown spot on each corner of the collar and one on the hind margin of the tegulae; mesonotum blackish brown, changing to dusky gamboge yellow on the sides, the axillae being almost entirely yellowish; hidden portion of the occiput and of the pronotum, the metanotum, propodeum and dorsum of the abdomen black, the latter with the sides behind the vibrissal plates narrowly whitish. Antennal scape black, with base, apex, and a narrow line on the upper margin white; pedicel black at base, the apical two-thirds white; first two funicle joints blackish, the third somewhat dusky, and the last three yellowish white; club slightly more yellowish. Legs dirty whitish, with a dusky mark on the upper surface of all the femora, smaller and darker on the middle pair; the tibiae with two blackish annuli, narrow on the middle pair and wider on the front and hind pair; the tarsi more yellowish, the last joint blackish. Wings hyaline, the veins dusky yellowish. 
Male.-Front and vertex no longer than wide; ocelli in a rightangled triangle, the posterior pair one-half their own diameter from the eye margin. Antennal scape much narrower than in the female, only one-fourth as wide as long; pedicel a little shorter than the first funicle joint; funicle cylindrical, barely increasing in width distad, the first three joints subequal in length and distinctly longer than wide, the last three joints slightly shorter, but still longer than wide unless they collapse or flatten on drying, when the fifth and sixth are about as wide as long; club elongate oval, rather pointed at apex, barely wider than the last funicle joint and as long as the last two and one-half of the fourth joint of the funicle. Length: 0.75 to $1.0 \mathrm{~mm}$.

Coloration similar to the female, but the mesonotum is pure dull black with the yellow on the sides less extensive and more contrasting; the black of occiput may encroach on the vertex to the ocellar region; face entirely pale yellowish. The antennal scape and apex of pedicel yellowish white; base of pedicel, an oval spot on inner face of scape, and upper margin of the outer face except at base and apex black; the funicle and club uniformly pale brown.

Described from seventeen females, one male (type, allotype, and paratypes $a$ to $p$ ) reared from Kermes essigii King on Quercus agrifolia, Pasadena, California, August 7, 1912 (P. H. Timberlake), and four females, two males (paratypes $q$ to $v$ ) reared from Kermes galliformis Riley, Murray, Utah, September 16-21, 1914 (P. H. Timberlake).

The paratypes from Murray, Utah, differ slightly from the Pasadena specimens in having the mesonotum more yellowish with less black, and in having the last funicle joints as long as wide. The male from Pasadena is poorly preserved, so that a comparison in this sex is not possible, but the coloration seems nearly identical.

Type.-Cat. No. 18370, U.S.N.M.

\section{AENASIOIDEA LATISCAPUS Girault.}

Aenasioidea latiscapus Girault, Can. Ent., vol. 43, 1911, p. 173.

Female.-Front and vertex about one-half longer again than wide; ocelli in an equilateral triangle, the posterior pair about their own diameter from the eye margin and a little farther removed from the occipital rim; antennal scrobes rather narrow and deep, uniting above. Antennal scape one-half as wide as long, widest across the middle; pedicel nearly as long as the first two funicle joints combined; funicle cylindrical but slightly increasing in width distad, the first four joints distinctly longer than wide, the last two hardly so, the sixth being as wide as long, the third joint longest, the fourth slightly shorter, other four joints subequal and noticeably shorter; club oval, as long as the last three funicle joints combined and nearly twice as wide as the preceding joint. Wings uniformly 
ciliated; oblique hairless streak slightly wider below and interrupted, with the cut-off portion rather widely separated from the posterior border of the wing. Ovipositor barely protruded, at least when material is mounted in balsam, probably not noticeably so in life or dry material. Length: $1.1 \mathrm{~mm}$.

Front, vertex, and mesonotum rather pale orange yellow; face, cheeks, underparts, and most of the abdomen much paler yellow; center of occiput dusky; concealed part of pronotum, a narrow, transverse line on the anterior margin of the mesoscutum, the metanotum, propodeum, and a transverse band at the base of abdomen blackish; collar of pronotum and the tegulae pale yellowish. Antennal scape black, with the base, a narrow line on upper margin and apical fourth whitish; basal third of pedicel and the first funicle joint black; apex of the pedicel and rest of the funicle and club yellowish white, with the second funicle joint somewhat dusky. Legs pale yellowish, with the tip of the last joint of the tarsi blackish. Wings hyaline, the veins pale yellowish.

\section{Male.-Not known.}

Redescribed from three females (cotypes) reared from Kermes pubescens Bogue, Urbana, Illinois, June 25, 1908 (A. A. Girault), loaned by the Illinois State Laboratory of Natural History.

\section{APHYCOPSIS, new genus.}

Comes closest to Aphycus Mayr, and is similar in general shape of head and body, type of coloration, sculpture, and vestiture of body. The structure of the abdomen also seems to be identical as far as can be made out in the limited material at hand. The more striking differences are as follows:

Female.-Antennal scape not flattened or expanded but clavate cylindrical, much thicker at apex than at base, with a groove for the reception of the pedicel; the pedicel nearly as thick at apex as long, and but little longer than the first funicle joint; funicle about as in Aphycus, but the pubescence is comparatively coarse and bristle-like; club oval, somewhat obliquely rounded above at apex, and about as long as the last three funicle joints combined. Venation of wings the same, except that the postmarginal vein is much longer than in Aphycus, and nearly as long as the stigmal. The tibiae of the middle legs enlarged at apex, and the middle tarsi swollen.

Male.-Not known.

Type of genus.-Aphycus australiensis Howard. 


\section{APHYCOPSIS AUSTRALIENSIS (Howard).}

Fig. 33 .

Aphycus australiensis HowARd, Proc. U.S.Nat. Mus., vol. 21, 1898, pp. 241, 245.

Female.-Front and vertex one-half longer again than wide; ocelli in an obtuse-angled triangle, the posterior pair about their own diameter from the eye margin; antennal scrobes deep and moderately wide, converging and nearly uniting above, the facial prominence well elevated; eyes nearly bare. Antennal scape subcylindrical with the apical half somewhat swollen and excavated on the under side, nearly four times longer than greatest diameter; pedicel about equal to the third funicle joint in length and greatest width; all funicle joints of nearly equal length, the first, fifth, and sixth a trifle shorter, all increasing somewhat in width distad, the first a little longer than wide, the second about equal in length and width, the following more transverse, the sixth being nearly twice as wide as the first; club somewhat oval, truncate at base, obliquely rounded at apex, its first joint over twice as long as the third, its width slightly greater than that of the last funicle joint, and its total length equal to the last three funicle joints combined; all parts of antennae covered with moderately thick, stiff, bristlelike hair. Wings uniformly ciliated; oblique hairless streak narrowed above and extending below almost to the posterior border of wing and nearly connecting with the basal hairless streak. Ovipositor very slightly protruded. Length, $1.4 \mathrm{~mm}$.

Color nearly uniformly orange yellow, slightly dusky on the mesonotum; front and face somewhat brighter or more cadmium yellow; collar of pronotum whitish, but tegulae concolorous though paler than body, both unmarked with darker color; propodeum and center of the dorsum of abdomen brown; legs and antennae concolorous with the body, the club of antennae slightly brownish, and the tip of the last joint of tarsi blackish brown. Wings hyaline, the veins pale yellowish.

Redescribed from two female (cotypes) reared from Pseudococcus sp. on Eucalyptus, Melbourne, Victoria, Australia (A. Koebele).

Type.-Cat. No. 5045, U.S.N.M.

\section{Genus ASTYMACHUS Howard.}

Astymachus Howard, Proc. U. S. Nat. Mus., vol. 21, 1898, p. 238.

The type and only known species, Astymachus japonicus Howard. ${ }^{1}$ will be easily recognized from Doctor Howard's description and need not be further considered here.

Type.-Cat. No. 5031, U.S.N.M. 


\section{Genus APHYCUS Mayr.}

Aphycus Mayr, Verh. zool.-bot. Ges. Wien, vol. 25, 1876, p. 695.

Female.-Head rounded triangular, the occiput concave, the dorsal aspect rounded, the plane of front meeting the facial plane at nearly a right angle, but the angulation rounded off; face nearly flat, sloping downward and backward to the mouth, antennal scrobes usually rather weak, well separated by the facial prominence of cuneate form; cheeks nearly as long as the greatest diameter of the eyes; front and vertex varying considerably in width, but usually much longer than wide; arrangement of ocelli varying from an acute to a right-angled triangle. Antennae inserted close to the mouth, their bases well separated; 11 -jointed, comparatively short, pubescent; the scape flattened vertically, either linear or with a broad leaflike expansion below; pedicel obconical, usually about as long as the first three funicle joints, sometimes a little shorter; funicle joints in most cases wider than long and increasing noticeably in width distad; club rather large; either pointed or truncate at apex, in shape more or less oval, generally wider than the funicle and about two-thirds as long. Mandibles tridentate with the nearly equal teeth rather blunt. Thorax of about the same width as head, robust, the mesoscutum considerably wider than long, the axillae cuneate, meeting medially, the scutellum subtriangular, with rounded base and rather acutely angled apex. Abdomen usually of the same width as thorax and a little shorter, flattened horizontally, ovate to broadly ovate, the apex rather obtusely rounded, the ovipositor not inclosed by the fifth ventral sclerite which reaches about to the center of the venter; the ovipositor sheaths feaching to the apex of abdomen or slightly beyond, more rarely protruded to any considerable length; dorsal vibrissae of abdomen situated about onethird the total length of abdomen from its base. Legs rather short, the middle tibial spur short and stout, not as long as the basal tarsal joint. Wings either hyaline, with an integumentary spot, or banded with areas of dense, dark-colored cilia; oblique hairless streak always present, running from the stigmal vein proximad nearly if not quite to the posterior border of wing; submarginal vein not reaching to the middle of wing except in some of the smaller, shortwinged species; marginal vein punctiform, the postmarginal reduced to a mere spur, stigmal vein moderate in length and straight; costal cell of hind wing narrow but extending to the hooklets.

Sculpture of head and thorax alutaceous, not punctate; head, including eyes, frequently but not conspicuously pubescent; mesonotum with a grayish or white recumbent vestiture of scattered hairs, rather short and stiff, especially prominent in the dark-colored species. Coloration always nonmetallic, of varying shades of yel- 
low, white, brown, and black, yellow usually predominating; antennae usually banded with black and white, rarely of uniform color.

Male.-Closely resembles the female in structural characters, but the head is thinner antereo-posteriorly, the front and vertex wider; eyes smaller and the ocelli larger. Antennae always slenderer, the scape not so widely dilated below, the flagellum more pubescent, and the club always solid. The pedicel in most of the species is as long as the first two or three funicle joints combined, but in a few species the whole antenna shows a more primitive structure, the scape being comparatively short and narrow, the pedicel no longer than the first funicle joint alone, the flagellum still more pubescent, cylindrical or increasing but very slightly in width distad.

The male usually differs but slightly from the female in color but in a few species is much darker. The antennae are frequently not so distinctly banded, and in many species the flagellum is uniformly brownish.

\section{Type of genus.-Encyrtus apicalis Dalman.}

The species of Aphycus are numerous and of exceptional economic importance, as they are parasitic in different species of Lecanium and related genera, and in many cases serve as an efficient check upon the increase of their hosts. Species of the following genera of the Coccinae are known to be parasitized, sometimes even by more than one species: Pulvinaria, Lichtensia, Filippia, Ceroplastes, Coccus, Toumeyella, Lecanium, Saissetia, and Physokermes. Species of Aphycus have also been reared from Tachardia and Eriococcus, but records of Diaspine hosts nust be looked upon with suspicion.

In 1898 Howard ${ }^{1}$ published a table to separate the species in the female sex, and this with many modifications has served as the basis for the following table. This will aid in the identification of the species, and the author hopes that it will prove to be reliable in the great majority of cases.

\section{ANALYTICAL KEY OF SPECIES. ${ }^{2}$}

\section{FEMALES.}

1. Wings uniformly ciliated and without tegumentary markings..............9. Wings either with a band of weaker, paler colored cilia, or with a tegumentary spot.

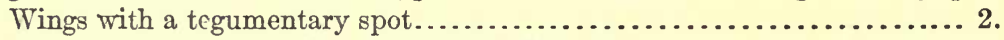

Wings alternately banded with dark and pale cilia................ 4 .

1 Proc. U. S. Nat. Mus., vol. 21, p. 240.

2 Since this synopsis was drawn up the description of A phycus praevidens Silvestri has appeared (Boll. Portici Lab., vol. 9, 1915, p. 295, fig. 52). In the female sex praevidens runs to lounsburyi Howard but the posterior ocelli are more distant from the eye margin; the antennae about the same except that the first three funicle joints are black instead of the first four, and the club is not entirely black; coloration evidently paler, yellowish instead of dark or dusky orange yellow, the metanotum and propodeum without brown markings, the dorsum of the abdomen paler with the brown less extensive. The male is more like pulvinariae Howard in having the flagellum uniformly brown, and the dorsum of the body is described as ochraceous brown or darker than in either lounsburyi or pulvinariae. 
2. Scape of antenna not expanded, club yellow or whitish................ 3 . Scape moderately expanded, club black, preceding joints whitish.

1. maculipennis, new species.

3. Antennae entirely yellowish white, ovipositor slightly protruded.

2. albicornis, new species. Club yellow, preceding joints mostly brown, ovipositor strongly protruded.

3. apicalis (Dalman).

4. Alternate bands on wings not conspicuously contrasting.................. 6 . Dark colored ciliary bands conspicuous and contrasting with pale areas.

Scape widely expanded, wings with only one pale band ............... 5 .

Scape narrower, about one-third as wide as long, an additional pale area at base of wing.................................. lecanii Howard.

5. Mesonotum blackish brown................... 5. fuscipennis Howard.

Mesonotum ochraceous....................... 6. schwarzi, new species.

6. Ocelli in an acute-angled triangle, pale band of wings narrow............. 7 . Ocelli in an equilateral triangle.

Pale band narrow and interrupted on the anterior border of wing, dorsum of abdomen blackish...................... 7. rileyi, new species.

Pale band wide and extending across disk of wing, dorsum of abdomen pale brown............................ 8. subfasciatus, new species.

7. Tibiae marked with one or two pair of small brown dots.................. 8 . Tibiae with heavy blackish annuli................... 9. johnsoni Howard.

8. Coloration pale orange yellow, no black on the propodeum or dorsum of abdomen.

10. cockerelli Howard.

Coloration bright orange yellow, propodeum and dorsum of abdomen blackish

brown................................ similis, new species.

9. Scape not expanded below, or less than one-third as wide as long........... 23.

Scape expanded, at least one-third as wide as long.

Club black or blackish brown, preceding joints whitish............ 10.

Club yellow except at base, preceding joints black.

12. physokermis, new species.

10. Mesonotum orange yellow or yellowish........................... 11 .

Mesonotum blackish brown...................... 13. coquilletti Howard.

11. Ocelli in an acute-angled triangle..................................

Ocelli in an equilateral triangle or nearly so.

Tibiae immaculate...................................... 14 .

Tibiae dotted or banded with blackish........................... 12 .

12. Cheeks not marked with brown next to the mouth...................... 13 .

Cheeks and face brown next to the mouth, front and vertex not over one-half

longer again than wide................ 14. melanostomatus, new species.

13. Scape moderately expanded, front and vertex twice as long as wide or nar-

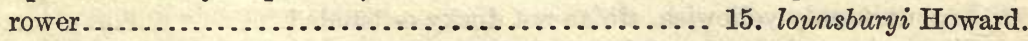
Scape very wide, front and vertex wider than in the preceding

16. punctipes (Dalman).

14. Metanotum, propodeum and abdomen blackish in great part............. 15. Metanatum and propodeum orange yellow, abdomen except the margins brown.

17. albopleuralis Ashmead.

15. Mesonotum bright orange yellow, front and vertex nearly twice as long as wide.

18. kingi, new species.

Mesonotum pale yellow, front and vertex about three-fourths longer again than wide.................................... mayri, new species.

16. Mesoscutum not marked with blackish........................... 17 . Mesoscutum with curved, transverse blackish line on each side near base.

20. lichtensiae Howard. 
17. Tibiae dotted or banded with brown or black....................... 19 .

Tibiae immaculate.

Ovipositor not extending beyond tip of abdomen................ 18.

Ovipositor protruded slightly, no black on occiput, propodeum or abdomen.

21. rusti, new species.

18. First four funicle joints subequal, last two longer...... 22. pulvinariae Howard. First and last funicle joints longer, second to fifth subequal.

23. claviger, new species.

19. Pedicel black or brown at base, with apex white or yellowish ............. 20 . Pedicel brown with a longitudinal streak of white on the upper side.

24. maculipes Howard.

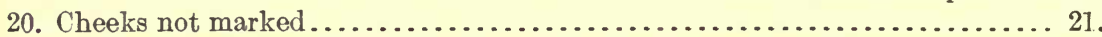

Cheeks blotched with brown next to the mouth...... 25. californicus Howard.

21. Scape moderately or narrowly expanded......................... 22 . Scape one-half as wide as long, club nearly as wide as long, rounded at apex.

26. annulipes (Ashmead). ${ }^{1}$

22. Head and eyes nearly bare, scape narrowly expanded, narrower than club.

15. lounsburyı Howard. Head and eyes moderately to thickly pubescent, scape usually moderately wide, or wider than club.......................... 22. pulvinariae Howard.

23. Ovipositor not protruding or only slightly ......................... 26 . Ovipositor protruded about one-fourth the length of abdomen.

Ocelli in an acute-angled triangle............................ 24.

Ocelli in a right-angled triangle............... 27. oaxacae Howard.

24. Front and vertex over one-half longer again than wide, scutellum and mesopleura concolorous with the scutum ..................................

Front and vertex about one-half longer again than wide, scutellum and most of mesopleura blackish....................... 28. ceroplastis Howard.

25. Abdomen except the sides blackish.............. 29. mexicanus Howard. Abdomen with but little trace of infuscation at the center... 30. eruptor Howard.

26. Front and vertex narrow, ocelli in an acute-angled triangle.............. 27. Front and vertex wide, ocelli in an equilateral triangle.. 31. stomachosus Girault.

27. Club blackish with most of the second and the third joint pale........... 30 . Club entirely brown or blackish.................................. 28.

28. Club brown, funicle either yellowish or brownish.................... 29. Club and first three funicle joints black, last three funicle joints white.

32. eriococci, new species.

29. Scape and pedicel brown, the funicle yellowish, general color of body yellowish brown, more yellow beneath................... 33. brunneus Howard. Antennae entirely brownish, general color black, shining but not metallic.

34. nitens Kourdumoff.

30. Legs uniformly yellowish, tibiae not dusky or banded................... 31 . Tibiae (posterior pair at least) dusky, vertex and notum "testaceous," face yellow................................. 35. hederaceus (Westwood).

31. Scape marked with a small, longitudinal streak on upper margin near apex.... 33. Scape marked with a large, quadrate, oblique spot near or beyond the middle.. 32 .

32. Scape widest just before apex, last two funicle joints a little wider than long.

36. alberti Howard.

Scape widest at the middle, last two funicle joints about twice as wide as long.

37. philippiae Martelli.

\footnotetext{
1 The type of $A$. annulipes (Ashmead) has lost both wings, and it is possible but not likely that they were banded inconspicuously, although Dr. Ashmead does not mention this character. If the wings are banded, the species would run to $A$. similis, from which it differs in having the antennae much shorter and the club rounded at apex.
} 
33. Coloration orange yellow or bright sulphur yellow......... 38. flavus Howard. Coloration pale clay yellow with the sutures of notum lined with blackish.

39. luteolus, new species.

MALES.

1. Antennae short, less pubescent, pedicel longer than first funicle joint........ 2 . Antennae long, thickly pubescent, pedicel shorter than first funicle joint, all funicle joints longer than wide.

Front and vertex about as wide as long, ocelli in an equilateral triangle, tibiae not banded...................... 1. maculipennis, new species.

Front and vertex wider than long, ocelli in an obtuse-angled triangle, tibiae banded.......................... 14. melanostomatus, new species.

2. Wings uniformly ciliated and transparent........................... Wings with a band of more transparent cilia at end of stigmal vein.

Scape rather wide, its lower margin noticeably curved................. 3 .

Scape narrow, wing with two areas of transparent cilia... 4. lecanii Howard.

3. Notum orange yellow........................................ 4 . Notum blackish brown....................... 5. fuscipennis Howard.

4. Eyes and front less densely pubescent with short pile................... Eyes and front densely pubescent with long pile, notum bright orange yellow.

9. johnsoni Howard.

5. Head and notum dark orange yellow, antennae short, club as long as last four funicle joints.......................... 7. rileyi, new species. Head and sides of mesoscutum paler yellow, antennae long, club no longer than last three funicle joints...................... 8. subfasciatus, new species.

6. Scape narrow and not expanded................................. 14 . Scape wide and more or less expanded below.

Front and vertex longer than wide, ocelli in an acute-angled or equilateral triangle........................................... 7 .

Front and vertex as wide as long, ocelli in a right-angled triangle, notum black, yellow on sides..................... 19. mayri, new species.

7. Ocelli in an acute-angled triangle, front and vertex about twice as long as wide. 13. Ocelli in an equilateral triangle or nearly so, front and vertex about one-half longer again than wide.......................................

8. Club not paler than funicle, either concolorous or darker................ 9. Club yellow except at base, the preceding funicle joints black.

12. physokermis, new species.

9. Cheeks not marked with brown............................... 10 Cheeks with a brown spot, tibiae with brown annuli.... 40. oregonensis Howard.

10. Tibiae dotted with brown or black............................. 11 . Tibiae unmarked.

Dorsum of abdomen almost entirely yellowish.....21. rusti, new species.

Dorsum of abdomen black with whitish margins..... 41. amoenus Howard.

11. Coloration deep orange yellow, or with a brownish tinge on notum........ 12. Coloration pale orange yellow, scape black except the base, apex, and a narrow line on upper margin....................... 10. cockerelli Howard. 12. Funicle and club uniformly pale brownish.......... 22. pulvinariae Howard. Last two funicle joints yellowish white, rest of funicle and the club brownish.

15. lounsburyi Howard.

13. Scape rather narrow, pedicel brown at base only.......20. lichstensiae Howard. Scape wider, more expanded below, pedicel brown with a longitudinal paler streak................................ 24. maculipes Howard. 
14. General color yellowish brown or blackish........................ 17 . General color yellow or orange yellow with the dorsum of abdomen sometimes blackish brown.

Notum bright orange yellow.

Notum pale clay yellow, dorsum of abdomen more or less blackish.

39. luteolus, new species.

15. Scape with a small streak of black on upper margin near apex............ 16. Scape marked with an oblique fascia near the middle... 37. philippiae Martelli.

16. Front and vertex only one-fourth longer again than wide, funicle and club uniformly brownish........................... 31. stomachosus Girault. Front and vertex considerably narrower, club usually darker at base than preceding funicle joints............................. 38. flavus Howard.

17. Collar of pronotum whitish with black dot on each corner............. 20 .

Collar of pronotum entirely black, or concolorous with mesoscutum.

Antennae uniformly brownish .............................. 18.

Antennae not uniformly colored ............................... 19.

18. Coloration dark yellowish brown; head yellowish.... 42. immaculatus Howard. Coloration shining black....................... 34. nitens Kourdumoff.

19. Scape yellowish with upper and lower margins darker, cheeks mostly blackish.

23. claviger, new species.

Scape yellowish with an oblique fascia near apex, cheeks mostly yellow.

36. alberti Howard.

20. Venter of abdomen more or less brownish.......................... 21 .

Venter yellowish like rest of underparts............... 30. eruptor Howard.

21. Mesopleura brown............................ 28. ceroplastis Howard.

Mesopleura yellow........................... 29. mexicanus Howard.

In addition to the species given in the above tables, there are in the United States National Museum several unplaced males, which may prove to be the opposite sex of some of the species already described. One interesting species represented only by males (Charlottesville, Virginia) runs in that sex to Aphycus maculipennis and melanostomatus, but differs from either in being almost entirely black in coloration. Another species (also from Charlottesville) runs to Aphycus mayri, and differs in the male sex, in having the mesoscutum entirely black and the pleura except the anterior margin blackish. It is apparent, therefore, that although the North American of Aphycus have been made known for the most part, there still remains much work in correctly assigning and describing the males. This work is the more important, as species which are very similar in the female sex may differ widely in the male sex, for the males may be either essentially like the females in coloration or much different.

It has been found necessary to suppress only one of the described species, Aphycus flaviceps Howard described from supposed females, proving to be identical with the male type of maculipes. It may be pointed out, however, that Aphycus oregonensis Howard, also described from supposed females, in all probability will prove to be the male sex of californicus. The latter species itself is nearly iden- 
tical with certain variations of the eastern pulvinarix and may prove to be a geographical race, separated mainly by slight differences in color.

\section{APHYCUS MACULIPENNIS, new species.}

Figs. 11, 36.

A phycus lecanii KInG (not Howard), Can. Ent., vol. 31, 1899, p. 140.

Female.-Front and vertex twice as long as wide; ocelli in an acute-angled triangle, the posterior pair about half their own diameter from the eye margin; antennal scobes broad and shallow, the facial prominence not much elevated; eyes with a sparse, fine pubescence. Antennal scape about two and one-third times as long as wide, widest just beyond the middle; pedicel a trifle longer than the first two funicle joints combined; first three funicle joints subequal in length, the fourth and sixth slightly longer, and the fifth still more so, the first two and the fifth about as long as wide, the others a little wider than long; club oval, bluntly rounded at both ends, one-fourth wider than last funicle joint and as long as the three preceding joints combined. Disk of wing uniformly ciliated, but the cilia at base of wing beneath submarginal vein are thinner, weaker, and paler colored; oblique hairless streak not reaching the posterior margin of wing. Length, 0.8 to $1.25 \mathrm{~mm}$.

Front, vertex, upper rim of occiput, and entire mesonotum bright orange yellow; face, cheeks, most of occiput, collar of the pronotum, tegulae and underparts creamy white, with the usual dots on collar and tegulae and the apical half of venter brown; concealed part of pronotum, the metanotum, propodeum, and dorsum of abdomen brown, with the basal corners of the latter creamy white. Antennal scape black, with the upper margin white, broadly on the inner face, more narrowly on the outer surface; pedicel except at tip, first two funicle joints, base and under side of the third joint and club black, remainder of antenna white. Legs concolorous with underparts, the tibiae not marked, the tarsi more yellowish, with the tip of the last joint blackish. Wings with a large, brownish spot moderately distinct beneath stigmal vein, sharply limited basally by the oblique hairless streak, entirely tegumentary in nature and not due to the ciliation.

Male.-Head much shrunken in all available specimens, but the front and vertex apparently about as wide as long; ocelli in an equilateral triangle, the posterior pair about their own diameter from the eye margin. Antennal scape a little shorter and narrower than in the female; pedicel a little wider than the first funicle joint and no longer; funicle joints all of about the same length, the last three slightly wider, but longer than wide, the first three considerably longer than wide, all provided with a moderately long pubescence; 
club hardly wider than the last funicle joint, about as long as the last two, and one-half of the fourth joint of funicle, oval in shape and bluntly rounded at apex. Wings as in female, but the oblique hairless streak nearly reaches to posterior margin. Length, 0.75 to $0.9 \mathrm{~mm}$.

Entire upper parts, including front, vertex, upper half of occiput, and pronotum, together with the venter of abdomen, blackish brown; face, cheeks, lower half of occiput, tegulae and pleura pale brownish yellow, the tegulae with the usual brown spot on posterior margin. Antennae brown, with a paler spot across the inner surface of scape near the middle. Legs pale yellowish, unmarked except that the tip of last tarsal joint is blackish. Wings as in the female, but the brown spot is fainter.

Described from seven females, six males (type, allotype, and paratypes $a$ to $k$ ) reared from Lecanium corylifex Fitch, Lawrence, Mass., 1898 (Geo. B. King), Insectary No. $8450^{\circ}$ and $8450^{\circ 4}$.

Type.-Cat. No. 18364, U.S.N.M.

\section{APHYCUS ALBICORNIS, new species.}

Female.-Front and vertex twice as long as wide; ocelli in an equilateral triangle, the posterior pair about their own diameter from eye margin; antennal scrobes shallow; eyes with a thick, but very short, fine pubescence. Antennal scape flattened, linear, not expanded; pedicel as long as the first three funicle joints combined; joints one to three of funicle of equal length and increasing in width with the last three, so that the sixth is more than twice as wide as the first, the last three joints nearly twice as long as the preceding, especially the fifth, which is slightly longer than the fourth and sixth, all wider than long except the first, which is about as wide as long; club broadly ovate, rounded at apex, about as long as the last four funicle joints combined, and after collapsing, one-third wider than preceding joint. Wings with a transverse, curved band at end of stigmal vein of weaker, nearly colorless cilia, cilia also on posterior margin near base of wing become transparent or colorless; oblique hairless streak distinct above, but obscured near posterior margin of wing where the cilia are weaker. Ovipositor slightly protruded and unusually slender. Length, $1.0 \mathrm{~mm}$., exclusive of ovipositor.

Head and body, including face, cheeks, occiput, pronotum, and pleura, except the paler prepectal plates, deep, bright orange yellow, the abdomen on each side having a blackish streak inclosing the vibrissal plates; collar of pronotum not paler or not noticeably so and without the usual dots on the corners; tegulae whitish, with their posterior margin pale brown. Antennae nearly uniformly yellowish white, with the club purer white. Legs yellowish white, 
unmarked except for a brownish streak on upper side of hind tibiae near their base, and tip of last joint of tarsi blackish. Wings with a large, tegumentary, brown band across the disk beneath the marginal vein, extending distad to end of stigmal vein with a convex margin, separated from the very slightly dusky apex of wing by the band of colorless cilia and broken below by a narrow, pale line running parallel and close to the posterior margin of wing; extreme base of wing also infuscated; the veins unusually dark brown.

Described from one female (type) reared from Pulvinaria sp., Ikeda, near Kobi, Japan, May 25, 1901 (C. L. Marlatt), and labeled "Shi-de-Kobashi."

Type.-Cat. No. 18363, U.S.N.M.

\section{APHYCUS APICALIS (Dalman).}

Encyrtus apicalis Dalman, Svensk. Vet.-Akad. Handl., vol. 41, 1820, p. 153. Aphycus apicalis MAYr, Verh. zool.-bot. Ges. Wien, vol. 25, 1876, pp. 695, 696. Microterys apicalis Тномзол, Hym. Skand., vol. 4, 1876, p. 169.

Female.-Front and vertex twice as long as wide; ocelli in an equilateral triangle, the posterior pair a little over one-half their own diameter from the eye margin; antennal scrobes distinct, narrow, converging above but not uniting; eyes with a fine, short pubescence. Antennae lost in single available specimen, but the scape is described as non-expanded by European authorities. Wings not uniformly ciliated, the cilia weak and transparent in a broad, curved band at the end of the stigmal vein, and on the basal part of wing beneath the submarginal vein, proximad of the band the cilia beneath marginal vein strong and dark colored, and on apex of wing moderately developed; oblique hairless streak rather indistinct above, interrupted at the middle with the lower part expanded but separated from posterior margin of wing by a few weak, colorless cilia. Ovipositor protruded about one-half the length of abdomen. Length: $1.1 \mathrm{~mm}$., exclusive of ovipositor.

Head entirely ferrugineous orange yellow; upper parts except a narrow whitish line on collar of pronotum blackish brown, with the sides of mesoscutum orange yellow, and the axillae, metanotum and propodeum paler brown; underparts of thorax orange yellow, with the mesopleura slightly brownish and the metapleura entirely blackish brown; venter of abdomen blackish brown, contrasting with the orange yellow exserted portion of the ovipositor; tegulae whitish with the posterior margin brown. Antennae described by European authorities as having the scape dusky ferrugineous, the flagellum brownish except the club which is yellowish white. Legs pale yellow with the middle and posterior tibiae more or less pale brownish except at apex, and tip of last joint of all tarsi brown. Wings with a large, tegumentary, brown spot beneath stigmal and apical fourth 
of submarginal vein, reaching across disk of wing, obliquely interrupted by the hairless streak, and subinterrupted below by a narrow line of paler color running parallel to the posterior margin of wing, the spot augmented also by character of the ciliation described above; veins pale yellowish:

Redescribed from one female of European origin but without locality label. This species evidently varies in coloration as according to Mayr the notum of thorax may be either brown or orange yellow.

\section{APHYCUS LECANII Howard.}

Figs. 10, 40.

Aphycus lecanii Howard, Proc. U.S.Nat.Mus., vol. 21, 1898, pp. 240, 242.

Female.-Front and vertex about two and one-third times as long as wide; ocelli in an acute-angled triangle, the posterior pair about one-half their own diameter from the eye margin; antennal scrobes shallow and wide; eyes with a rather dense, but short, fine pubescence. Antennal scape about one-third as wide as long, widest beyond the middle; pedicel about as long as the first three funicle joints combined; all funicle joints equal or nearly so in length, gradually increasing in width after the second, the sixth being nearly twice as wide as the first two, all wider than long; club oval with truncate base and rounded apex, nearly one-half wider again than the last funicle joint and as long as the last five preceding joints combined. Wings not uniformly ciliated, cilia blackish on area beneath stigmal vein and on apical fourth of disk, and pale or whitish on an intervening curved band and on most of area beneath the subniarginal vein; oblique hairless streak reaching only about onehalf of the way across disk of wing from stigmal vein, obscured below by the weak ciliation. Length: 0.8 to $1.0 \mathrm{~mm}$.

Front, vertex and mesonotum rather dull orange yellow, the mesonotum frequently becoming dusky after death; face, cheeks, and underparts pale yellowish white, the cheeks sometimes brighter yellow and with a blackish brown spot on lower corner, and the middle of venter on each side of ovipositor sheath pale brownish; concealed portion of the occiput and of the pronotum, the metanotum, propodeum, and dorsum of abdomen blackish brown, the latter with a broad, transverse whitish band near base nearly or quite interrupted in the middle, and with a lateral, submarginal white streak behind the vibrissal plates; collar of pronotum and tegulae whitish, each with the usual brown dots. Antennal scape, base of pedicel, first three funicle joints and club black, the scape with base, apex and a narrow line on the upper margin of the outer face white, but on inner face the white expands and covers whole surface except a large spot on lower apical corner; apex of pedicel 
and last three funicle joints pale yellow. Legs yellowish white, with a pale brown spot on upper side of the femora near apex, and with two blackish brown annuli on all tibiae, sometimes interrupted; tarsi pale brownish yellow, the last joint hardly darker. Wings with contrasting bands of dark and whitish cilia as described above; veins pale brownish.

Male.-Front and vertex a little less than twice as long as wide; ocelli arranged as in the female. Antennal scape a little narrower than in the female, widest across the middle; pedicel shorter and wider, about as long as the first two and one-half of the third funicle joint combined; first funicle joint rounded, a trifle wider than long, following joints distinctly wider than long and increasing in width, the first four subequal in length, the last two somewhat longer; club usually not wider than preceding joint, widest across the base and tapering to bluntly rounded apex, as long as the last four funicle joints combined. Wings as in the female. Length: 0.7 to $0.9 \mathrm{~mm}$.

Coloration very nearly as in the female, but the dark markings of abdomen more extensive and sometimes nearly pure black, with the transverse, basal white band reduced to a spot on each side of dorsum, and the submarginal lateral streaks present but shorter and yellowish in color. The black on antennal scape somewhat more extensive, and the first three funicle joints and club more brownish.

Redescribed from thirteen females, ten males (cotypes) reared from Lecanium on pine (probably Physokermes insignicola Craw) and Lecanium on Heteromeles and Quercus agrifolia, two males from Los Angeles County, California, remainder of specimens ${ }^{1}$ from Alameda County, California (A. Koebele), Koebele's Nos. $193^{\circ}, 215^{\circ}$, and $406^{\circ}$; also a large series of both sexes reared from Physokermes insignicóla (Craw), Santa Maria, California, August 4-24, 1911 (R. C. Wylie), from Lecanium pubescens Ehrhorn and Lecanium corni Bouché, Berkeley, California, March 30 to May 5, 1911 and 1912 (H. J. Quayle, P. H. Timberlake).

The male described by Dr. Howard is a much different insect and appears to be a new species of Blastothrix.

Type.-Cat. No. 5034, U.S.N.M.

\section{APHYCUS FUSCIPENNIS Howard.}

Fig. 1.

Aphycus fuscipennis Howard, Proc. U.S.Nat.Mus., vol. 21, 1898, pp. $240,241$.

Female.-Front and vertex about two and one-half times as long as wide; ocelli in a very acute-angled triangle, the posterior pair a little less than their own diameter from the eye margin; antennal 
scrobes shallow and broad, uniting above, the facial prominence very slight; eyes weakly pubescent. Antennal scape over one-half as wide as long, widest across the middle; pedicel as long as the first three funicle joints combined; all funicle joints wider than long, and increasing in width distad, the last two slightly longer than the preceding, the sixth about twice as wide as long; club about one-fifth wider than preceding joint, subrectangular with the apex truncate, nearly as long as the last four funicle joints combined. Wings not uniformly ciliated, all cilia very dense and black except for a narrow, curved band at end of stigmal vein where the cilia are colorless although as dense as elsewhere; oblique hairless streak extending about two-thirds of the way across disk from the stigmal vein. Length: 1.0 to $1.4 \mathrm{~mm}$.

Front, vertex, and rim of occiput pale yellow, face and cheeks yellowish white, the latter with a brown streak on their lower corners extending narrowly nearly across the oral margin of face; center of occiput, concealed part of pronotum, and most of thorax above blackish brown, the mesoscutum narrowly edged with yellowish on the sides; collar of pronotum and the tegulae whitish, the former with a small, round, blackish brown dot on each corner, the latter with a light brown spot on posterior margin; abdomen above nearly pure black with a yellowish white, narrow, submarginal streak on each side posterior to the vibrissal plates; underparts yellowish white, the venter of abdomen with the sides narrowly and a broad, median, longitudinal band blackish brown. Antennal scape black with upper margin white, and a pale, oval spot on outer face at and near the base; base of pedicel, first three funicle joints and club nearly pure black; apex of pedicel and last three funicle joints white. Legs yellowish white, the femora with two interrupted bands, the tibiae with three narrow annuli of blackish brown; tarsi more yellowish with last joint blackish. Wings conspicuously dusky, due entirely to the black ciliation, and with a narrow whitish band at end of stigmal vein, of which the basal margin is concave and the apical margin straight and transverse.

Male.-Front and vertex about one and a half times as long as wide; ocelli in nearly an equilateral triangle, the posterior pair nearly touching the eye margin; eyes thickly pubescent. Antennae as in the female except that the scape is much narrower, about onefourth as wide as long, its lower margin forming a slight curve, the funicle and club a little slenderer. Wings have the ciliary infuscation much less conspicuous than in the female, and developed to about the same degree as found in the females of $A$. rileyi. Length: $1.3 \mathrm{~mm}$.

Coloration almost the same as in the female, but the spot on the cheeks is much smaller or nearly obsolete; the yellowish white on 
sides of abdomen replaced with dusky reddish; the vertex in region of the posterior ocelli blackish brown; and antennae with the dark parts more brownish, the scape blackish brown with the upper margin and spot on lower margin of outer face near the base whitish, pedicel, the first and part of next two funicle joints and the club blackish brown, rest of flagellum yellowish.

Redescribed from six females, two males (cotypes) reared from Lecanium on Arctostaphylos pungens, Sonoma County, California (A. Koebele), and one female from Mountain View, California (E. M. Ehrhorn). The latter specimen differs from the types in being smaller (1.0 mm. long) and in having the scape somewhat narrower, or not over one-half as wide as long.

Type.-Cat. No. 5033, U.S.N.M.

\section{APHYCUS SCHWARZI, new species.}

Fig. 2.

Female.-Structural details as in A. fuscipennis, but the front and vertex is slightly more than twice as long as wide, and becoming narrower posteriorly. Length: $1.15 \mathrm{~mm}$.

Face and cheeks yellowish white, a spot on lower corners of cheeks smaller and blacker than in fuscipennis, and becoming much fainter on each side of oral margin of face; front, vertex and upper rim of occiput pale dilute brown; mesonotum pale ochraceous brown, becoming darker on the posterior border of the scutum, the axillae and scutellum, and the scutum with a narrow, curved, blackish line on each side near the base; collar of pronotum and tegulae whitish, each with the usual dots; center of occiput, concealed part of pronotum, the metanotum, propodeum and dorsum of abdomen blackish, the latter with lateral margins yellowish white except that the black extends narrowly along the front margin of the first five segments down to the venter for a short distance; underparts yellowish white, the venter with a narrow, median, longitudinal dark band along the ovipositor sheath. Antennal scape blackish with a spot on outer face at base, the upper margin narrowly and apex broadly yellowish white; base of pedicel, first three funicle joints and club blackish, and the remainder of antenna yellowish white. Legs yellowish white, banded as in fuscipennis except that the femoral bands are fainter and reduced. Wings the same but the white band is wider.

Described from one female (type) collected in the Santa Rita Mountains, Arizona, June 11 (Hubbard and Schwarz). Mr. Schwarz states that it must have been taken in Madeira Canyon.

Type.-Cat. No. 18365, U.S.N.M. 
7. APHYCUS RILEYI, new species.

Figs. 7, 38.

Aphycus maculipes Howard (part), Bull. No. 5 (old ser.), U. S. Dept. Agric., Bur. Ent., 1885, p. 18.

Female.-Front and vertex varying from one-fourth longer again than wide to twice as long as wide; ocelli in an equilateral triangle, the posterior pair one-half to fully their own diameter from eye margin; antennal scrobes shallow and broad, the facial prominence but slightly elevated; eyes hardly pubescent. Antennal scape about twice as long as wide or narrower in smaller specimens, widest at or just beyond the middle; pedicel as long as the first three funicle joints combined; funicle joints all wider than long, the sixth about twice as wide as the first, first three subequal in length and width, the last two slightly longer, especially the fifth; club subrectangular, the apex truncate or very bluntly rounded, about one-third wider than the last funicle joint and as long as the five preceding joints combined. Wings not uniformly ciliated, the cilia beneath stigmal vein and on the apical fourth of wing heavy and dark colored, those on an intervening, narrow, curved band weak and paler colored, the pale band interrupted, however, on the upper margin of wing; oblique hairless streak not reaching the lower margin of wing nor connecting with the almost obsolete basal hairless streak. Length: 0.75 to $1.3 \mathrm{~mm}$.

Upper part of face above the lower corners of eyes, front, vertex, and mesonotum dark orange yellow, the anterior margin of the scutum sometimes black; rest of face, cheeks, occiput, and venter of abdomen sordid yellowish white; the pleura, collar of pronotum, and tegulae more creamy white, with a brown dot on each corner of the pronotum, and tegulae with their hind margin brown; concealed part of pronotum, the metanotum, propodeum, and dorsum of abdomen blackish brown, the lateral margins of the latter sordid yellowish. Antennal scape black, with base, apex, and a narrow line on upper margin, more indistinct on the inner face, yellowish white; basal half of pedicel, first two funicle joints, and club black; apex of pedicel and last four funicle joints yellowish white. Legs sordid yellowish white, the tibiae with two subinterrupted, brownish annuli varying somewhat in intensity; last joint of tarsi blackish. Wings nearly hyaline, with a ciliary infuscation on basal half and at apex, and an intervening, narrow, curved, whitish band incomplete on the anterior margin of disk; the veins yellowish.

Male.-Front and vertex about one-third longer again than wide; ocelli in a slightly obtuse-angled triangle, the posterior pair about their own diameter from eye margin. Antennal scape much narrower than in female, hardly over one-fourth as wide as long, but lower margin rounded; pedicel nearly as long as the first four funicle 
joints combined; first two funicle joints subequal in length and width, but little wider than long, the following increasingly wider, the sixth being about twice as wide as the first, the fifth noticeably longer than the others; club more oval and rounded at apex than in the female, about one-fourth wider than preceding joint and as long as the last four joints of funicle combined. Wings as in female. Length, 0.7 to $1.2 \mathrm{~mm}$.

Coloration similar to the female but the center of occiput is dusky or blackish, the black margin of scutum generally more pronounced, the center of the scutum sometimes suffused with dusky, and with two dusky lines on each side near the base, the dorsum of the abdomen without the pale margins, and the dark parts of antennae more brownish. The scape, base of pedicel, first one or two funicle joints, and club brown to blackish brown; the base, apex, and line on upper margin of scape, apex of pedicel, and last four funicle joints yellowish to orange yellow.

Described from one female, twelve males (type, allotype, and paratypes $a$ to $k$ ) reared from Lecanium sp., on Japanese persimmon, Millheim, Texas, April 28 to May 12, 1896 (J. H. Krancher); one female, one male (paratypes $l$ and $m$ ) reared from an unknown host on sumach, St. Louis, Missouri, August 28, 1878 (C. V. Riley); five females (paratypes $o$ to $s$ ) reared from Lecanium corni Bouché, Ithaca, New York, May 10, 1895 (M. V. Slingerland); one female (paratype $n$ ) reared from Lecanium corni Bouché on ash, Guelph, Ontario, June 9, 1907 (T. D. Jarvis); one male (paratype $t$ ) Lansing, Michigan (A. J. Cook); and one male (paratype $u$ ) South Kirtland, Ohio, labeled "A. C. 3524."

Type.-Cat. No. 18366, U.S.N.M.

\section{APHYCUS SUBFASCIATUS, new species.}

Figs. 6, 39.

Female.-Front and vertex about twice as long as wide; ocelli in an equilateral triangle, the posterior pair nearly their own diameter from the eye margin; antennal scrobes shallow and the facial prominence moderately elevated; eyes with a slight, very short pubescence. Antennal scape about one-half as wide as long, widest across the middle; pedicel a little longer than the first three funicle joints combined; funicle joints all subequal in length except the fifth which is about one-fourth longer, all distinctly wider than long except the fifth, the sixth about twice as wide as the first or second; club subrectangular, the apex truncate, about one-third wider again than the preceding joint and as long as the last four funicle joints combined. Wings as in $A$. rileyi except that the band of transparent cilia is wider and extends entirely across disk of wing. Ovipositor barely protruded beyond apex of abdomen. Length, $1.7 \mathrm{~mm}$. 
Front, vertex, most of occiput, and entire mesonotum pale orange yellow; face, cheeks, sides of occiput, collar of pronotum, tegulae, almost the entire underparts, the metanotum, propodeum and abdomen paler yellow, with the center of the dorsum of abdomen brownish, a brown spot on each side of metapostnotum and propodeum partly on each, and the usual brown dots on collar of pronotum and tegulae nearly obsolete; concealed part of pronotum blackish. Antennal scape black with the base and apex rather broadly and a narrow line on upper margin yellowish white; base of pedicel, first two funicle joints and a part of the third and club black; apical two-thirds of pedicel, last three funicle joints and apex of the third yellowish white. Legs yellowish with last joint of the tarsi and two narrow, interrupted annuli on all the tibiae blackish. Wings inconspicuously dusky on base and apex, with a transverse band at end of stigmal vein more transparent, entirely due to character of ciliation; the veins pale brownish.

Male.-Front and vertex about one-half longer again than wide; ocelli nearly in an equilateral triangle, the posterior pair fully their own diameter from the eye margin. Antennal scape narrower than in the female, about one-third as wide as long; pedicel and funicle about the same except that the fifth joint of funicle is relatively shorter and wider; club more oval and bluntly rounded at apex, no wider than the preceding joint and as long as the last three joints combined. Length, $1.5 \mathrm{~mm}$.

Coloration similar to that of female, but the mesonotum more dusky orange especially along the sutures and the sides of the scutum paler; center of occiput, the metanotum, propodeum and entire dorsum of abdomen nearly pure black; dots on corners of the pronotal collar distinct and blackish. Antennae orange yellow with the lower half of scape except at base and apex, the base of pedicel and club black, and the first funicle joint slightly dusky. Dusky and transparent bands of wings less distinct.

Described from six females, two males (type, allotype, and paratypes $a$ to $f$ ) reared from Lecanium cerasifex on elm, Columbus, Kansas, May 11-18, 1908 (W. J. Moore), and one female (paratype $g$ ) labeled "Oklahoma, 864."

Type.-Cat. No. 18367, U.S.N.M.

9. APHYCUS JOHNSONI Howard.

Figs. 8, 37.

Aphycus johnsoni Howard, Proc. U.S. Nat.Mus., vol. 21, 1898, pp. 241, 244.

Female.-Front and vertex about twice as long as wide; ocelli in an acute-angled triangle, the posterior pair about one-fourth their own diameter from the eye margin; antennal scrobes shallow and the facial prominence but slightly elevated; eyes with a very short, fine 
pubescence. Antennae longer than in allied species, the funicle joints and club frequently not collapsing after death; scape about twice as long as wide or a little narrower, widest at or beyond the middle; pedicel as long as the first three funicle joints combined; funicle joints of nearly equal length with the fifth and sometimes the sixth slightly longer, the first three hardly increasing in width and a little wider than long, last three increasing in width so that the sixth is about twice as wide as the first joint, the fourth and sixth and sometimes the fifth wider than long; club subrectangular, truncate at apex, no wider than the preceding joint and as long as the last three funicle joints combined or a little more, or if collapsing more rounded at apex and wider than the last funicle joint. Wings as in A. rileyi but the transparent band of cilia may be incomplete also on the lower margin of disk. Length, 1.2 to $1.4 \mathrm{~mm}$.

Front, vertex, and mesonotum dark orange yellow, with dusky shadings on the scutellum and a narrow, transverse, blackish line on each side of scutum in the type, but frequently without dusky or blackish markings and rarely much brighter orange yellow in color; center of occiput, concealed part of pronotum, the metanotum, propodeum and dorsum of abdomen black or blackish, the latter with the sides behind the vibrissae shading into dusky yellowish or whitish, sometimes more distinctly so; face, cheeks and underparts pale yellowish, with venter of abdomen dusky whitish; collar of pronotum and tegulae whitish with the usual brown markings. Antennal scape black with the base, apex, and line on upper margin narrowly yellowish white; basal half of pedicel, first two funicle joints and club black; rest of pedicel and funicle yellowish white, with the third funicle joint sometimes dusky. Legs pale yellowish; the anterior femora with a brown spot near apex, the hind femora with an obscure streak of brown on outer surface; front tibiae with three distinct brown annuli, the third one at apex, middle and hind tibiae with two annuli and a brown spot at the knee joint; last joint of the tarsi tipped with blackish. Wings with faint ciliary banding usually as in $A$. rileyi; the veins pale brownish.

Male.-Front and vertex one-half longer again than wide; ocelli nearly in an equilateral triangle, the space between posterior pair slightly greater than distance from either to the anterior ocellus; eyes more pubescent than in the female. Antennae nearly as in the female except that the scape is much narrower or nearly four times longer than wide with the lower margin gently rounded. Length, $1.25 \mathrm{~mm}$.

Coloration as in the female except that the sides of abdomen behind the vibrissae are narrowly reddish; and the scape of antennae black on outer surface with the base, apex and a narrow line on the upper margin yellow, entirely yellow on inner face except a black 
streak along the lower margin, the base of pedicel brownish, the club black, rest of pedicel and funicle yellow with the first funicle joint slightly dusky.

Redescribed from one female (type) reared from Lecanium on elm, Champaign, Illinois, April 29, 1896 (W. G. Johnson), one female, one male reared from Lecanium fitchii Signoret, Trenton, Ontario, and five females reared from Lecanium nigrofasciatum Pergande, Mount Alto, Pennsylvania, June, 1913 (F. L. Simanton).

Type.-Cat. No. 5040, U.S.N.M.

\section{APHYCUS COCKERELLI Howard.}

Fig. 9.

Aphycus cockerelli Howard, Proc. U.S.Nat.Mus., vol. 21, 1898, pp. 240, 243.

Female.-Front and vertex twice as long as wide; ocelli in an acute-angled triangle, the posterior pair a little over one-half their own diameter from the eye margin; antennal scrobes broad and shallow, the facial prominence but slightly elevated; eyes barely pubescent. Antennal scape about one-half as wide as long, widest across the middle; pedicel as long at the first three funicle joints combined; first two funicle joints slightly wider than long and subequal, the next two increasing in width but not in length, the sixth slightly longer than the first four, the fifth still more so, both about twice as wide as the first joint; club very broadly oval, bluntly rounded or subtruncate at apex, about one-fourth wider than the preceding joint and a little longer than the last three funicle joints combined. Wings with the ciliation not conspicuously darkened yet with a narrow, curved band of greater transparency at end of the stigmal vein, which attains neither anterior nor the posterior border of the wing; oblique hairless streak obliterated above before reaching the stigmal vein, interrupted below with the cut-off portion almost connecting with the rather distinct basal hairless streak. Length, $1.25 \mathrm{~mm}$.

Front, vertex, occiput, mesonotum, metanotum, propodeum, and dorsum of abdomen pale cadmium yellow, purer or brighter yellow on the head and brownish on the metanotum, propodeum, and middle of the abdomen; face, cheeks, collar of pronotum, tegulae, and entire underparts creamy yellowish white, the usual dots on collar and tegulae obsolete; concealed part of the pronotum brown. Antennal scape except base, apex, and a narrow line on the upper margin, the basal third of pedicel, first two funicle joints, and club black, the rest of antenna yellowish white. Legs concolorous with underparts; the middle tibiae marked with two minute, brown dots on the outer surface near base, dots on other tibiae much fainter and nearly obsolete; last joint of the tarsi blackish at apex. Wings hyaline, the more transparent band hardly visible unless wing is mounted in balsam; the veins pale yellowish. 
Male.-Front and vertex about one and three-fourths times as long as wide; ocelli in an equilateral triangle, the posterior pair a little over one-half their own diameter from the eye margin. Antennal scape hardly more than one-fourth as wide as long, its lower margin slightly curved, widest before the middle and tapering gradually to the apical end; pedicel as in the female, rest of antenna broken off in single available specimen. Wings uniformly ciliated, showing no trace of the ciliary banding. Length, $1.2 \mathrm{~mm}$.

Coloration nearly as in female, but the upper half of the center of occiput, the concealed part of the pronotum, the metanotum, propodeum, and dorsum of abdomen blackish, the latter with the sides behind the vibrissae narrowly bright yellow; collar of pronotum and the tegulae whitish, the former with a very pale brownish dot on each corner, the latter not marked. Antenna as much as known colored as in the female, but the pale parts more yellowish. Legs as in female except that the tibial dots are a little heavier. Wings entirely hyaline, the veins pale yellowish.

Redescribed from five females, one male (cotypes) reared from a Lecanium on osage orange, Las Cruces, New Mexico (T. D. A. Cockerell).

Type.-Cat. No. 5038, U.S.N.M.

11. APHYCUS SIMIIIS, new species.

Fig. 19.

Female.-Front and vertex about twice as long as wide; ocelli in an acute-angled triangle, the posterior pair about one-half their own diameter from the eye margin; eyes with a very fine, sparse pubescence. Antennal scape one-half as wide as long, widest across the middle; pedicel as long as the first three funicle joints combined; first funicle joint a little wider than long, following three of the same length as the first but increasingly wider, the fifth about three-fourths longer again than the preceding joints, the sixth a little shorter than the fifth and fully twice as wide as the first; club subquadrate, about one-fourth longer than wide, very bluntly rounded or subtruncate at apex, nearly one-third wider than the last funicle joint and nearly as long as the last four preceding joints combined. Wings with a narrow, curved band of more transparent cilia at end of stigmal vein, which becomes obsolete on the anterior margin of disk; oblique hairless streak reaching from the stigmal vein about two-thirds of the way across the disk, and without a distinct cut-off portion. Length, 0.9 to $1.3 \mathrm{~mm}$.

Front, vertex, and mesonotum bright orange yellow; face, cheeks, occiput, and underparts pale yellow; concealed part of the pronotum, a spot on each side of the metanotum and propodeum situated partly on both, and the dorsum of the abdomen brown or blackish brown, the lateral margins of the latter from base to apex yellow; collar of prono- 
tum and tegulae whitish, the former with a small, brown dot on each corner, and the posterior margin of the latter slightly brownish. Antennal scape, except the base, apex, and a narrow line on the upper margin, the basal third of pedicel, first funicle joint, and lower side of the second joint and the club black; rest of antenna yellowish white. Legs concolorous with the underparts; middle tibiae with two pair of small, brown dots, the front and hind tibiae with two pair of larger, nearly confluent, but much paler dots; last joint of all tarsi tipped with blackish. Wings hyaline with the more transparent, ciliary band described above; the veins pale brownish.

Described from nine females (type and paratypes $a$ to $h$ ) reared from a Lecanium on Japanese persimmon, Millheim, Texas, April 24 to May 12, 1896 (J. H. Krancher), Insectary No. $7042^{\circ}$.

Type.-Cat. No. 18368, U.S.N.M.

\section{APHYCUS PHYSOKERMIS, new species.}

Figs. 13, 42.

Female.-Front and vertex a little less than twice as long as wide; ocelli nearly in an equilateral triangle, the posterior pair usually slightly nearer each other than either to the anterior ocellus, and about one-half their own diameter from the eye margin; antennal scrobes shallow and broad; eyes nearly bare. Antennal scape three times as long as wide, widest across the middle; pedicel nearly as long as the first four funicle joints combined; first four funicle joints of equal length, increasing very slightly in width, all but the first distinctly wider than long, last two joints subequal in length and width, decidedly longer and wider than the preceding joints, and over twice as wide as the first; club oval in shape, rounded at apex, one-fifth wider than last funicle joint and nearly as long as the preceding five joints combined. Wings uniformly and densely ciliated; oblique hairless streak narrowed above and interrupted below, the cut-off portion not connecting with the basal streak. Body more robust than in allied species, the abdomen considerably wider than the thorax; ovipositor very slightly protruding. Length, 0.9 to $1.5 \mathrm{~mm}$.

Front, vertex, and mesonotum dull orange yellow, brighter on the head; face, cheeks, and underparts pale lemon yellow, the venter of abdomen more gamboge yellow, with a blackish brown infuscation on each side of the middle, the center of occiput and the mesosternum also dusky; collar of pronotum whitish with a black dot on each comer; tegulae yellowish white and broadly marked with brown on outer, apical corner; concealed part of pronotum, the metanotum, propodeum, and dorsum of abdomen blackish brown, the latter with lateral margins behind the vibrissae yellowish. Antennal scape black with basal third and spot at apex yellowish white; base of pedicel, funicle, and basal margin of club black; apex of pedicel and 
most of the club lemon yellow. Legs concolorous with the underparts, the tarsi more brownish yellow with the tip of the last joint blackish; middle tibiae with two broad, interrupted, blackish brown annuli, hind tibiae with annuli wider but paler, and on the front pair the annuli are reduced to dusky markings. Wings hyaline, the veins pale yellowish brown.

Females vary in the intensity of the tibial markings, the extent of the infuscation on the venter, and in some the yellow streak on the sides of the dorsum of abdomen is wider and extends anteriorly even to the base of abdomen.

Male.-Front and vertex about one-half longer again than wide, ocelli in an equilateral triangle. Antennae as in the female, but the scape is much narrower and the club is barely wider than the last funicle joint. Length: 0.8 to $1.0 \mathrm{~mm}$.

Coloration similar to the female, but the black on abdomen is often more intense and the yellow on the sides is reduced and sometimes obsolete; venter may lack the dusky markings, and the mesonotum is sometimes tinted with brownish, especially on the middle of the scutum and on the scutellum.

Described from fourteen females, four males (type, allotype, and paratypes $a$ to $p$ ) reared from Physokermes insignicola (Craw), Santa Maria, California, April 22-26, 1911, 1912, and November 28 to December 11, 1911 (R. C. Wylie). Many additional specimens in the author's collection reared with the above may be considered metatypes.

Type.-Cat. No. 18369, U.S.N.M.

\section{APHYCUS COQUILLETTI Howard.}

Fig. 12.

Aphycus coquilletti Howard, Proc. U.S.Nat.Mus., vol. 21, 1898, pp. 241 , 244.

Female.-Front and vertex twice as long as wide; ocelli in an acute-angled triangle, the posterior pair about one-fourth their own diameter from the eye margin; antennal scrobes rather deep and narrow and the facial prominence larger and more elevated than usually; eyes not pubescent. Antennal scape about one-third as wide as long, widest across the middle, the lower margin evenly rounded; pedicel a little longer than the first three funicle joints combined; first four funicle joints equal in length, the first two hardly wider than long, last two joints noticeably longer and wider than the preceding, wider than long, the sixth nearly twice as wide as the first joint; club oval, more rounded at apex than at base, about one-third wider than the preceding joint and as long as the last five funicle joints combined. Wings narrow, uniformly ciliated; 
oblique hairless streak interrupted below with the cut off portion connecting with the distinct basal hairless streak. Length: $0.8 \mathrm{~mm}$.

Front, vertex, and sides of the occiput cadmium yellow; face and cheeks paler with a very pale brownish spot on the lower corners of the latter; tegulae except the usual brown spot behind, the entire underparts and abdomen pale yellowish, the dorsum of the latter brownish in the middle; collar of pronotum white with a brown dot on each corner; concealed part of the pronotum and occiput, the mesonotum, metanotum, and propodeum blackish brown, the mesoscutum fading to yellowish narrowly on the sides. Antennal scape black with the base, apex, and line on upper margin broadly white; base of pedicel, first four funicle joints, and club blackish brown, the latter becoming yellowish at apex; apex of pedicel and last two funicle joints pale yellowish. Legs concolorous with the underparts, with two narrow, interrupted brown annuli on the tibiae, nearly obsolete on the front pair; apex of last joint of the tarsi dusky. Wings hyaline, the veins pale yellowish.

Redescribed from two females (cotypes), Los Angeles, California (D. W. Coquillett).

One female reared from Pulvinaria bigeloviae Cockerell, Murray, Utah, June 2, 1913 (P. H. Timberlake), differs from cotypes as follows: All dark markings more intense or nearly pure black; upper part of cheeks and sides of occiput concolorous with front and vertex; the spot on lower corners of cheeks next to the mandibles large and blackish; sides of the mesoscutum hardly paler; dorsum of abdomen very dilute blackish brown, with the sides behind vibrissae pale yellowish; venter of abdomen more grey than yellowish and becoming fuscous at the middle; tibial bands of legs not interrupted and blacker. Length: $0.9 \mathrm{~mm}$.

Type-Cat. No. 5041, U.S.N.M.

14. APHYCUS MELANOSTOMATUS, new species.

Figs. 18, 53.

Encyrtus punctipes DaLmaN (part), Svensk. Vet.-Akad. Handl., vol. 41, 1820, p. 371.

Encyrtus punctipes, var. $2^{\circ}$, Nees, Hym. Ichn. affin. Monogr., vol. 2, 1834, p. 202.

Female.-Front and vertex about one-third longer again than wide; ocelli nearly in an equilateral triangle, the posterior pair slightly farther apart than either to the anterior ocellus, and about their own diameter from the eye margin; antennal scrobes indistinct, the face being almost evenly concave with a slight prominence between the bases of the antennæ; eyes covered with a short but dense pubescence. Antennal scape about one-half as wide as long, widest across the middle; pedicel as long as the first two joints of funicle and onehalf of the third combined; first four funicle joints subequal in length, 
the first slightly longer and increasing slightly in width, the last two wider than the preceding and longer, the fifth especially longer and about as long as wide, the sixth wider than long and about twice as wide as the first joint; club oval, rather rounded at apex, about one-third wider again than preceding joint and a little longer than the last three funicle joints combined. Wings uniformly and densely ciliated; oblique hairless streak interrupted below, the cut-off portion not reaching posterior margin of wing. Length, 0.7 to $1.5 \mathrm{~mm}$.

Front, vertex, upper part of face above lower corners of eyes and mesonotum deep orange yellow, the latter slightly darker and often with a curved, faint blackish line on each side of the base of the scutum; face and cheeks yellowish white, with the black of the occiput extending broadly on to the lower corners of the cheeks and as a narrow brown band entirely across the oral margin of face; occiput, except the orange yellow upper rim and yellowish white sides above, concealed portion of pronotum, the metanotum, propodeum, and dorsum of the abdomen dull black, the latter with the margins behind the vibrissae white; pronotal collar whitish with a brown dot on each corner; tegulae, except for a brown spot on posterior margin, and the underparts sordid yellowish white, the venter of the abdomen dusky in the middle. Antennal scape black with a narrow line on upper margin and a roundish spot on lower, basal corner of the outer surface yellowish white; basal third of pedicel, first three and a part of fourth funicle joint, and club blackish; rest of antenna yellowish white. Legs yellowish white; all tibiae with two blackish annuli; and last joint of the tarsi blackish. Wings hyaline, the veins pale yellowish.

Male.-Front and vertex wider than long; ocelli in an obtuseangled triangle, the posterior pair fully their own diameter from the eye margin. Antennal scape much narrower than in the female, about three times as long as wide; pedicel a trifle shorter than the first funicle joint; all funicle joints subequal in length, increasing slightly in width, the first distinctly longer than wide, others about as wide as long; club narrow and rather pointed at apex, no wider than the preceding joint and a trifle longer than the last two funicle joints combined; flagellum on the whole long, slender and thickly pubescent. Length, 1.0 to $1.15 \mathrm{~mm}$.

Vertex, occiput, a greater part of cheeks and lower margin of face, concealed part of pronotum, most of notum of thorax and the abdomen including venter black or blackish brown, being nearly pure, dull black on the notum and shading into yellowish on the sides of the scutum; front orange yellow; greater part of face, cheeks next to the eyes, collar of pronotum, tegulae and underparts of thorax yellowish white, the collar having a black dot on each corner, and the tegulæ a brown spot on the posterior margin. Antennae pale yel$10600^{\circ}$-Proc.N.M.vol.50-16-39 
lowish brown, the lower side of scape and apex of pedicel paler. Legs and wings as in female.

Described from fourteen females, eleven males (type, allotype, and paratypes $a$ to $w$ ) reared from a Lecanium on linden, Ermelunden, Sealand, Denmark, June, 1906 (J. P. Kryger). The following material, which may be considered as metatypes, also examined: Many specimens of both sexes reared with the above types, preserved in alcohol; seven males reared from a Lecanium on oak, Dyrehaven, Sealand, Denmark, July 12, 1907 (J. P. Kryger). Coloration of all the above specimens including the types has been modified to some extent by long immersion in alcohol, the face and cheeks especially having been discolored so as to resemble the front with a slight pinkish tinge. Also one female, one male on "minutien nadeln" without data, determined by Mayr as A. punctipes, the female having a narrow cross band of white on the orange-colored or upper part of face; and seven females, seventeen males reared from Lecanium fuscum (Gmelin) on oak, England, June, 1890 (J. W. Douglas), the females having the mesoscutum behind the transverse lines and the scutellum more dusky than usually.

Type-Cat. No. 18371, U.S.N.M.

\section{APHYCUS LOUNSBURYI Howard.}

Fig. 24.

Aphycus lounsburyi HowaRD, U.S.Nat.Mus., vol. 21, 1898, pp. 241, 244.

Female.-Front and vertex apparently (being much shrunken in cotypes) nearly three times as long as wide; ocelli in an acute-angled triangle, the posterior pair close to the eye margin; antennal scrobes broad and shallow; eyes nearly nonpubescent. Antennal scape about one-third as wide as long, widest just beyond the middle; pedicel as long as the first three funicle joints combined; first four funicle joints of nearly equal length, wider than long and hardly increasing in "width, last two joints considerably longer and wider, the sixth a trifle longer than the fifth, both a little wider than long; club oval, rounded at apex, about one-third wider than the preceding joint and a little longer than the last four funicle joints combined. Wings uniformly ciliated; the oblique hairless streak but little wider below, interrupted, the cut-off portion separated from the basal hairless streak on the posterior margin of wing. Length: $0.7 \mathrm{~mm}$.

Front and vertex bright orange yellow; face, cheeks, and under parts pale yellowish; mesonotum dusky orange yellow; concealed part of the occiput and the pronotum, the metanotum, propodeum, and dorsum of abdomen brown; collar of pronotum and tegulae sordid whitish, the former with a minute, blackish dot on each corner, 
the latter with the posterior margin pale brown. Antennal scape black with a very narrow line on upper margin, the apex and a broad band on the basal third of the lower margin white; base of pedicel, first four funicle joints and club black; apical two-thirds of pedicel, last two funicle joints and sometimes the underside of the third and fourth joints white. Legs pale yellowish; middle tibiae with a pair of distinct, brown dots near base, another pair at the middle, and a narrow, brown annulus at the apex; hind tibiae similar, but the markings fainter; front tibiae with the apical annulus faint and the two pair of dots replaced by a large but faint brownish blotch on the anterior or upper surface; last joint of the tarsi faintly blackish. Wings hyaline, the veins pale yellowish.

Redescribed from three females (cotypes) in poor condition, reared from Saissetia oleae (Bernard), Cape Town, South Africa (C. P. Lounsbury). The fourth cotype has been lost by dropping from the card point.

The following material also examined: Seven females, one male reared from the same host, Cape Colony, South Africa (C. P. Lounsbury), and two females from the same host and locality (through H. S. Smith), California State Insectary No. 655cp.

The females differ from the types as follows: Front and vertex varying from twice to nearly two and one-half times as long as wide; ocelli in an equilateral triangle or nearly so, but in three specimens in a more or less acute-angled triangle, the posterior pair about onefourth their own diameter from eye margin. Ovipositor protruded about one-tenth the length of abdomen. Length: $1.4 \mathrm{~mm}$.

Coloration nearly as in types but the front, vertex, and mesonotum uniformly dark orange yellow, but the dark parts nearly black instead of brown; dorsum of abdomen with the lateral margins narrowly whitish posterior to the vibrissae. half way to the apex, and the anterior corners of the basal tergites invaded by the whitish of the venter; tibial bands and dots heavier and blackish and with an additional dot at the knee joint.

Male.-Front and vertex a little less than twice as long as wide; ocelli in an equilateral triangle. Antennal scape narrower than in the female and the club smaller or no longer than the last three funicle joints combined. Wings as in the female, but the cut-off portion of the oblique hairless streak larger and connecting with a branch of the basal hairless streak on the posterior border of wing. Length: $1.3 \mathrm{~mm}$.

Coloration as in the female, except that the front and vertex are bright sulphur yellow, with the face and cheeks but slightly paler; marginal pale streak on abdomen wider and more yellowish with a narrow, more brownish extension reaching the apex. Antenna as in 
the female, except that the dark parts of the flagellum are brown instead of black.

Type.-Cat. No. 5042, U.S.N.M.

\section{APHYCUS PUNCTIPES (Dalman).}

Encyrtus punctipes Dalman, Svensk. Vet.-Akad. Handl., vol. 41, 1820, p. 154, pl. 8 , fig. 60 .

Aphycus punctipes Mayr, Verh. zool.-bot. Ges. Wien, vol. 25, 1876, pp. 696,697. Microterys punctipes Tномsоn, Hym. Skand., vol. 4, 1876, p. 168.

No authentic specimens of this species have been studied, and its position in the synoptic table was determined solely from the descriptions of Dalman and Mayr. Under this name, however, in the United States National Museum were found four distinct species, three from Europe determined by Walker and Mayr. Two of these are described in this paper as new under the names of melanostomatus and mayri. The third species, also apparently is not punctipes (Dalman), and is closely related to lichtensiae Howard from Ceylon. The fourth species under this name was determined by Ashmead, and the single specimen from South Kirtland, Ohio, has been made a paratype of rileyi, new species. It is needless to add that Ashmead's record of punctipes from North America is unreliable.

\section{APHYCUS ALBOPLEURALIS Ashmead.}

Fig. 22 .

Aphycus albopleuralis AshmeAd, Journ. N. Y. Ent. Soc., vol. 12, 1904, p. 155.

Female.-Front and vertex one and one-half times longer than wide; ocelli in an equilateral triangle, the posterior pair about onefourth their own diameter from the eye margin; eyes nearly smooth, but the front and vertex with a sparse pubescence. Antennal scape nearly one-half as wide as long, widest across the middle; pedicel as long as the first three funicle joints combined; funicle joints of nearly equal length, the last two slightly longer, all wider than long and increasing in width so that the sixth is twice as wide as the first; club broadly oval, subtruncate at apex, about one-fourth wider than preceding joint and nearly as long as the last four joints of funicle combined. Wings uniformly ciliated; oblique hairless streak narrow throughout, interrupted below, the cut-off portion small and connecting with a branch of the basal streak, the latter extends forward on posterior margin to point opposite the stigmal vein. Length: 1.5 to $1.6 \mathrm{~mm}$.

Front, vertex, mesonotum, mentanotum, and propodeum bright orange yellow; face, cheeks, occiput, and underparts pale yellowish white; a blackish oval spot on the concealed part of the pronotum; collar of pronotum and tegulae whitish, the former with a minute, pale brownish dot on each corner; dorsum of abdomen brown at the 
center and base, the margins posterior to the vibrissae broadly yellow and anterior to the vibrissae more yellowish brown. Antennal scape black, with base, apex and a narrow line on dorsal margin white; base of pedicel, first four funicle joints, and club brown, the funicle joints paler on the upper side, especially the third and fourth; rest of antenna yellowish white. Legs pale yellowish white with the last joint of the tarsi brown. Wings hyaline, the veins pale yellowish.

Male.-Not known.

Redescribed from four females (two of them cotypes) from Gifu, Japan (Y. Nawa).

Type.-Cat. No. 7176, U.S.N.M.

\section{APHYCUS KINGI, new species.}

Fig. 5 .

Female.-Front and vertex nearly twice as long as wide; ocelli in an equilateral triangle, the posterior pair about one-half their own diameter from the eye margin; antennal scrobes broad and shallow, the facial prominence but slightly elevated; eyes nearly bare. Antennal scape about one-half as wide as long, widest across the middle; pedicel only a little longer than the first two funicle joints combined; first four funicle joints subequal in length, the last two longer, the first three hardly wider than long, the next three increasing in width so that the sixth is about twice as wide as the first; club oval, subtruncate at apex, nearly a third wider again than the preceding joint and as long as the last three funicle joints combined. Wings nearly uniformly ciliated but a triangular area beneath the lower third of the oblique hairless streak with the cilia less dense; oblique hairless streak extends uninterrupted from the stigmal vein to the posterior margin of wing. Length: $1.0 \mathrm{~mm}$.

Front, vertex, upper rim of occiput, and mesonotum orange yellow; face, cheeks, sides of occiput, and entire underparts sordid yellowish white, with the venter of abdomen more dusky; concealed part of occiput and pronotum, the metanotum, propodeum and dorsum of abdomen uniformly blackish brown; collar of pronotum and tegulæ yellowish white, the former with a small brownish dot on each corner, and the posterior third of the latter pale brown. Antennal scape black with the extreme base, apex, and a very narrow line on the upper margin yellowish white; pedicel, except the dorsal, apical margin, the first two funicle joints, and a part of the third, and club blackish brown; rest of antenna yellowish white. Legs uniformly yellowish white with the last joint of the tarsi blackish. Wings hyaline, the veins pale yellowish.

Male.-Not known. 
Described from three females (type and paratypes $a$ and $b$ ) reared from Pulvinaria species, Lawrence, Massachusetts, 1889 (Geo. B. King), Insectary No. $1844^{\circ}$.

Type.-Cat. No. 18372, U.S.N.M.

19. APHYCUS MAYRI, new species.

Fig. 17.

Encyrtus punctipes, var. $\beta$, Dalman, Svensk. Vet.-Akad. Handl., vol. 41, 1820, p. 371 .

Encyrtus hedaraceus Walker (not Westwood), Ent. Mag., vol. 5, 1838, p. 107.

Female.-Front and vertex about one and three-fourths times as long as wide; ocelli in an equilateral triangle, the posterior pair one-half their own diameter from the eye margin; antennal scrobes shallow; front, vertex, and eyes with a sparse, fine pubescence. Antennae and wings very nearly as in A. albopleuralis Ashmead, but the club is proportionately a little wider, and the basal hairless streak on posterior margin of wing extends but a short distance beyond the end of the oblique hairless streak. Length: 1.0 to $1.2 \mathrm{~mm}$.

Front and vertex orange yellow, the mesonotum clay yellow; face, cheeks, and occiput colored nearly like the front and vertex but more pinkish (apparently discolored by immersion in alcohol, in life probably paler yellow); underparts pale yellow; concealed part of pronotum, the metanotum, propodeum, and dorsum of abdomen brownish black, the latter narrowly margined with yellowish-white posterior to the vibrissae; collar of pronotum and tegulae whitish with the usual pale brown markings. Antennal scape black with base, apex, and line on the dorsal margin whitish; base of pedicel black, apical half yellowish white; first two funicle joints and club black, third funicle joint brown, and the last three yellowish white. Legs concolorous with the underparts, unmarked except that the middle and hind tibiae have a brown dot at the knee joint, and the last joint of the tarsi blackish, wings hyaline, the veins pale brownish.

Male.-Front and vertex but little longer than wide; ocelli in a right-angled triangle, the posterior pair about one-fourth their own diameter from the eye margin. Antennae nearly as in the female, the principal difference being that the scape is only about one-third as wide as long. Length: 0.8 to $1.1 \mathrm{~mm}$.

Front orange yellow, the vertex blackish across the posterior ocelli; face, cheeks, and sides of the mesoscutum pale yellowish, a vertical brown band on cheeks descending nearly to the mandibles; most of the occiput, concealed part of the pronotum, the mesonotum except the sides of mesoscutum, and the rest of the upper parts brownish black, the dorsum of abdomen having a wide yellow margin posterior to the vibrissae; collar of pronotum and tegulae whitish marked with pale brown in the usual manner. Antennae brown, the 
scape with a longitudinal, more blackish stripe through middle of the outer surface, the base and the dorsal, inner margin yellowish white, the pedicel becoming yellowish white on upper side at apex. Legs as in the female except that the tibiae have a faint dusky shading on their outer surface. Wings hyaline, the veins pale brownish.

Described from nineteen females, seven males (type, allotype, and paratypes $a$ to $x$ ) reared from Lecanium coryli (Linnaeus), Dyrehaven, Sealand, Denmark, June, 1906 (J. P. Kryger). The following metatypes also examined: Four females swept from grass, Gentofte, July 13, 1905; six females, five males reared from a Lecanium on linden, Dyrehaven, June 16,1906; and two females, one male reared from the same host, Ermelunden, June, 1906, all localities in Sealand, Denmark (J. P. Kryger). Also one female, one male badly broken, labeled "Germany" and determined by Mayr as A. punctipes.

The synonymy given above can be verified only by the examination of material in the European collections, but is presumably correct. Walker's description of hederaceus agrees fairly well with the male of this species.

Type.-Cat. No. 18373, U.S.N.M.

\section{APHYCUS LICHTENSIAE Howard.}

Figs. 14, 41.

Aphycus lichtensiae Howard, Proc. U. S. Nat. Mus., vol. 18, 1896, p. 640.

Female.-Front and vertex about three times as long as wide; ocelli in a very acute-angled triangle, the posterior pair close to eye margin; antennal scrobes shallow and broad; front and vertex thickly pubescent, the eyes with a short, sparse pile. Antennal scape about one-third as wide as long, widest just beyond the middle; pedicel a trifle longer than the first three funicle joints combined; first four funicle joints of nearly equal length, the fifth about twice as long, the sixth somewhat shorter than the fifth, all wider than long except the fifth and increasing gradually in width distad; club oval, rounded at apex, about one-third wider than the preceding joint and as long as the last four joints of funicle combined. Wings uniformly and densely ciliated; oblique hairless streak narrowed above and not nearly reaching the stigmal vein, interrupted below with the cut-off portion widely separated from the posterior margin of wing. Length: $1.2 \mathrm{~mm}$.

Front and vertex bright orange yellow; face and cheeks pale rose color (this coloration undoubtedly due to immersion in alcohol at some former time, the original color probably some shade of yellow. paler than vertex or notum), a narrow streak of blackish brown on lower corners of cheeks continued across the oral margin of face; mesonotum pale orange yellow with a transverse blackish brown line on each side of the base of the scutum; concealed part of occiput 
and pronotum, the posterior half of metanotum, propodeum, and dorsum of abdomen blackish brown, the margins of the latter behind the vibrissae sordid creamy white; collar of pronotum, tegulae, and entire under parts sordid whitish, the collar with a blackish brown dot on each corner, and the tegulae with a pale brown spot on the middle of the posterior margin; metascutum orange brown, and a narrow line on the anterior margin of the metapostnotum whitish. Antennal scape blackish brown, the inner surface with a narrow, yellowish white line on the dorsal margin including base and apex and nearly interrupted just beyond the middle, outer surface the same but the apex more broadly yellowish white and a streak of the same color on the lower margin near base; base of pedicel and club blackish brown; first four funicle joints brownish, last two and apex of pedicel yellowish white. Legs pale yellowish, all tibiae with three blackish brown, rather broad annuli, the third band at apex and on the hind pair reduced to a spot on the outer surface, the middle and hind tibiae with an additional dot on outer surface at the knee joint; last joint of the tarsi blackish. Wings hyaline, but the dense ciliation imparts a slight duskiness; the reins pale yellowish.

Male.-Front and vertex two and one-half times as long as wide; ocelli in an acute-angled triangle, the posterior pair nearly touching the eve margin. Antennal scape about four times as long as wide, widest across the middle, the lower margin slightly rounded; pedicel a little shorter than the first three funicle joints combined; first four funicle joints of equal length and increasing slightly in width, last two somewhat longer and wider, all noticeably wider than long except the first; club oral and rather pointed at apex, hardly wider than the last funicle joint and about as long as the last four preceding joints combined. Length: $1.1 \mathrm{~mm}$.

Coloration similar to that of the female, but the posterior half of vertex brown and the mesonotum dusky in the middle, sometimes almost the entire scutellum and the scutum behind the transverse lines dusky, the lateral streaks on the dorsum of the abdomen shorter and more yellowish. Antennae paler, the scape yellowish, with the dorsal and ventral margins narrowly brown; base of pedicel and club brown; first fire funicle joints pale brown, becoming pale distad, the sixth joint and apical half of pedicel yellowish.

Redescribed from five females, three males (cotypes), reared from Lichtensia species, Punduloya, Ceylon (E. E. Green), Insectary No. $6909^{\circ}$.

Type-Cat. No. 3259, U.S.N.M. 
21. APHYCUS RUSTI, new species.

Female.-Front and vertex about twice as long as wide; ocelli in an acute-angled triangle, the posterior pair about one-half their own diameter from the eye margin; eyes almost without pubescence. Antennal scape about one-third as wide as long, widest across the middle; pedicel as long as the first three funicle joints combined; funicle joints all wider than long, increasing gradually in width so that the sixth is about twice as wide as the first, the first four of equal length, the last two about one-fourth longer than the preceding; club oval, obtusely rounded at apex, about one-fourth wider than the preceding joint and as long as the last four funicle joints combined. Wings uniformly ciliated; oblique hairless streak widened below and extending nearly to the posterior margin of disk, with a barely cut-off portion connecting with a branch of the basal hairless streak. Ovipositor protruded slightly, or about one-tenth the length of abdomen. Length, 1.2 to $1.3 \mathrm{~mm}$.

Front, vertex, and mesonotum rather deep orange yellow; rest of the head and body nearly uniformly pale sulphur yellow; concealed part of the pronotum hardly with a trace of blackish in type, but with a blackish band in the three paratypes; dorsum of abdomen with a basal, inconspicuous pale brownish cross band. Antennal scape black with base, apex, and line on dorsal margin yellowish white; pedicel brown with the lower side except at base whitish; first four funicle joints brown, the last two yellowish white; club blackish brown. Legs uniformly pale yellowish, with the last joint of the tarsi tipped with blackish. Wings hyaline, the veins pale yellowish.

Male.-Front and vertex somewhat less than twice as long as wide; ocelli in an equilateral triangle, the posterior pair about one-third their own diameter from the eye margin. Antenna much as in female, but scape narrower, varying from a little less than one-third to onefourth as wide as long; pedicel a little shorter, about equal to the first two funicle joints and one-half of the third combined; club smaller, tapering from the base to the rounded apex, no wider than the preceding joint and as long as the last three funicle joints combined. Wings as in female. Length, 0.8 to $1.2 \mathrm{~mm}$.

Coloration nearly as in the female, the concealed part of the pronotum blackish and the dorsum of abdomen nearly uniformly pale yellow. Antennal scape colored as in female, but the flagellum nearly uniformly pale brownish, the underside of the pedicel paler or yellowish. Legs and wings as in the female.

Described from four females, six males (type, allotype, and paratypes $a$ to $h$ ) reared from Pulvinaria species on sweet potato, Sullana, Piura, Peru, February 23 to March 6, 1912 (E. W. Rust), all mounted in balsam. Received from Messrs. C. H. T. Townsend and E. W. 
voL. 50.

Rust under their number $35^{\circ} 3 \mathrm{~h}$, and one female and male returned (paratypes $g$ and $h$ ).

Type.-Cat. No. 18374, U.S.N.M.

22. APHYCUS PULVINARIAE Howard.

Figs. 15, 2343.

Aphycus pulvinariae Howard Rep. Ent., U. S. Dept. Agric., 1881, p. 365.

Female.-Front and vertex about twice to two and one-fourth times as long as wide; ocelli in an acute-angled triangle, the posterior pair about one-fourth to one-half their own diameter from the eye margin; antennal scrobes shallow and rather broad; eyes moderately to rather thickly pubescent, the pile very short and fine. Antennal scape varying from somewhat less than one-half to about one-third as wide as long, widest near the middle and usually a little wider than the club; pedicel about as long as the first three funicle joints combined; first four funicle joints subequal in length, the last two a little longer, first three hardly wider than long, the succeeding joints increasingly wider, the sixth about twice as wide as the first; club oval, bluntly rounded at apex, about one-fourth wider than the last funicle joint and as long as the last four combined. Wings uniformly ciliated; oblique hairless streak narrowed above and interrupted below, the cut-off portion indistinctly connecting with the basal hairless streak. Length, 0.75 to $1.1 \mathrm{~mm}$.

Front, vertex and mesonotum orange yellow; face, cheeks, upper rim and sides of occiput, collar of pronotum, tegulae and underparts pale yellowish, the collar with a blackish brown dot on each corner, and the tegulae with a pale brown spot on the posterior margin; concealed part of the occiput and pronotum, the metanotum, propodeum, and dorsum of abdomen brown to blackish brown, the sides of the latter narrowly to broadly pale yellowish, or the metanotum, propodeum, dorsum of abdomen and most of the occiput may vary to entirely yellowish. Antennal scape black with the base and apex more or less broadly and a narrow line on the dorsal margin white; base of pedicel, first two to four funicle joints and club black or blackish brown, the apex of club often paler or even yellowish; rest of antenna yellowish white. Legs pale yellowish; tibiae with two pairs of dots near base and at middle, or with only the basal pair, rarely with none, the dots when present varying from brown to blackish; tip of the last joint of the tarsi blackish. Wings hyaline, the veins pale brownish.

Male.-Front and vertex about one-half longer again than wide; ocelli in an equilateral triangle or nearly so. Antennae much as in the female, but the scape narrower, hardly expanded in the middle, about four times longer than wide, and the club smaller or about as long as the last three funicle joints. Length, 0.5 to $0.8 \mathrm{~mm}$. 
Coloration as in female, but the metanotum and dorsum of abdomen usually blacker and varying only in the width of the marginal yellow streak on the abdomen; tibiae dotted in all specimens examined but in some more faintly. Antennae brown, the scape darker with base and apex pale or whitish, apex of pedicel yellowish, and the sixth funicle joint rarely paler.

Redescribed from the following material: Two females (cotypes) reared from Pulvinaria vitis (Linnaeus), Davenport, Iowa (J. D. Putnam); six females, three males, Fort Assinniboine, Montana, April 25, 1890 (H. G. Hubbard); six females, two males, reared from Pulvinaria on plum, Florence, South Carolina, or Fayetteville, North Carolina (notes not indicating which place), May 21-26, 1894, Insectary No. $6222^{\circ}$; one female, four males, reared from Lecanium on wild goose plum, Charlottesville, Virginia, May 16-20, 1890 (C. H. Hedges); six females, one male, reared from Lecanium fletcheri Cockerell, Ottawa, Canada, June 25, 1895 and 1896 (James Fletcher); one female, one male, reared from Lecanium on plum, Wooster, Ohio, June 22, 1895 (F. M. Webster); three females, Jacksonville, Florida (W. H. Ashmead), two of them erroneously labeled as types of Aphycus annulipes (Ashmead), Cat. No. 4751, U.S.N.M., the third labeled cotype; nine females, five males, reared from Lecanium on Japanese persimmon, Millheim, Texas, April 24-28, 1896 (J. H. Krancher); three females reared from Pulvinaria acericola (Walsh and Riley), Mount Alto, Pennsylvania, July 1, 1913 (F. L. Simanton); three females reared from the same host, Agricultural College, Mississippi (G. W. Herrick); two females reared from Pulvinaria species, Lawrence, Massachusetts, 1889 (Geo. B. King); four females, one male, reared from Lecanium cerasifex Fitch, College Station, Texas (C. E. Sanborn); one female, Myrtle, Georgia, May, 1906 (A. A. Girault); one male reared from Lecanium species, St. Anthonys Park, Minnesota (F. L. Washburn); four females, one male, reared from Lecanium corni Bouché on ash, Guelph, Ontario, June 9, 1907 (T. D. Jarvis); five females reared from Lecanium on sycamore, Columbus, Ohio, June 2, 1905 (E. C. Colton); five females, three males, reared from Lecanium corni Bouché and a Pulvinaria on willow, Columbus, Ohio, May 20, '1906 (R. W. Harned); one female, one male, Salem, Ohio; two females, one male, reared from Lecanium cerasifex Fitch, Columbus, Kansas, May 11, 1903 (W. J. Moore); and three males reared from Pulvinaria vitis (Linnaeus) on box elder, Salt Lake City, Utah, August 3-10, 1913 (P. H. Timberlake). The third cotype has apparently been lost.

Type.-Cat. No. 2611, U.S.N.M. 
23. APHYCUS CLAVIGER, new species.

Figs. 25, 44.

Female.-Front and vertex a little over twice as long as wide; ocelli in an acute-angled triangle, the posterior pair about one-fourth their own diameter from the eye margin; eyes with a fine, short pubescence. Antennal scape about two and one-half times longer than wide, widest just beyond the middle and a little narrower than the club; pedicel as long as the first three funicle joints combined; funicle joints two to five of equal length, the first a trifle longer and the sixth but little longer than the first, all increasing gradually in width so that the sixth is nearly twice as wide as the first, and all but the first wider than long; club oval, rounded at apex, nearly twice as wide as the last funicle joint and a little longer than the five preceding joints combined. Wings uniformly ciliated; oblique hairless streak narrowed above and almost obliterated on the lower half, the cut-off portion being very small and widely separated both from the upper portion and from the posterior margin of wing. Length, $0.8 \mathrm{~mm}$.

Front, vertex, and mesonotum orange yellow; face, cheeks, and entire underparts sordid pale yellowish; collar of pronotum and tegulae whitish, the former with the blackish dot on each corner connecting with the blackish coloration on the concealed part of the pronotum, the tegulae unmarked; concealed part of occiput and pronotum blackish brown; metanotum, propodeum, and dorsum of abdomen brown, the latter with the lateral margins yellowish, especially behind the vibrissae. Antennal scape black with the base and apex yellowish white; basal half of pedicel black, the apex orange yellow; first three funicle joints blackish brown, the last three orange yellow; club black, shading into orange yellow on the apical half. Legs pale yellowish, with the last joint of the tarsi brownish. Wings hyaline, the veins pale yellowish.

Male.-Front and vertex about one-half longer again than wide; ocelli in an equilateral triangle, the posterior pair about one-fourth their own diameter from the eye margin. Antennal scape hardly expanded below, about three times as long as wide; pedicel as long as the first four funicle joints combined; first five funicle joints subequal in length, the sixth considerably longer, all increasing slightly in width so that the sixth is about one-third wider again than the first and all wider than long; club oval, rather pointed at apex, about one-third wider than the preceding joint and nearly as long as the funicle. Wings have the oblique hairless streak more prominent than in the female, the cut-off portion being of usual size but not reaching the posterior margin of wing. Length, $0.7 \mathrm{~mm}$. 
Front orange yellow shading into brownish black on vertex; occiput, most of cheeks, and entire upper parts of thorax and abdomen, including the pronotal collar, brownish black; face and underparts sordid yellowish; tegulae yellowish at base and blackish brown on the posterior half. Antennal scape pale yellowish, with the dorsal and ventral margins except at base pale brown; pedicel brown, with the apex yellowish; funicle and club uniformly brown. Legs and wings as in the female.

Described from two females, one male (type, allotype, and paratype), Auckland, New Zealand. This species is most closely related to alberti Howard.

Type.-Cat. No. 18375, U.S.N.M.

\section{APHYCUS MACULIPES Howard.}

Fig. 16.

Aphycus maculipes Howard, Bull. No. 5, old ser., U. S. Dept. Agric., Bur. Ent., 1885, p. 18.

A phycus flaviceps Howard, Proc. U. S. Nat. Mus., vol. 21, 1898, pp. 241, 246.

Female-Front and vertex about two and one-half times longer than wide; ocelli in an acute-angled triangle, the posterior pair about one-half to nearly their own diameter from the eye margin; antennal scrobes rather deep and the facial prominence well developed; front and vertex with rather abundant long pile, the eyes sparsely to thickly pubescent, the pile very short and fine. Antennal scape nearly one-half as wide as long, widest across the middle; pedicel as long as the first three funicle joints combined; first four funicle joints of nearly equal length, the fifth one-third longer and the sixth a little shorter than the fifth, the first three about as long as wide, the fourth and sixth wider than long, the fifth longer than wide, the last not quite twice as wide as the first; club oval, rounded at apex, somewhat wider than the last funicle joint and a little longer than the last three combined. Wings uniformly ciliated; oblique hairless streak narrowed above and interrupted below, the cut-off portion small, round, and connecting with a branch of the basal hairless streak which extends forward on the posterior margin of wing to the angulation opposite the stigmal vein. Length, 0.9 to $1.4 \mathrm{~mm}$.

Front, vertex and mesonotum bright orange yellow; face, cheeks and occiput sulphur yellow, the center of occiput dusky; underparts entirely pale straw yellow; collar of pronotum and tegulae sordid white, the former with a black dot on each corner and the latter with a brown spot on the posterior margin; concealed part of the pronotum, most of the metapostnotum, the propodeum and dorsum of abdomen blackish brown, the lateral margin of the latter paler and changing to a straw yellow streak behind the vibrissae; almost the entire metascutum and the anterior margin of the metapostnotum sulphur yellow; 
in one specimen, however, the metanotum, propodeum and dorsum of abdomen are almost entirely yellowish with but a slight trace of brown. Antennal scape black with apex, base and a narrow line on inner surface of dorsal margin white; pedicel blackish brown whitish only on upper, apical corner; first two funicle joints, most of the third and a part of the fourth blackish brown, the dark coloration gradually fading to the yellowish white of the last two joints; club black. Legs pale yellowish, the tarsi more brownish yellow with the tip of the last joint blackish; tibiae with two pair of brown dots and an additional dot at the knee joint, most distinct on the middle legs and nearly obsolete on the front pair. Wings hyaline, the veins pale yellowish.

Male.-Structure of head and wings as in female, but the ocelli being larger the posterior pair come closer to the eye margin. Antennal scape about one-fourth as wide as long; pedicel as long as the first two and one-half of the third funicle joint; first four funicle joints of equal length, the last two subequal and a little longer than the preceding, first three hardly wider than long, the last three more distinctly transverse, the sixth about twice as wide as the first; club oval, obtusely rounded at apex, hardly wider than the preceding joint and as long as the last three funicle joints combined. Length, 0.8 to $1.1 \mathrm{~mm}$.

Coloration nearly as in female, but the front sulphur yellow instead of orange; band on occiput above the neck blackish; pale streak on sides of abdomen a little wider, deeper yellow and more distinctly enclosing the vibrissal plate. Antennal scape with the white more extensive, leaving an oval black spot on the expanded portion; pedicel funicle and club nearly uniformly brown, the apex of pedicel whitish and the last two funicle joints slightly paler. Wings and legs as in the female, but the tibial dots are paler.

Redescribed from the following material: Two females, one male (cotypes, the second male type apparently lost), reared from Lecanium species on Quercus aquatica, Bluffton, South Carolina, May 7, 1883 (Dr. J. H. Mellichamp); three males (cotypes of A. flaviceps Howard, U.S.N.M., Cat. No. 5049, two of them badly broken), reared from a Lecanium species, Champaign, Illinois (W. G. Johnson); one female reared from Coccus hesperidum Linnaeus, Nuevo Laredo, Mexico, January 4,1895 , Insectary No. $2326^{\circ}$ and another female without data but probably reared with the preceding.

Type.-Cat. No. 2644, U.S.N.M.

\section{APHYCUS CALIFORNICUS HOWard.}

Fig. 21.

Aphycus californicus Howard, Proc. U. S. Nat. Mus., vol. 21, 1898, pp. $241,245$.

Female.-Front and vertex about twice as long as wide; ocelli in an acute-angled triangle, the lateral pair about one-fourth their own diameter from the eye margin; antennal scrobes broad and shallow, eyes 
with a moderately thick but fine, short pubescence. Antennal-scape about two and one-fourth times longer than wide, widest across the middle; pedicel as long as the first four funicle joints combined; first four funicle joints subequal in length and wider than long, the last two considerably longer, the fifth nearly twice as long as the preceding, all joints gradually increasing in width so that the sixth is nearly twice as wide as the first; club oval, obliquely rounded at apex, onethird wider than the preceding joint and about as long as the last five funicle joints combined. Wings uniformly ciliated; oblique hairless streak narrowed above and interrupted below, the cut-off portion more or less connecting with a branch of the basal hairless streak. Length: 0.7 to $0.9 \mathrm{~mm}$.

Front, vertex and mesonotum orange yellow; face and cheeks paler yellow, the latter with a large blackish brown blotch next to the mandibles and connecting with the dark coloration of the occiput; tegulae and underparts sordid yellowish white, the former with a brown spot on the posterior margin and the venter of abdomen dusky in the middle; collar of pronotum whitish with a blackish brown dot on each corner; concealed part of occiput and pronotum, the metanotum, propodeum and dorsum of abdomen blackish brown, the latter fading to yellowish white on the sides behind the vibrissae. Antennal scape black with base, apex and a narrow line on dorsal margin yellowish white; base of pedicel, first three or four funicle joints and club blackish; rest of antenna yellowish white. Legs pale yellowish white, the tibiae with two narrow, interrupted blackish brown annuli nearly obsolete on the front pair, and the last joint of the tarsi tipped with blackish. Wings hyaline, the veins pale brownish.

Male.-Not known. It is probable, however, that oregonensis will prove to be the male of this species.

Redescribed from two females (cotypes) reared from a Lecanium on Adenostoma fasiculatum, Alameda County, California, June, 1887 (A. Koebele), Koebele's No. $252^{\circ}$; and two females reared from Lecanium corni Bouché, Santa Rosa, California, June 15, 1908 (E. M. Ehrhorn). The following Eastern specimens hardly differ and must be considered to belong here, at least until the species is better known from larger series: One female, Oakland, Maryland, July 12; and one female reared from Lecanium nigrofasciatum Pergande, Harrisburg, Pennsylvania, October 22, 1909 (P. R. Myers), Myers' No. 269.

Type.-Cat. No. 5043, U.S.N.M. 
26. APHYCUS ANNULIPES (Ashmead).

Coccophagus annulipes Ashmead, Can. Ent., vol. 14, 1882, p. 37.

Aphycus annulipes Howard, Bull. No. 5, old ser., U. S. Dept. Agric., Bur. Ent., 1885, pp. 19, 41.

Female.-Front and vertex about twice as long as wide; ocelli in an acute-angled triangle, the posterior pair nearly their own diameter from the eye margin; front, vertex and eyes nearly free from pubescence. Antennal seape about one-half as wide as long; pedicel as long as the first three funicle joints combined; funicle joints as far as can be made out all short and transverse, the sixth about twice as wide as the first and apparently hardly longer; club nearly as wide as long (after collapsing), rounded at apex, about one-fourth wider than the preceding joint and half as long as the funicle; antenna as a whole unusually short. Wings of type broken off and lost. Length, 1.2 mm. (estimated).

Front, vertex, and mesonotum bright orange yellow; face, cheeks, occiput, and underparts yellowish white; concealed part of pronotum, metapostnotum, and dorsum of abdomen (latter according to original description) brownish black; collar of pronotum and tegulae whitish, the former with a brown dot on each corner, the latter not marked. Antennal scape black with the dorsal margin and the base and apex more broadly white; base of pedicel and club black; first two funicle joints brownish, last four joints and apical half of pedicel yellowish white. Legs yellowish white; tibiae with two narrow, pale brown annuli, subinterrupted on the front pair, and broken into two dots on the middle pair (hind tibiae broken off); middle femora with faint brownish dots arranged nearly as on the middle tibiae; last joint of the tarsi tipped with blackish. Wings originally described as hyaline, the veins pale yellowish.

Redescribed from one female (cotype) reared from a Lecanium on Quercus aquatica, Jacksonville, Florida, April 17, 1881 (W. H. Ashmead). The second cotype female not found.

Two other females, Jacksonville, Florida, are labeled as types of annulipes under U.S.N.M. Cat. No. 4751, but must be later specimens and belong to pulvinariae Howard. A third female from the same locality, erroneously labeled cotype, is also pulvinariae.

Type.-Cat. No. 1477, U.S.N.M.

\section{APHYCUS OAXACAE Howard.}

Aphycus oaxacae Howard, Proc. U. S. Nat. Mus., vol. 21, 1898, pp. 241, 246.

Female.-Front and vertex as wide as long; ocelli in a right-angled triangle, the posterior pair about one-third of their own diameter from the eye margin; antennal scrobes deep and narrow, uniting above and together, forming a notch in the anterior margin of the front, the facial prominence well elevated; pubescence slight on both 
front and eyes. Antennal scape hardly flattened, slender, reaching just to the level of the front and vertex; pedicel of the usual length; first funicle joint a little longer than wide, the rest of antenna broken off. Wings uniformly ciliated; oblique hairless streak narrow, interrupted below, the cut-off portion large and separated from posterior margin of disk; basal hairless streak extending halfway from the point opposite the end of the oblique streak to the angulation. Ovipositor protruded about one-fifth the length of abdomen. Length, $1.3 \mathrm{~mm}$., exclusive of the ovipositor.

Front, vertex, and mesonotum brownish orange yellow shading into black on the anterior margin of the mesoscutum; face and a narrow band on the upper part of the cheeks next to the eye margin creamy white; a transverse band on upper part of face above the lower corners of the eyes, a lunate mark between bases of the antennae, lower two-thirds of cheeks with a narrow line across oral margin of the face, and the occiput black; concealed part of pronotum, the metanotum, propodeum, and abdomen black, the venter of the latter with a wide submarginal streak of whitish on each side; pleura and sternum of thorax yellowish white, with the mesosternum and a rather narrow band across the middle of mesopleura, brown; collar of pronotum and tegulae whitish, the former with a large, black dot on each corner almost connecting with the black of the center, the latter with the posterior margin brown. Antennal scape black, with a whitish dot above at apex and a rather narrow, whitish, oblique band near base; base of pedicel black, the apical third whitish; funicle and club originally described as dark brown. Legs yellowish white; tibiae with two rather wide, complete brown annuli, indistinct on the front pair and with an additional dot at the knee joint; middle tibiae with a third band at the apex, but the knee joint hardly marked; hind tibiae with an additional dot at the knee joint and the additional apical band indistinct. Exposed part of ovipositor brown. Wings hyaline, the veins pale brownish.

Redescribed from one female (type) collected at Oaxaca, Mexico (A. Koebele).

Type.-Cat. No. 5047, U.S.N.M.

\section{APHYCUS CEROPLASTIS Howard.}

Fig. 30:

Aphycus ceroplastis Howard, Bull. No. 5, old ser., U. S. Dept. Agric., Bur. Ent., $1885, \mathrm{p} .18$.

Female.-Front and vertex about one-half longer again than wide; ocelli nearly in an equilateral triangle, the posterior pair about onehalf their own diameter from the eye margin; antennal scrobes rather deep and narrow; eyes nearly smooth. Antennal scape flat$10600^{\circ}$-Proc.N.M.vol.50-16-40 
tened on underside, five times longer than wide; pedicel nearly as long as the first two and one-half of the third funicle joint; first two and last two funicle joints nearly equal in length, the third noticeably longer and the fourth a little shorter, the first two about as long as wide, the third longer than wide and the last three wider than long, all increasing gradually in width so that the sixth is about twice as wide as the first; club oval, rounded at apex, one-third wider again than the preceding joint and as long as the last three and onchalf of the third funicle joint combined. Wings uniformly ciliated; oblique hairless streak widened but not interrupted below and connecting with a branch of the basal streak. Ovipositor protruded about one-sixth the length of abdomen. Length: 1.1 to $1.4 \mathrm{~mm}$., exclusive of ovipositor.

Head gamboge yellow with the upper half of the center of occiput blackish brown and the cheeks with a broad, oblique, pale brown band across the middle; concealed part of pronotum, the metanotum, propodeum and most of the dorsum of abdomen blackish brown, the base and sides of the latter anterior to the vibrissae gamboge yellow; collar of pronotum whitish with a blackish brown dot on each corner almost aways connecting with the brown of the center; mesonotum gamboge yellow with the anterior margin of the scutum and the entire scutellum blackish brown, or the middle of scutum and the axillae also brown shading into the yellow of the sides; most of mesopleura, the metapleura and venter of abdomen brown to blackish brown; anterior margin of mesopleura and propleura gamboge yellow; prepectal plates and tegulae yellowish white, the latter brownish on the apical margin. Antennae pale brown, the scape shading into yellowish at base and apex and with a darker brown streak on outer surface of apical half; pedicel yellowish at apex and the last two funicle joints more or less yellowish; club darker brown but paler at apex. Legs gamboge yellow with the tip of the last joint of the tarsi blackish. Wings nearly hyaline but marked with a very faint, roundish cloud beneath stigmal vein reaching about half way to the posterior margin of disk; veins pale yellowish. Exserted part of ovipositor gamboge yellow, shading into brownish at apex.

Male.-Front and vertex about one-fourth longer again than wide; ocelli in an equilateral triangle, the posterior pair nearly their own diameter from the eye margin. Antennae nearly as in the female, but slightly shorter and less robust, the club narrower, hardly wider than the preceding joint and about as long as the last three funicle joints combined. Length: $0.9 \mathrm{~mm}$.

Upper parts black, including vertex of head, upper half of occiput and all of pronotum except the narrow, white collar, the lateral margin of the mesocutum shading into yellowish; front yellow; face, lower part of cheeks next to mandibles and lower half of the occiput 
paler yellow; upper half of cheeks and sides of the head pale brown; propleura, prepectal plates and anterior margin of the mesopleura pale yellow; rest of mesopleura and the metapleura brown; venter of abdomen dusky. yellowish. Antenna almost uniformly brown, the apical third of pedicel whitish. Legs and wings as in the female.

Redescribed from eight females, one male (cotypes) reared from Ceroplastes species on Artemisia, Silver City, New Mexico, March, 1879 (H. H. Rusby); two females reared from Ceroplastes irregularis Cockerell, Mesilla Park, New Mexico, October 16, 1896 (C. H. T. Townsend); and one female from Mesilla Park, New Mexico, March 16 (T. D. A. Cockerell). The remaining four females and one male from the type series are apparently lost.

Type.-Cat. No. 2643, U.S.N.M.

\section{APHYCUS MEXICANUS Howard.}

Figs. 32, 49.

Aphycus mexicanus Howard, Proc. U. S. Nat. Mus., vol 21, 1898, pp. $241,247$.

Female.-Front and vertex about two and one-half times longer than wide; ocelli in an acute-angled triangle, the posterior pair about one-fourth their own diameter from the eye margin; antennal scrobes broad and rather deep; eyes rather thickly pubescent with a short, fine pile. Antennal scape flattened on the underside, but not expanded, about five times longer than wide; pedicel a little longer than the first two funicle joints combined; first funicle joint small, about one-half as long as the second and as long as wide, the second, fourth, and fifth subequal in length and a little longer than the third and sixth, all increasing gradually in width so that the last is about twice as wide as the first but only the last distinctly wider than long, the second being longer than wide; club oval, obtusely rounded at apex, about one-fourth wider again than the preceding joint and a little longer than the last three funicle joints combined. Wings uniformly ciliated; oblique hairless streak narrowed above and interrupted below, the cut-off portion connecting with a rather indistinct branch of the basal hairless streak; stigmal vein longer and slenderer than usually. Ovipositor protruded about one-fourth the length of abdomen. Length: 1.4 to $1.5 \mathrm{~mm}$., exclusive of ovipositor.

Front, vertex and mesonotum dull orange yellow; face, cheeks, and underparts varying to cadmium yellow with the upper part of face usually lemon yellow; center of occiput dusky; concealed part of pronotum, the metanotum to a more or less degree, propodeum and dorsum of abdomen blackish brown, the lateral and apical margins of the latter cadium yellow posterior to the vibrissae; collar of pronotum dirty white with a blackish dot on each corner; propleura, prepectal plates and tegulae yellowish white, the latter brown on 
the posterior margin. Antennal scape yellow on the inner side, black on upper margin and the outer surface except at base and apex and with an indistinct, median, longitudinal yellowish streak; basal two-thirds of pedicel and club black, both shading into yellowish at apex; first four funicle joints blackish brown, the fifth dusky at base, last two joints otherwise yellow. Legs concolorous with underparts, the tip of last joint of the tarsi blackish. Exserted portion of ovipositor cadmium yellow but becoming dusky at apex; wings hyaline, the veins pale yellowish.

Mate.-Front and vertex nearly twice as long as wide; ocelli in a slightly acute-angled triangle; the posterior pair close to the eye margin. Antennae much as in the female, but the first funicle joint more than half as long as the second, the second, third, and fourth joints subequal in length, the last two a little longer, and the club a little narrower than in the female and more tapering toward the apex. Length: $0.9 \mathrm{~mm}$.

Face, cheeks, and front dull orange yellow approaching cadmium yellow; vertex, occiput, and upper parts of thorax and abdomen dull black; collar of pronotum narrowly whitish with a black dot on each corner uniting below with the black of the concealed portion; mesoscutum slightly yellowish on each side close to the tegulæ; tegulæ pale yellowish with their posterior margin brown; under side of thorax cadmium yellow, the venter of abdomen blackish brown. Antennal scape brown on the upper side, yellowish below; pedicel brown with apex yellowish; funicle and club nearly uniformly brown. Legs and wings as in the female.

Redescribed from nineteen females, five males (cotypes) reared from Ceroplastes species, Mexico City, Mexico (C. H. T. Townsend), and two females (cotypes) reared from Ceroplastes cirripediformis Comstock; Baton Rouge, Louisiana, December 25, 1897 (H. A. Morgan). In reference to the name and larger series Mexico City should be considered the type locality.

Type.-Cat. No. 5050, U.S.N.M.

\section{APHYCUS ERUPTOR Howard.}

Figs. 31, 50.

A phycus eruptor HowaRD, Rep. Ent., U. S. Dept. Agric., 1881, p. 364, pl. 23, fig. 5 .

Female.-Front and vertex about two and one-half times longer than wide; ocelli in an acute-angled triangle, the posterior pair about one-half their own diameter from the eye margin; antennal scrobes rather shallow and broad; eyes with a very fine, sparse pubescence. Antennal scape flattened below but not expanded, about five times longer than wide; pedicel as long as the first two and one-half of the third funicle joint; first funicle joint small and roundish, a little wider 
than long, following joints longer with the second and sixth a little shorter than the others, all increasing gradually in width so that the last is twice as wide as the first joint, but only the sixth is considerably wider than long; club oval, rounded at apex, about one-third wider than the preceding joint and as long as the last three funicle joints combined. Wings as in mexicanus. Ovipositor protruded about onefifth the length of abdomen. Length: $1.1 \mathrm{~mm}$., exclusive of ovipositor.

Front and vertex brownish orange yellow; face, cheeks, occiput, and entire underparts dull gamboge yellow; upper side of thorax and abdomen bright cadmium yellow, with a brown spot on each side of the propodeum and the apical half of the abdomen more gamboge yellow; concealed part of pronotum black; collar of pronotum, prepectal plates, and tegulæ whitish, the collar with a small blackish dot on each corner, and the tegulæ brownish on the posterior margin. Antennae in general concolorous with the face, the scape with a longitudinal brown streak on upper margin of the outer surface, the base of pedicel brown, the first three funicle joints dilute brownish, fading gradually into the pure yellowish of the last three joints, club black but becoming yellowish brown at apex. Legs concolorous with the underparts, the tip of last joint of the tarsi blackish. Exserted part of ovipositor gamboge yellow. Wings hyaline, the veins pale yellowish.

Male.-Front and vertex about one and two thirds times longer than wide; ocelli in a less acute-angled triangle than in the female, the posterior pair about one-fourth their own diameter from the eye margin. Antennae nearly as in the female, but the first three funicle joints more roundish, the funicle as a whole and the club more slender. Length: $1.0 \mathrm{~mm}$.

Front, vertex, and upper rim of occiput nrange yellow with a brownish spot between the posterior ocelli; face, cheeks, and most of the underparts, including the venter of abdomen, gamboge yellow, the prepectal plates and upper anterior part of the mesopleura more lemon yellow; upper concealed part of occiput and pronotum, most of mesonotum, metanotum, propodeum, and dorsum of abdomen brownish black, the mesoscutum fading into gamboge yellow on the sides next to the tegulæ, and margins of the scutellum and part of metanotum brownish yellow; collar of pronotum and tegulæ yellowish white, the former with a black dot on each corner, the latter with the posterior margin blackish brown. Antennal scape and pedicel yellowish brown, marked with darker brown as in the female; flagellum brown, fading into yellowish on the last two funiclo joints and at apex of club. Legs and wings as in the female.

Described from five females, three males reared from Ceroplastes sp., Fort Myers, Florida, July $23^{\circ}$ to August 1, 1907 (E. A. Back), 
Morrill, Nos. 2006 and 2007; and one male (metatype and erroneously labeled with type No. 2609, U.S.N.M.), collected in northern Virginia, June, 1879 (Th. Pergande). The latter specimen is in poor condition, but agrees as far as preserved with the males from Florida. The type female and male could not be found, but the insect described above agrees fairly well with Howard's description, and apparently the only reason to doubt the identification lies in the fact that the types were reared from a Lecanium instead of a Ceroplastes.

Type-locality.-Fort George, Florida.

Type.-Cat. No. 2609, U.S.N.M.

\section{APHYCUS STOMACHOSUS Girault.}

Figs. 29, 46.

Aphycus stomachosus Giraule, Psyche, vol. 16, 1909, p. 77.

Aphycus flaviceps Krna (not Howard), Can. Ent., vol. 31, 1899, p. 141.

Female.-Front and vertex about one-half longer again than wide; ocelli in a slightly acute-angled triangle, the posterior pair about their own diameter from the eye margin; antennal scrobes broad and shallow, facial prominence not much elevated; eyes with a sparse, extremely short, fine pubescence. Antennal scape flattened and a little wider at the middle, about three times longer than greatest width; pedicel as long as the first three funicle joints combined; first three funicle joints subequal in length and width and about as long as wide, the last three increasingly wider and more transverse, and the last two also slightly longer than the preceding, the sixth not quite twice as wide as the first; club oval, obtusely rounded at apex, about one-third wider again than the preceding joint, and nearly as long as the last five funicle joints combined. Wings uniformly ciliated; oblique hairless streak narrowed above and interrupted below, the cut-off portion separated from the posterior margin of disk and from the basal hairless streak. Ovipositor slightly protruded. Length: 0.7 to $1.2 \mathrm{~mm}$.

General color deep bright orange yellow, most vivid on the front, vertex, and mesonotum; face, cheeks, and underparts a little paler; collar of pronotum concolorous with a black dot on each corner; occiput entirely orange yellow, but the pronotum has a narrow blackish transverse band on the concealed portion; tegulae yellowish white, with their posterior margin blackish brown; prepectal plates paler than rest of pleura or yellowish white; metanotum, propodeum, and most of the dorsum of abdomen more or less brownish. Antennæ concolorous with the face; scape with a small spot of brownish at the middle, on dorsal margin; first four funicle joints brownish and base of club blackish brown. Legs a little paler yellow than underparts, the tip of the last joint of the tarsi blackish. Wings hyaline, the veins palo brownish. 
Male.-Front and vertex about one-fourth longer than wide; ocelli in an equilateral triangle or nearly so, the posterior pair about their own diameter from the eye margin. Antennae very nearly as in the female, but the club slenderer, more truncate at apex, and as long as the last four joints combined. Length: 0.7 to $1.2 \mathrm{~mm}$.

Coloration as in the female, but the face, cheeks, and underparts decidedly paler than notum or chrome yellow, the prepectal plates concolorous with the rest of pleura; metanotum, propodeum, and central part of the dorsum of abdomen darker brown. Antennal scape and pedicel as in the female, but the funicle and club pale brown with the sixth funicle joint sometimes a little paler.

Redescribed from four females (cotypes) reared from Lecanium nigrofasciatum Pergande, Carbondale, Illinois, June, 1908 (A. A. Girault); two males from the same host, Lawrence, Massachusetts, February 11, 1899 (Geo. B. King); two females, one male reared from same host, February 5, 1897, Insectary No. $472^{\circ}$; two females, Salem, Ohio, September, 1903; and a large series of both sexes reared from the same Lecanium, Mount Alto, Pennsylvania, during May and June, 1913 (F. L. Simanton), Quaintance No. 6130.

Type.-Cat. No. 11997, U.S.N.M.

\section{APHYCUS ERIOCOCCI, new species.}

Female.-Front and vertex three times longer than wide; ocelli in a strongly acute-angled triangle, the posterior pair almost touching eye margin and about their own diameter apart; antennal scrobes broad and shallow; eyes nonpubescent. Antennal scape strongly flattened but not expanded below, the lower margin gently curved, a little over four times as long as wide; pedicel as long as the first three and one-half of the fourth funicle joint combined; first three funicle joints equal in length, the fourth slightly longer, the last two equal and a littlo longer than the fourth, all increasing gradually and slightly in width distad, the sixth about one-half wider again than the first, the first three a little wider than long, the sixth considerably so, but the fourth and fifth about as long as wide; club elongate oval, tapering distad, and slightly obliquely truncate at apex, one-third wider again than the preceding joint and as long as the last five funicle joints combined. Wings uniformly ciliated; oblique hairless streak not reaching to the stigmal vein and interrupted below, the small cut-off portion well separated from the posterior margin of disk and from the basal streak; the latter reaching nearly to the angulation or to a point opposite the end of the stigmal vein. Ovipositor protruded about one-eighth the length of the abdomen. Length: $0.9 \mathrm{~mm}$., exclusive of ovipositor.

Front, most of occiput, face, and cheeks pale chrome yellow, becoming whitish at the oral margin, and a very narrow blackish line 
on the cheeks at roots of mandibles; vertex pale clay yellow; center of occiput dilute blackish; concealed part of pronotum, the metanotum, propodeum, and dorsum of abdomen brownish black, the lateral and apical margin of the latter broadly white; mesonotum dark brown shading into clay yellow on the lateral margin of the scutum and scutellum and on the axillae; collar of pronotum, tegulae, and underparts ivory white, the collar of pronotum with a blackish dot on each corner, the tegulae brownish on their posterior margin, and the venter of abdomen dusky in the center. Antennae black with the basal and apical third of scape, the apical half of pedicel and last three funicle joints white. Legs white, with the tarsi more yellowish and apex of the last joint blackish; tibiae with two rather wide, subinterrupted blackish annuli, fainter on the front pair and with an additional dot at apex and at knee joint of the middle and hind pair. Wings hyaline, the veins pale brownish. Exserted part of ovipositor yellowish becoming blackish at apex.

Male.-Not known.

Described from two females (type and paratype) reared from Eriococcus howardi Ehrhorn on Quercus utahensis, Salt Lake City, Utah, July 4-6, 1914 (P. H. Timberlake).

Type.-Cat. No. 19121, U.S.N.M.

33. APHYCUS BRUNNEUS Howard.

Aphycus brunneus Howard, Bull. No. 5, old ser., U. S. Dept. Agric., Bur. Ent., 1885, p. 17.

The type and only known specimen of this species could not be found. As it was reared from a Diaspine host, Autacaspis rosae (Bouché) it can hardly be a true Aphycus and will probably prove to belong to Coccidencyrtus Ashmead. The type locality is Vineland, New Jersey.

Type.-Cat. No. 2642, U.S.N.M.

34. APHYCUS NITENS Kourdumoff.

Aphicus nitens Kourdumoff, Rev. Russe d'Ent., vol. 12, 1912, p. 334, fig. 7.

This species has not been seen by the writer. It was reared from Eriococcus greeni Newstead at the Poltava Experiment Station, Russia.

35. APHYCUS HEDERACEUS (Westwood).

Encyrtus hederaceus Westwood, Philos. Mag., ser. 3, vol. 10, 1837, p. 441.

Encyrtus fulvifrons WALKER, Ent. Mag., vol. 5, 1838, p. 109.

Aphycus hederaceus Mayr, Verh. zool.-bot. Ges. Wien, 1876, pp. 695, 696.

Specimens of this species also have not been seen and the synonymy is taken from Mayr. 


\section{APHYCUS ALBERTI Howard.}

Figs. 27, 48 .

Aphycus alberti Howard, Proc. U. S. Nat. Mus., vol. 21, 1898, pp. 241, 247.

Aphycus flavus Howard (part), Proc. U. S. Nat. Mus., vol. 21, 1898, p. 241.

Aphycus sp. near coquilletti Trmberlake, Journ. Econ. Ent., vol. 6, 1913, p. 294.

Female.-Front and vertex about three times longer than wide; ocelli in an acute-angled triangle, the posterior pair about one-fourth their own diameter from the eye margin; antennal scrobes broad and rather deep; eyes with an abundant but short, fine pubescence. Antennal scape flattened but not expanded below, a little less than four times as long as wide, widest on the apical half; pedical about as long as the first three funicle joints combined; first four funicle joints subequal in length, the last two about one-third longer, all increasing slightly in width so that the sixth is about one-third wider again than the first; club oval, rounded at apex, nearly twice as wide as the preceding joint and as long as the last five funicle joints combined. Wings uniformly ciliated; oblique hairless streak narrow throughout and interrupted below; the cut-off portion separated from the posterior margin of disk. Length, 0.7 to $0.9 \mathrm{~mm}$.

Front, vertex and upper parts of thorax and abdomen brownish orange yellow, the head brighter, the propodeum and center of abdomen more brownish; face, cheeks, occiput excepting a black spot on each side above the neck, and underparts paler or more cadmium yellow, the cheeks sometimes faintly tinted with brown next to the occiput; concealed part of pronotum with two small blackish brown spots, and the posterior margin of the collar whitish with a blackish dot on each corner; tegulae concolorous with underparts with their posterior margin brownish. Antennae concolorous with face, with a large blackish spot on lower side of the apical half of scape appearing on both outer and inner surface, basal half and two-thirds of pedicel and club respectively and first four funicle joints black or blackish. Legs concolorous with underparts with the tip of the last joint of tarsi blackish. Wings hyaline, the veins pale yellowish.

Male.-Front and vortex about twice as long as wide; ocelli in an acute-angled triangle, the posterior pair one-half their own diameter from the eye margin. Antennae nearly as in the female, but the scape is narrower or linear and the club smaller. Length, $0.5 \mathrm{~mm}$.

Front brownish orange yellow; most of vertex, the occiput and upper part of thorax and abdomen brownish black sometimes varying to brown, with the sides of mesoscutum and axillae, and lateral margins of the abdomen at the vibrissae narrowly brownish orange yellow; face, cheeks and underparts as in the female except that the venter of abdomen is more or less brownish or brownish orange yellow. Antennal scape and pedicel colored as in female but the funicle and 
club entirely blackish brown darkest on the club. Legs and wings as in the female.

Redescribed from one female, one male (cotypes) reared from Coccus hesperidum Linnaeus, Sydney, New South Wales (A. Koebele); three females, two males, from same host, Los Angeles County, California, April (A. Koebele), and seven females, two males with the same data but reared in August, Koebele's number $160^{\circ}$; one female from same host, Avalon, Catalina Island, California, September 12, 1912 (P. H. Timberlake); five females, four males from same host, Carpenteria, California, July 12 to August 27, 1911 (P. H. Timberlake); and a series of both sexes reared from the same host in reproduction experiments with females from Carpenteria.

The Koebele specimens from Los Angeles County were determined by Howard as flavus and constitute the California record for flavus in his 1898 paper.

Type.-Cat. No. 5051, U.S.N.M.

\section{APHYCUS PHILIPPIAE Martell.}

Aphicus philippiae Martelli, Boll. Portici Lab., vol. 2, 1908, pp. 236, 245-Masi, Boll. Partici Lab., vol. 3, 1908, p. 100, fig. 8.

This species has not been seen by the writer. It was reared from Filippia oleae (Costa), Catanzara and Gizzeria, Calabria, Italy, and from a Lecanium, Novara, Sicily.

\section{APHYCUS FLAVUS Howard.}

Figs. 26, 47 .

Aphycus flavus Howard, Rep. Ent., U. S. Dept. Agric., 1881, p. 365.

Female.-Front and vertex about twice as long as wide; ocelli in an acute-angled triangle, the posterior pair close to the eye margin; eyes nearly nonpubescent. Antennal scape flattened and narrow, about four times as long as wide, widest near the middle; pedicel a little longer than the first three funicle joints combined; first five funicle joints of nearly equal length, the sixth slightly longer, the last four increasing gradually in width so that the sixth is about twice as wide as the first, and all wider than long except the first two, which are about as long as wide; club oval, slightly pointed at apex, a little wider than the last funicle joint, and nearly as long as the last five funicle joints combined. Wings uniformly ciliated; oblique hairless streak widened and interrupted below, the cut-off portion separated from the posterior margin of disk and from the basal hairless streak. Length, 0.7 to $1.2 \mathrm{~mm}$.

Front, vertex, and upper surface of body bright orange yellow, the propodeum and dorsum of abdomen sometimes slightly brownish; face, cheeks, and underparts similar but paler yellow; collar of pronotum and tegulae pale yellowish with a blackish dot on each corner 
of the former, and the posterior margin of the latter brown; center of occiput usually yellow, sometimes blackish; the concealed part of pronotum either yellow or blackish. Antennae concolorous with face, with a small spot on upper margin of outer surface of scape near apex, base of pedicel, first three funicle joints and basal half of club brownish or blackish. Legs concolorous with underparts, with apex of the last joint of tarsi blackish. Wings hyaline, the veins pale yellowish.

Male.-Nearly like the female but the front and vertex a little wider and the antenna more slender. Length, 0.6 to $1.0 \mathrm{~mm}$.

Coloration as in the female except that the metanotum, propodeum, and dorsum of abdomen are dark brown with the lateral margins of the latter yellow. Antennae as in female except that the whole flagellum may be uniformly brown.

Redescribed from the following material: One female, Jacksonville, Florida (W. H. Ashmead); one female reared from Toumeyella Tiriodendri (Gmelin), Crescent City, Florida, March 18, 1895 (H. G. Hubbard); one female from the same host, Molino, Florida, May 25, 1894 (S. S. Harvey); four males from same host, Laurel, Maryland, June 11, 1912 (E. R. Sasscer); two females, five males reared from Tachardia on Acacia, San Diego, Texas, July 12, 1896 (E. A. Schwarz); one female, one male reared from Tachardia species on "Huajillo" with no locality given; three females, one male reared from Putvinaria pyriformis Cockerell, Port-of-Spain, Trinidad (P. Lachmere-Guppy); one female reared from Coccus hesperidum Linnaeus, Lima, Peru, December 21, 1909 (C. H. T. Townsend), Townsend No. $140^{\circ}$ 3a; a large series of both sexes reared from Pulvinaria species on sweet potato, Sullana, Piura, Peru, during February and March, 1912 (E. W. Rust), received from Messrs. Townsend and Rust under No. $35^{\circ} 3 \mathrm{a}$; one female, one male reared from Saissetia oleae (Bernard), Palermo, Sicily, received from H. S. Smith under California State Insectary No. $720 b$ and $d$.

The type female of this species from Palatka, Florida, could not be found. It was supposed to have been reared from Lepidosaphes beckii (Newman), but the record is undoubtedly erroneous.

There are slight but apparently constant differences in coloration in material from different localities which are probably due to local variation and not of specific value. The females from Trinidad have the face, cheeks, underparts of thorax, and the abdomen brilliant chrome lemon without dark markings on the concealed part of the occiput and pronotum. The material from Peru varies from bright orange to a little paler and there is a small transverse blackish spot on the concealed part of the pronotum. The males also differ in having but a slight brownish infuscation in the center of the dorsum of abdomen.

Type.-Cat. No. 2610, U.S.N.M. 
39. APHYCUS LUTEOLUS, new spectes.

Figs. 28, 45 .

Aphycus flavus Quayle (not Howard), Bull. 214, Cal. Agric. Exp. Stat., 1911, p. 476, figs. 28, 30.-Quayle and Rust, Bull. 223, Cal. Agric. Exp. Stat., 1911, pp. 190, 194, figs. 14, 18.

Aphycus species near flavus Trmberla ke, Journ. Econ. Ent., vol. 6, 1913, p. 294.

Female.-Front and vertex twice as long as wide; ocelli in an acute-angled triangle, the posterior pair about their own diameter from the eye margin; antennal scrobes rather deep and distinct; pubescence of eyes sparse and extremely short and fine. Antennal scape flattened but not expanded, very nearly linear with the lower margin slightly curved, about four times longer than wide; pedicel about as long as the first three funicle joints combined; first five funicle joints subequal in length, the sixth slightly longer, all gradually increasing in width so that the sixth is twice as wide as the first and all wider than long with the first two less distinctly so; club oval, rather pointed at apex, about one third wider again than the last funicle joint and as long as the last five preceding joints combined. Wings uniformly ciliated; oblique hairless streak widened and interrupetd below, the cut off portion uniting with a distinct branch of the basal hairless streak. Length: 0.7 to $1.1 \mathrm{~mm}$.

General color above pale clay yellow, the front and vertex somewhat more orange yellow; face, cheeks, and underparts brighter yellow or nearly chrome lemon; concealed part of pronotum, a dot on each corner of collar, posterior margin of tegulae and the sutures of mesonotum to a more or less degree blackish brown; collar of pronotum and tegulae otherwise yellowish white; metanotum, propodeum and most of the basal half of dorsum of abdomen dilute blackish brown. Antennae concolorous with the face, with a large spot on scape near apex above, base of pedicel on upper side, first three funicle joints and lower side of fourth, and basal half of club blackish. Legs concolorous with the underparts with the apex of last joint of tarsi blackish. Wings hyaline, the veins pale yellowish.

Male.-Front and vertex about one-half longer again than wide; ocelli in a slightly acute-angled triangle, the posterior pair about their own diameter from the eye margin. Antennae as in female but a little slenderer. Length: 0.7 to $0.8 \mathrm{~mm}$.

Coloration as in the female except for the following details: Front and vertex chrome lemon and concolorous with face and cheeks; dorsum of abdomen with the dark markings more extensive and deeper, often entirely blackish brown except on lateral margins posterior to the vibrissae; the flagellum of antennae entirely blackish brown. 
Described from six females, two males (type, allotype, and paratypes $a$ to $f$ ) reared from Coccus hesperidum Linnæus, Santa Paula, California, August 15-28, 1912; one female, three males (paratypes $g$ to $j$ ) from same host, Whittier, California, April 21, 1911; four females (paratypes $k$ to $n$ ) from same host, Carpenteria, California, September 20-22, 1912; two females (paratypes $o$ and $p$ ) from same host, Sacramento, California, November 22, 1912; one female (paratype $q$ ) reared from Saissetia oleae (Bernard), Chula Vista, California, September 5, 1912; and one female (paratype $r$ ) from the latter host, Sweetwater Dam, California, September 10, 1912 (P. H. 'Timberlake). Additional specimens in the writer's collection from most of the above localities may be considered as metatypes; also three females, two males reared from Coccus citricola Campbell, Claremont, California, July 10-17, 1912 and 1913 (R. E. Campbell). Type.-Cat. No. 18377, U.S.N.M.

\section{APHYCUS OREGONENSIS Howard.}

Fig. 54.

Aphycus oregonensis Howard, Proc. U. S. Nat. Mus., vol. 21, 1898, pp. 241, 246.

Male.-Front and vertex nearly twice as long as wide and ocelli in an acute-angled triangle (in the largest cotype) or front and vertex only about one-half longer again than wide and ocelli in an equilateral triangle or nearly so (in rest of cotypes, which are considerably smaller); posterior ocelli about one-half their own diameter from the eye margin; antennal scrobes broad and shallow; eyes with a fine, delicate pubescence. Antennal scape flattened and but slightly expanded, widest just beyond the middle, nearly four times longer than wide; pedicel as long as first two and one-half of the third funicle joint; first four funicle joints of equal length, the last two longer, the sixth a little longer than the fifth, first joint about as long as wide, the following increasingly wider, the last nearly twice as wide as the first; club oval, rounded at apex, hardly wider than the preceding joint and as long as the last four funicle joints combined. Wings uniformly ciliated; oblique hairless streak widened and interrupted below, the large cut-off portion uniting with an indistinct branch of the basal hairless streak. Length, 0.9 to $1.2 \mathrm{~mm}$.

Front, vertex, and mesonotum dull orange yellow; face, cheeks, occiput, and under parts yellowish white, the cheeks with a large brownish spot next to the mandibles, and the center of occiput above the neck dusky; concealed part of. pronotum, anterior margin of mesoscutum, most of metanotum, propodeum, and dorsum of abdomen brownish black; collar of pronotum and tegulae whitish, the former with a blackish dot on each corner, the latter with their posterior margin pale brown; sutures of mesonotum lined with blackish and the mesoscutellum slightly brownish. Antennal. scape blackish 
with a wide yellowish band on dorsal margin of inner surface, and base and apex yellowish on outer surface; pedicel brownish yellow on outer side and blackish on inner surface; funicle and club brown, with the last two funicle joints slightly paler. Legs pale yellowish; tibiae with two broad brown annuli at the base and near middle, fainter and narrower on hind pair and still fainter on front pair; last joint of the tarsi tipped with blackish. Wings hyaline, the veins pale yellowish.

Female.-Not known.

Redescribed from eight males (six of them cotypes) reared from a Pulvinaria on Ribes, Aumesville, Oregon, February 1-17, 1890 (F. S. Mattison). This species will presumably prove to be the male sex of californicus Howard.

Type.-Cat. No. 5048, U.S.N.M.

\section{APHYCUS AMOENUS Howard.}

Aphycus amoenus Howard, Journ. Linn. Soc. Lond., Zool., vol. 26, 1896, p. 150.

The type of this species was not accessible for study and no other specimens were examined. Judging from the description it is clasely related to rusti described from Peru but considerably darker in coloration. It was described from a single male collected at Balthazar, Grenada (H. H. Smith).

Type.--In the British Museum.

42. APHYCUS IMMACULATUS Howard.

Aphycus immaculatus Howard, Insect Life, vol. 6, 1894, p. 236, fig. 11.

The type, a single male mounted on a slide, was not found in the United States National Museum, and no other specimens are known. The species is apparentily similar to alberti Howard but distinct, judging from the description and figure. It was supposed to have been reared from Chrysomphalus aurantii (Maskell), but if it is a true Aphycus, the record is undoubtedly erroneous.

Type.-Cat. No. 1474, U.S.N.M.

43. APHYCUS HOWARDI Cockerell.

Aphycus howardi Cockerell, Can. Ent., vol. 30, 1898, p. 276.

The single type specimen of this species in the United States National Museum is so badly damaged that its relationship with the other species considered in this paper could not be determined, and it consequently was not included in the synoptic table. It should, however, be easily recognized by its bright scarlet coloration, which is unique. It was reared from Eriococcus tinsleyi Cockerell at Mesilla Park, New Mexico.

Type.-Cat. No. 19181, U.S.N.M. 


\section{EXPLANATION OF PLATES.}

\section{Plate 26.}

Antennae of female.

Fig. 1. Aphycus fuscipennis.

2. A. schwarzi.

3. Aenasioidea pulchella.

4. Ae. kermicola.

5. Aphycus kingi.

6. A. subfasciatus.

7. A. rileyi.

8. A. johnsoni.

\section{Puate 27.}

Antennae of female.

Fig. 9. A. cockerelli.
10. A. lecanii.
11. A. maculipennis.
12. A. coquilletti.
13. A. physokermis.
14. A. lichtensiae.
15. A. pulvinariae.
16. A. maculipes.

\section{Plate 28.}

Antennae of female.

Fig. 17. A. mayri.

18. A. melanostomatus.

19. A. similis.

20. Aenasioidea tenuicornis.

21. Aphycus californicus.

22. A. albopleuralis.

23. A. pulvinariae.

24. A. lounsburyi.

\section{Plate 29.}

Antennae of female.

Fig. 25. A. claviger.

26. A. flavus.

27. A. alberti.

28. A. luteolus.

29. A. stomachosus.

30. A. ceroplastis.

31. A. eruptor.

32. A. mexicanus.

33. Aphycopsis australiensis.

34. Pseudaphycus angelicus.

35. Pseudococcobius terryi. 
Plate 30.

Antennae of male.

Fig. 36. Aphycus maculivennis.

37. A. johnsoni.

38. A. rileyi.

39. A. subfasciatus.

40. A. lecanii.

41. A. lichtensiae.

42. A. physokermis.

43. A. pulvinariae.

44. A. claviger.

Plate 31.

Antennae of male excepting fig. 52 of female.

Fig. 45. Aphycus luteolus.

46. A. stomachosus.

47. A. flavus.

48. A. alberti.

49. A. mexicanus.

50. A. eruptor.

51. Pseudaphycus angelicus.

52. Acerophagus texanus.

53. Aphycus melanostomatus.

54. A. oregonensis. 


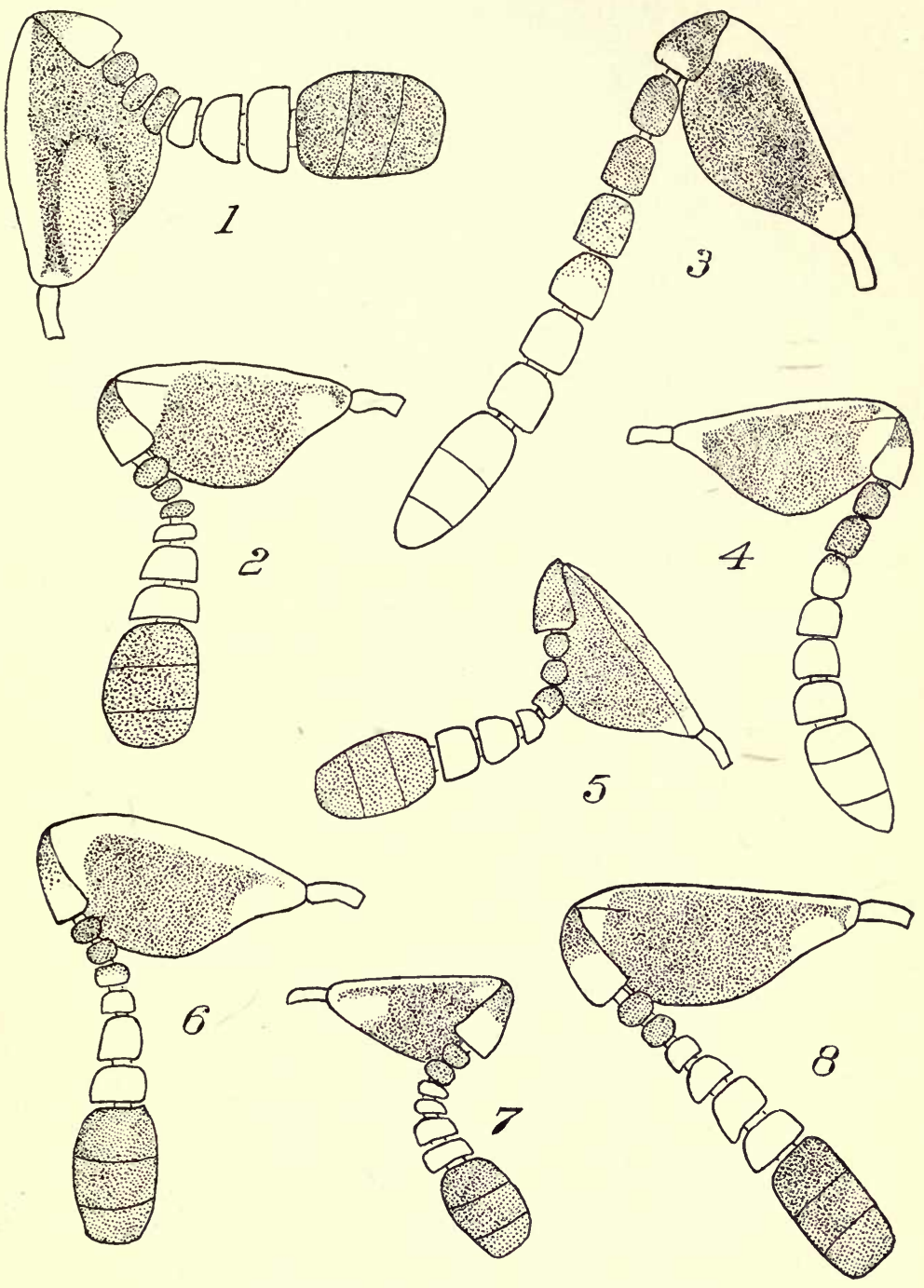

ANTENNAE of ApHycus and Aenasioidea.

For explanation of PLATE SEe PAge 639. 



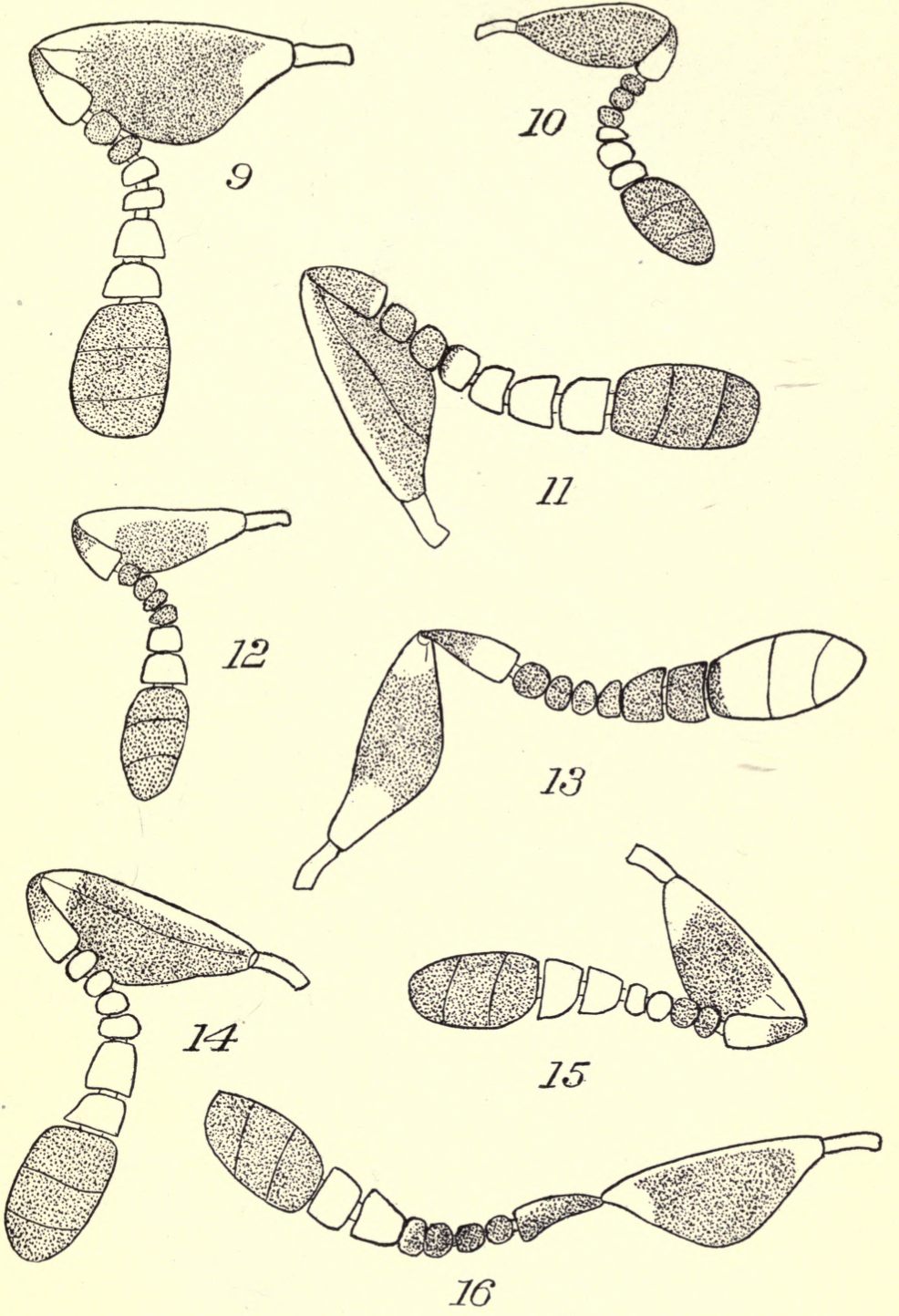

ANTENNAE of Aphycus.

For EXPLANATION OF PLATE SEE PAGE 639. 



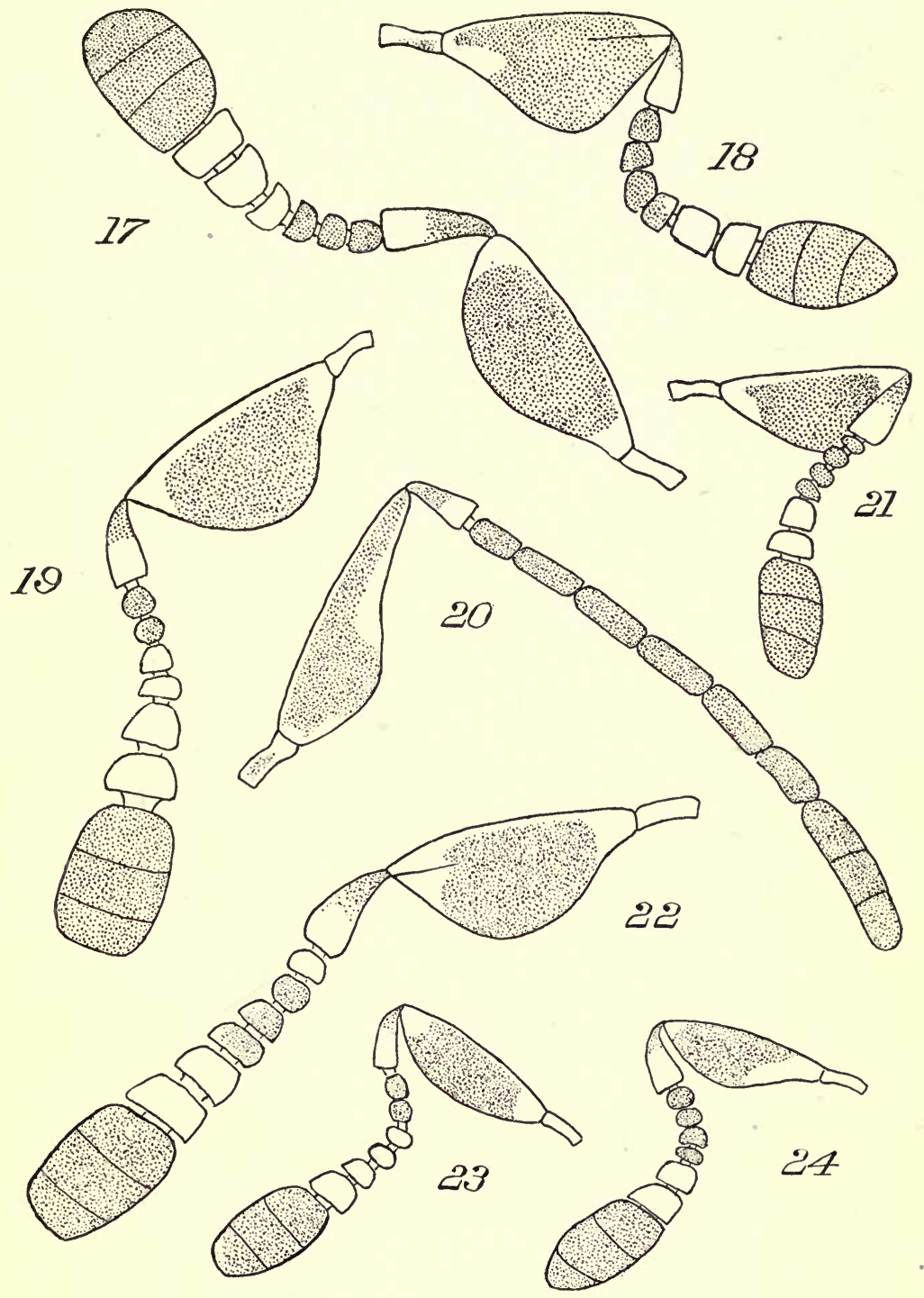

Antennae of Aphycus and Aenasioidea.

For EXPLANATION OF PLATE SEE PAGE 639. 



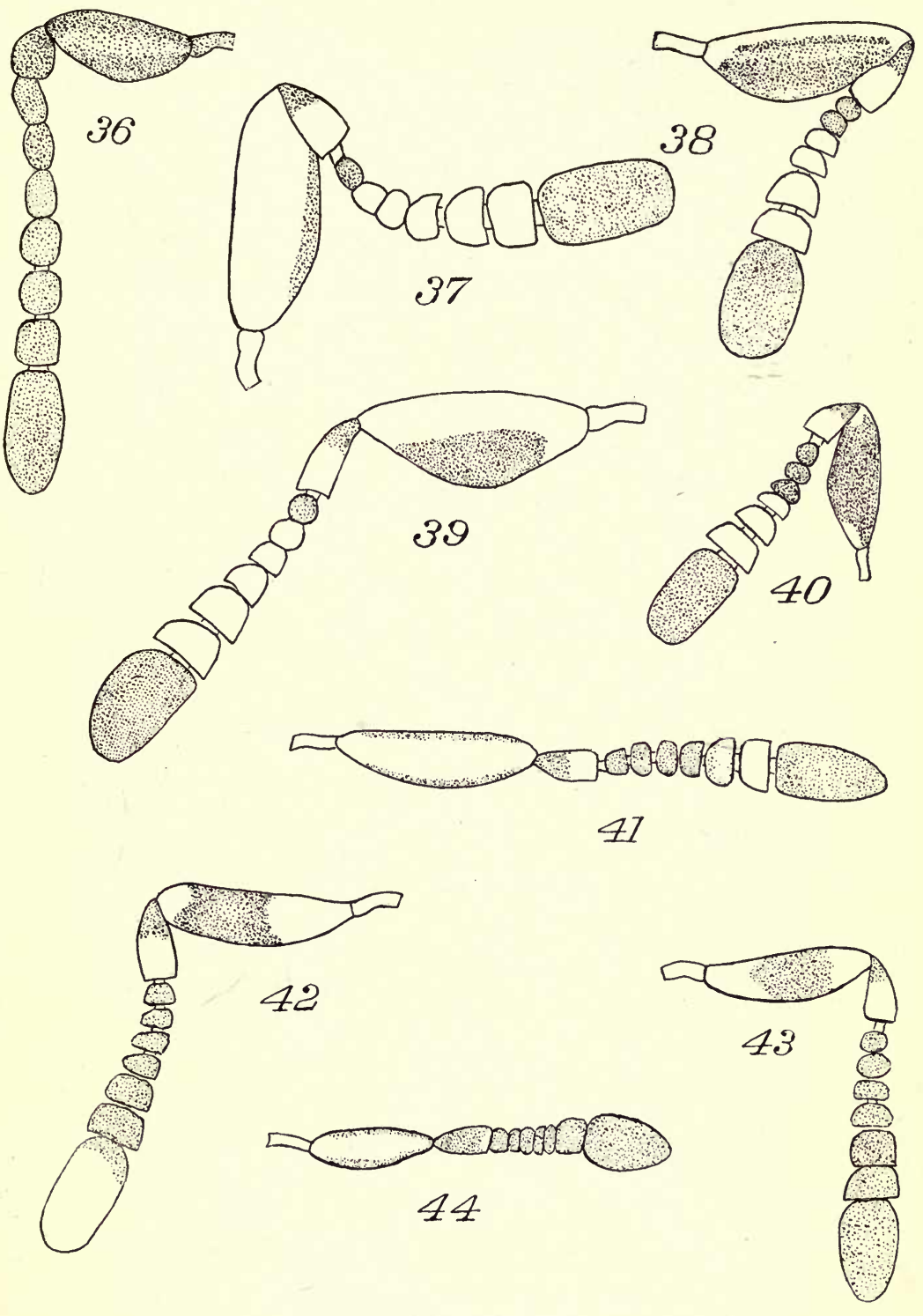

AntenNae of ApHycus.

For EXPLANATION OF PLATE SEE PAGE 640. 

U. S. NATIONAL MUSEUM

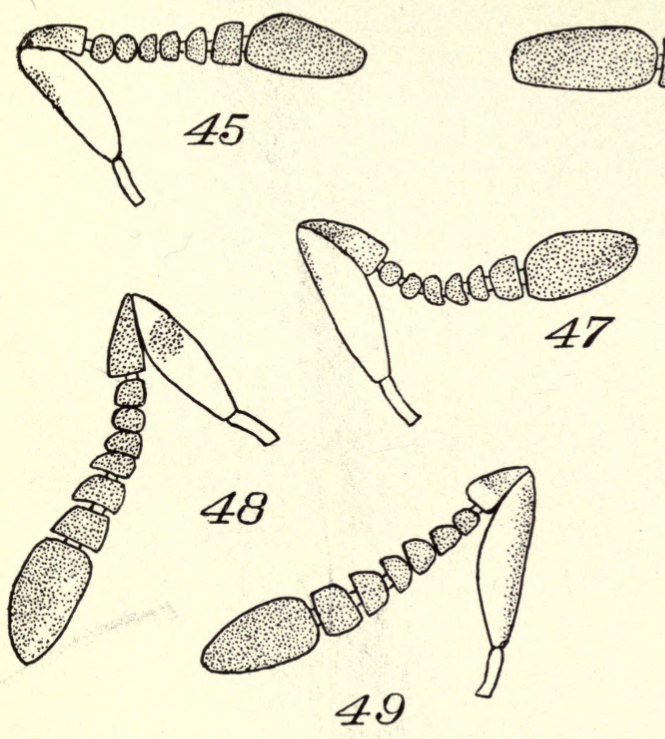

PROCEEDINGS, VOL. 50 PL. 31
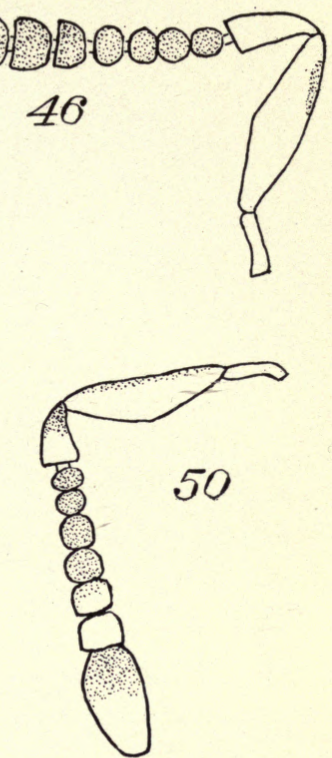

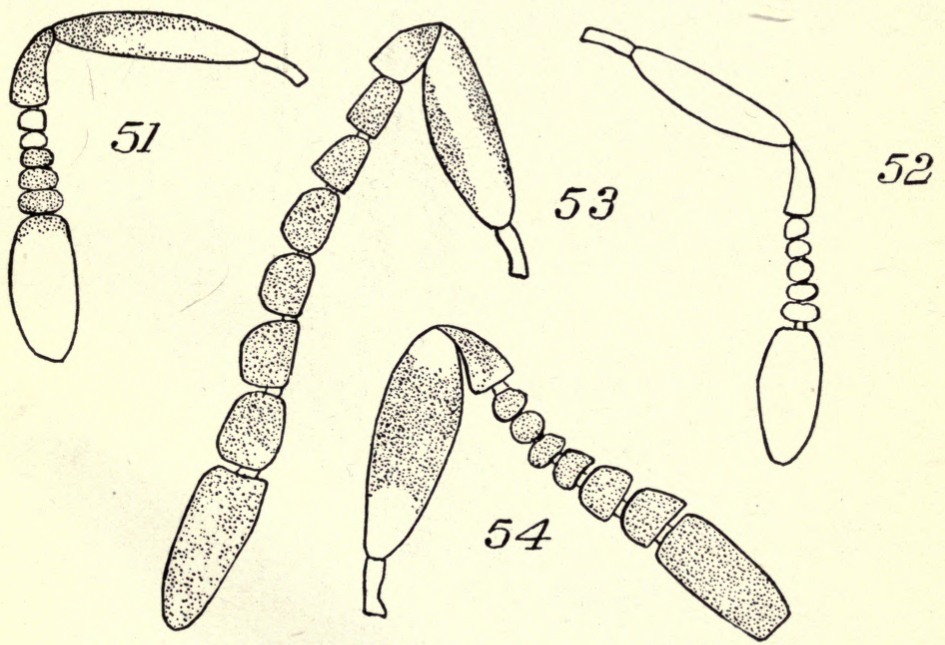

Antennae of Aphycus, Pseudaphycus, and Acerophagus.

For EXPLANation OF PLATE SEE PAGE 640. 


r.

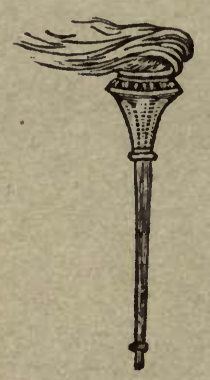






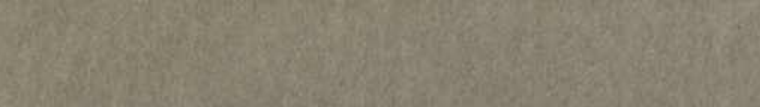


